\title{
A FRAMEWORK FOR BIM MODEL-BASED CONSTRUCTION COST ESTIMATION
}

\author{
A Thesis \\ presented to \\ The Faculty of California Polytechnic State University, \\ San Luis Obispo \\ In Partial Fulfillment \\ of the Requirements for the Degree \\ Master of Science in Civil and Environmental Engineering
}

by

Michael Thomas Clark

June 2019 
(ㄷ) 2019

Michael Thomas Clark

ALL RIGHTS RESERVED 
COMMITTEE MEMBERSHIP

TITLE: $\quad$ A Framework for BIM Model-Based Construction Cost Estimation

AUTHOR: Michael Thomas Clark

DATE SUBMITTED: June 2019

COMMITTEE CHAIR: Hani S. Alzraiee, Ph.D. PE PMP

Assistant Professor of Civil and Environmental Engineering

COMMITTEE MEMBER: Charles Chadwell, Ph.D. PE

Department Chair and Professor of Civil and Environmental Engineering

COMMITTEE MEMBER: $\quad$ Erik P. Kasper, Ph.D. PE

Professor of Civil and Environmental

Engineering 


\section{ABSTRACT \\ A Framework for BIM Model-Based Construction Cost Estimation \\ Michael Thomas Clark}

This thesis presents a framework to conduct a quantity take-off (QTO) and cost estimate within the Building Information Modeling (BIM) Environment. The product of this framework is a model-based cost estimating tool. The framework addresses the cost uncertainty associated with the detailed information defining BIM model element properties. This cost uncertainty is due to the lack of available tools that address detailed QTO and cost estimation using solely a BIM platform. In addition, cost estimators have little experience in leveraging and managing information within semantic-rich BIM models. Unmanaged BIM element parameters are considered a source of uncertainty in a model-based cost estimate, therefore they should be managed and quantified as work items.

A model-based system, which assists the estimators to conduct a QTO and cost estimate within the BIM environment, is developed. This system harnesses BIM element parameters to drive work items associated with the parameter's host element. The system also captures the cost of scope not modeled in the design team's BIM models. The system consists of four modules 1) establishing estimate requirements, 2) planning and structuring the estimate, 3) quantification and costing, and 4) model-based historical cost data collection. The complete system can produce a project cost estimate based on the 3D BIM Model.

This framework is supported by a computation engine built within an existing virtual design and construction (VDC) model review software. The computation engine supports BIM authoring and reviewing BIM data. The Framework's quantification and costing module was compared to existing methods in a case study. The outcomes of the model-based system demonstrated improved cost estimate accuracy in comparison to the BIM QTO method and improved speed compared to the traditional methods. The framework provides a systematic workflow for conducting a detailed cost estimate leveraging the parameters stored in the BIM models.

Keywords: BIM, VDC, QTO, Construction Cost Estimation, Automation in Construction, Model-Based Construction Cost Estimation 


\section{ACKNOWLEDGMENTS}

This work is dedicated to my family and friends. They are incredibly supportive. I'd especially like to thank my mother Liz, for her editing and computer science support. And to my father Greg who contributed his ideas and passion for construction. Their love and support helped immeasurably.

I am incredibly grateful for the guidance and advice provided by my advisor, Dr. Hani S. Alzraiee. This was his first year as a professor at Cal Poly and I admire how he hit the ground running. He is an incredible mentor and advisor, who challenged me to grow throughout this process. I am grateful that he provided advice and guidance to complete the thesis on time.

I'd like to thank Dr. Charles Chadwell, Civil Engineering Department Chair, for serving as a committee member. I appreciate his blend of knowledge that spans structural engineering and construction. He has been devoted to developing the construction engineering program within our department. This program is materializing, and I am proud to be a part of it. I am incredibly grateful to him for developing this opportunity.

Dr. Eric Kasper is humble, but he certainly deserves praise. He is a Professor of Structural Engineering and the Steel Bridge Team Advisor. I joined this team as a Freshman, 5 years ago. This club inspired me to pursue a career construction. I've grown to know Dr. Kasper well. He has supported and advised me on any question or idea I could conceive. He is an incredible role model and I appreciate his support.

Thank you to Terry M. Roy. His practical guidance from past construction estimating experiences kept me thinking practically. I had the pleasure of taking two classes with him which both influenced this research. He offered his time for interviews and even provided statements to include in this thesis. He affirmed the intentions of my work; do not replace estimators with automation, instead improve their capabilities and efficiency.

Finally, thank you to the CE Student Fund Initiative (SFI) for supporting my Conference Registration and Travel to Montreal. I am excited to present this research in June 2019 to the Canadian Society of Civil Engineers and the Construction Research Congress. 


\section{TABLE OF CONTENTS}

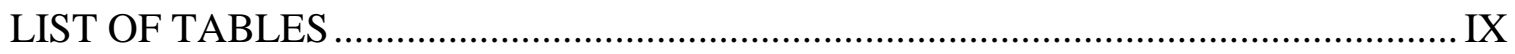

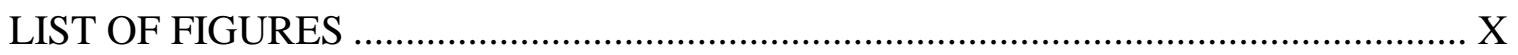

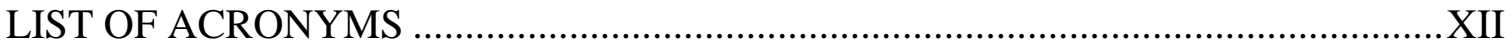

CHAPTER

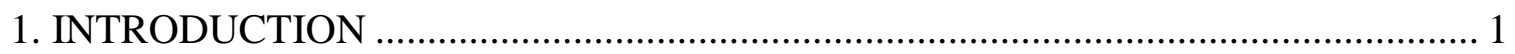

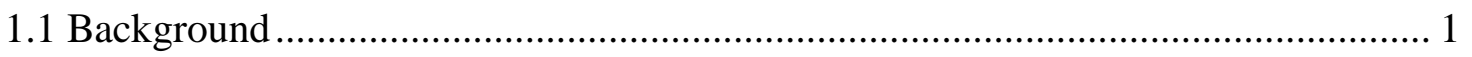

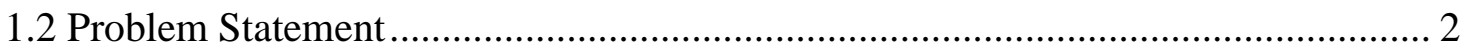

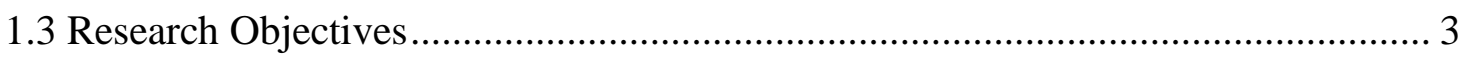

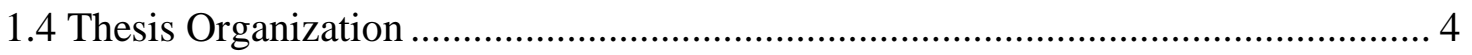

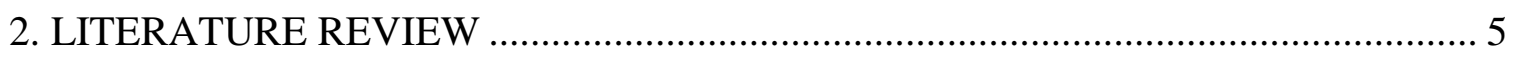

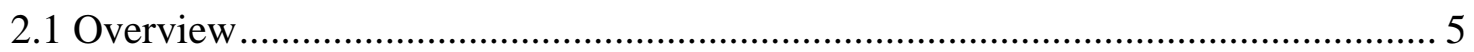

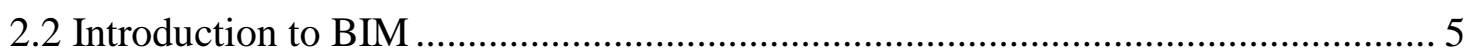

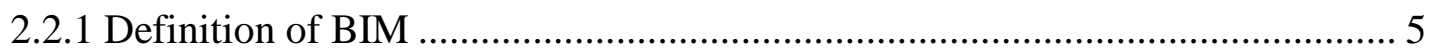

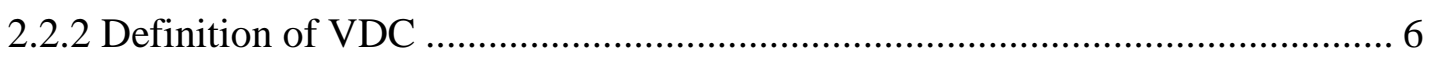

2.2.3 BIM and Construction Cost Estimating ......................................................... 8

2.2.4 VDC and the Contractor's Participation in Design......................................... 9

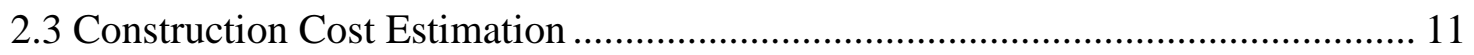

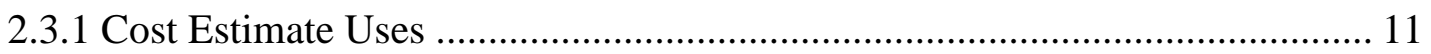

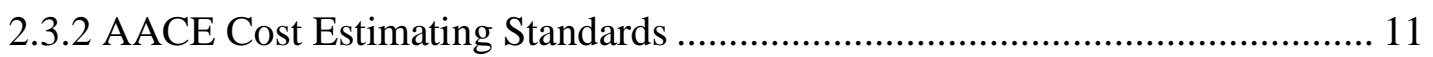

2.3.3 Traditional QTO and Cost Estimating Method................................................ 14

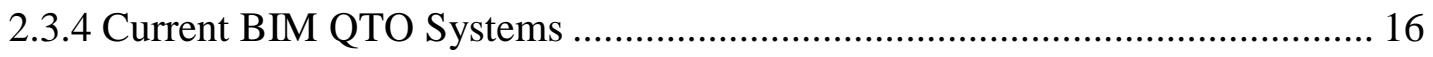

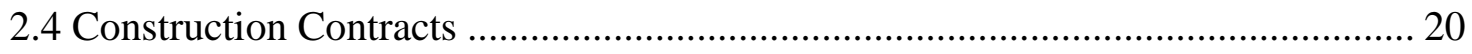

2.4.1 Delivery Methods \& Cost Estimation......................................................... 20

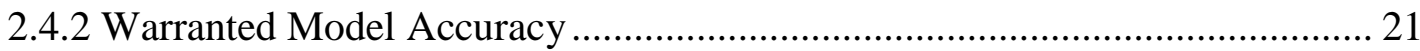

2.5 Complications in BIM for Model-Based Cost Estimation...................................... 22

2.5.1 Ontology of Model Elements.................................................................... 22

2.5.2 Model Level of Development ............................................................... 26

2.5.3 Interoperability of Software and Data......................................................... 27

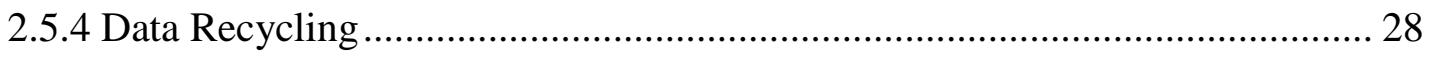

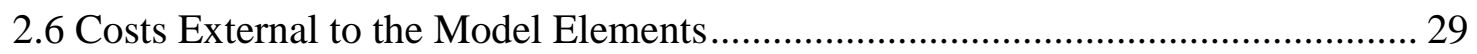

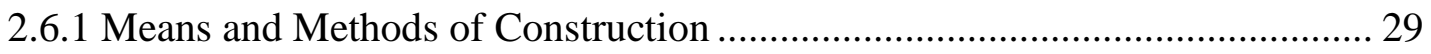

2.6.2 Multiple Quantities Driven by an Element ................................................... 30

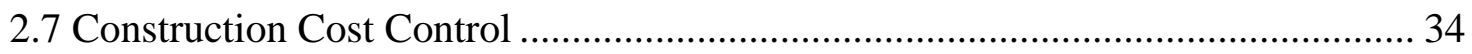

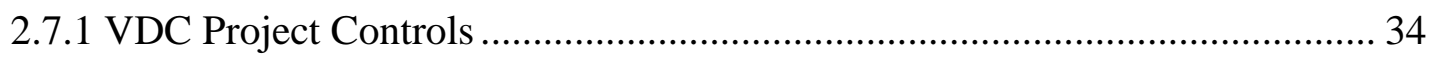

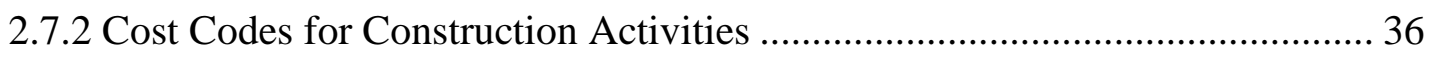




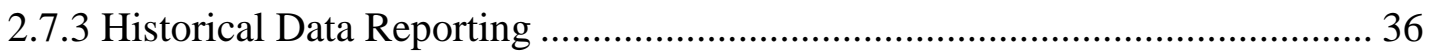

2.8 Industrial Manufacturing Perspective on Cost Estimation .................................... 37

2.8.1 Qualitative Versus Quantitative Cost Estimate Techniques ............................ 37

2.8.2 The Activity Based Costing Method.............................................................. 38

2.9 Summary of Identified Limitations.................................................................. 39

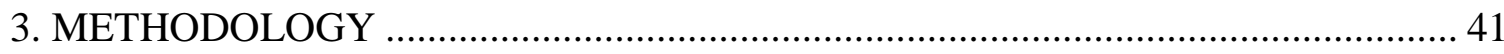

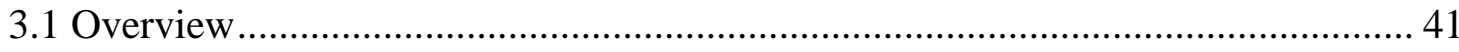

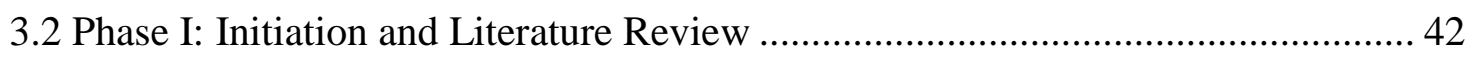

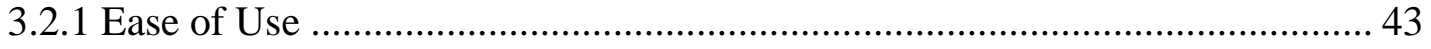

3.2.2 Estimator's Subjective Opinion of a Work Item's Cost ................................... 43

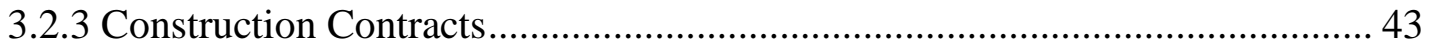

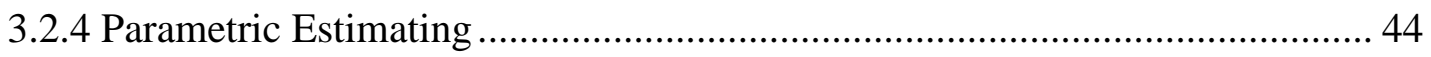

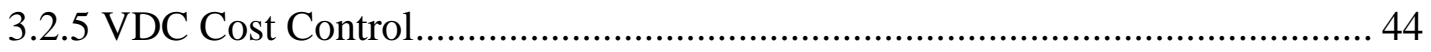

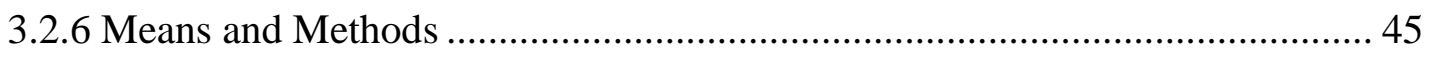

3.2.7 Flexible Mapping ………………........................................................... 45

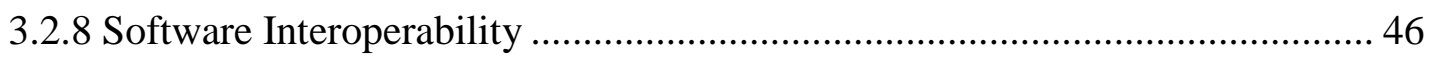

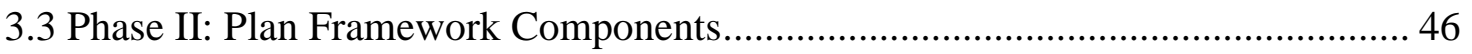

3.3.1 Structured Query Language and Business Intelligence ................................... 47

3.3.2 Navisworks Application Programming Interface Add-in ................................. 47

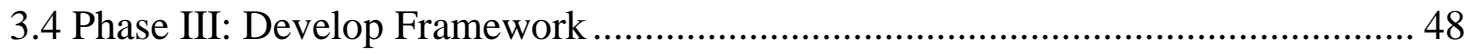

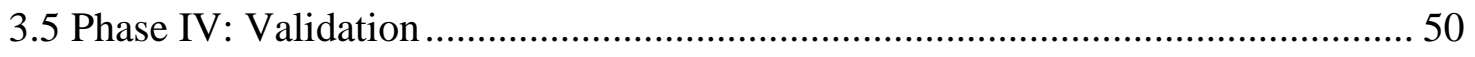

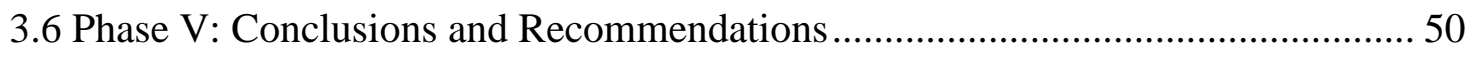

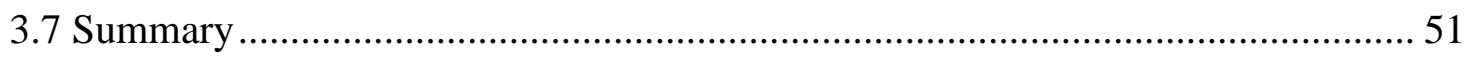

4. MODEL-BASED COST ESTIMATING FRAMEWORK …………..................... 52

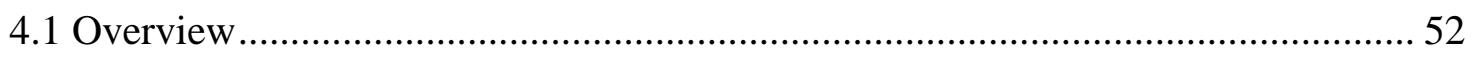

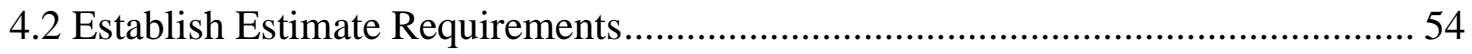

4.2.1 Construction Contracts: BIM Execution Plan............................................... 54

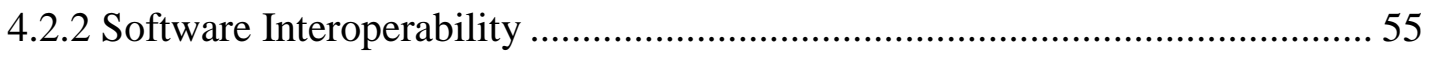

4.2.3 Check BIM Against Warranted Accuracy ………………………………....... 56

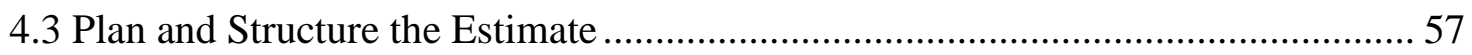

4.3.1 Design Flexible Data Maps to Other Stakeholders' BIM Models .................... 57

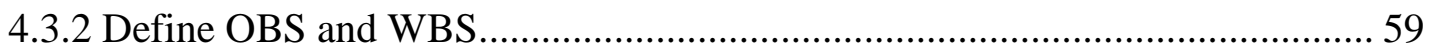

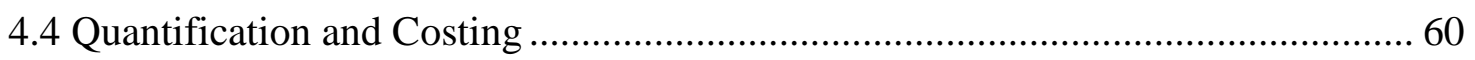

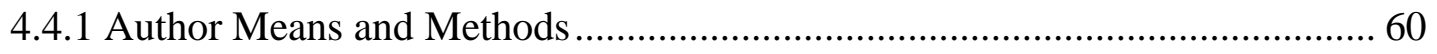

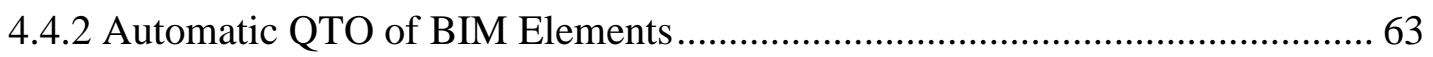

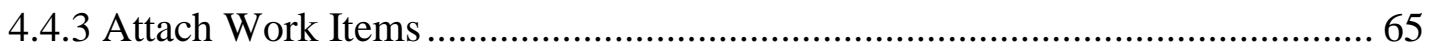

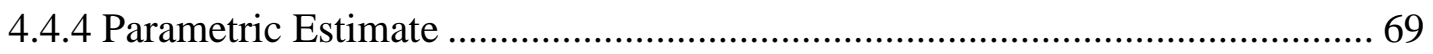

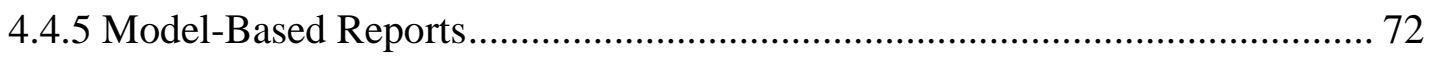

4.5 Model-Based Historical Cost Data Refinement.................................................. 73

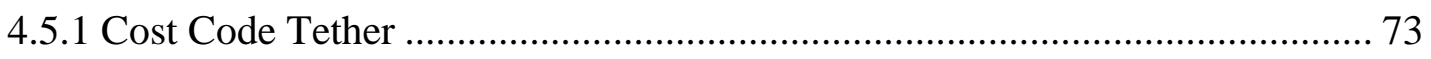


4.5.2 VDC Cost Control................................................................................... 75

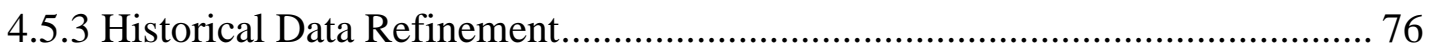

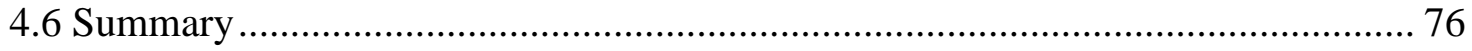

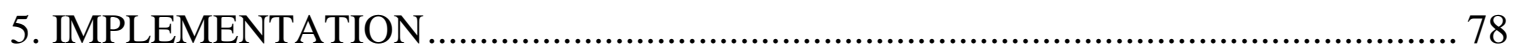

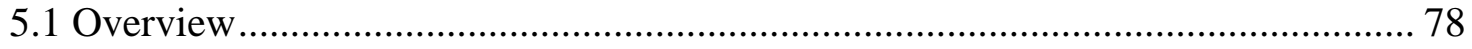

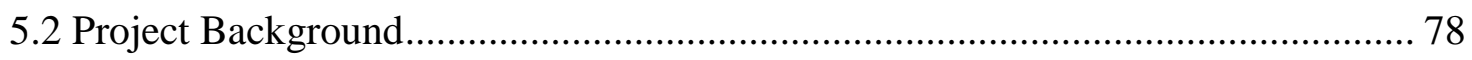

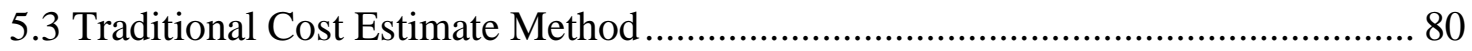

5.4 BIM QTO and Excel Estimate .................................................................... 86

5.5 Model-Based Cost Estimate..................................................................... 91

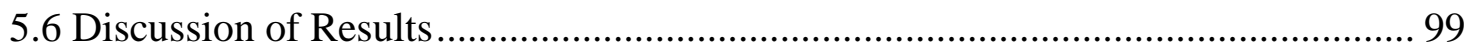

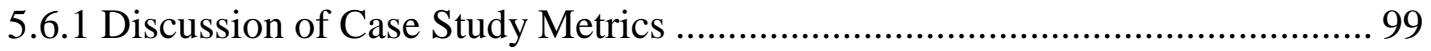

5.6.2 Results for Preparation of the Computation System ................................... 101

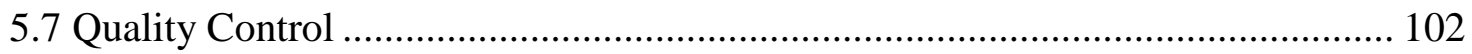

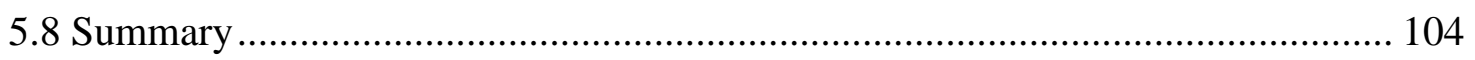

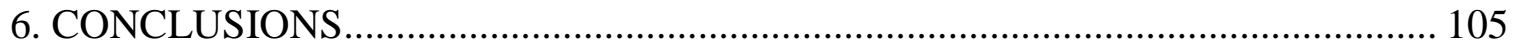

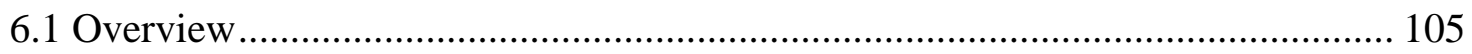

6.2 Contributions of the Proposed Framework ........................................................ 105

6.3 Limitations of the Proposed Framework ....................................................... 107

6.4 Future Developments .......................................................................... 109

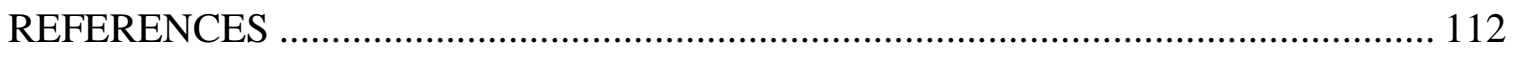

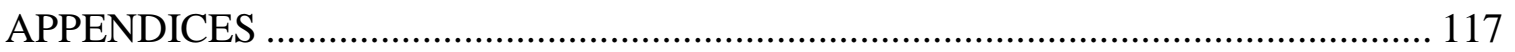

Appendix A: Power BI Cost Estimate Report ................................................... 117

Appendix B: All BIM elements in the Revit Model ............................................. 118

Appendix C: Parametric Estimate SQL Entity Amalgamated into an Excel Table.... 119 


\section{LIST OF TABLES}

Table

Page

1. Map of Limitations and Corresponding Literature Review Sections ........................ 42

2. SOG Quantities Established from the Traditional QTO ......................................... 84

3. BIM QTO Parameters Exported using the Navisworks Selection Inspector ................ 88

4. SQL Table with all BIM Parameters Used to Complete the Model-Based Cost Estimate.

5. Comparison of the Estimating Parameters captured in the Traditional Method Estimate to the Estimating Parameters captured in the Model-Based Cost Estimate... 99

6. Comparison of the Time to Complete and Estimated Cost Results of the Traditional Method Estimate versus the Model-Based Cost Estimate 100 


\section{LIST OF FIGURES}

Figure

1. QTO Time Savings with BIM (Olsen \& Taylor, 2017) .......................................... 8

2. AACE Cost Estimate Classification System (AACE RP 17R-97, 2011) .................... 13

3. AACE Cost Estimate Process Diagram (AACE RP 19R-97, 2003)........................... 14

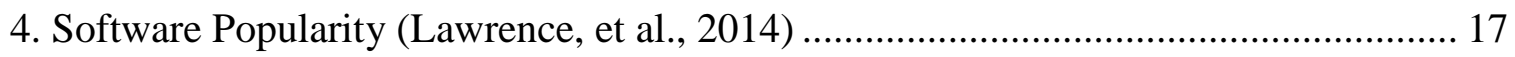

5. Navisworks QTO of Spread Footings, Highlighted Blue ........................................ 18

6. Assemble QTO of Masonry Walls, Highlighted Blue ............................................... 19

7. Ontological Cost Estimation Framework (Lee, Kim, \& Uy, 2014) ........................... 23

8. BIM Knowledge-Base Ontological Map (Niknam \& Karshenas, 2015) .................... 25

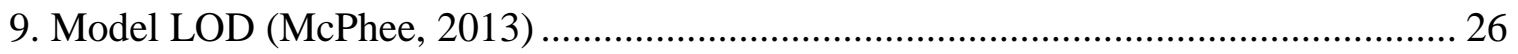

10. BIM Based Site Information Management (Lee, Park, \& Song, 2018) ..................... 28

11. BIM-Based Cost-Estimation Employing Flexible Mapping (Lawrence, et al., 2014) 31

12. A Flexible Mapping Process to Update an Existing Cost Estimate (Lawrence, et al,

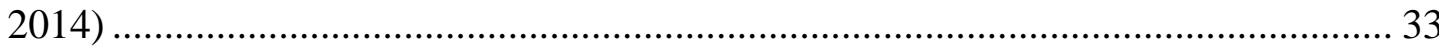

13. P6 and Assemble used in Model-Based Project Control (Scroggins, 2018).............. 35

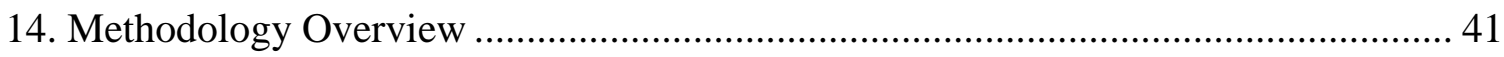

15. Conceptual Roadmap of Model-Based Cost Estimating System............................. 48

16. Skeleton of the Framework's Input, Environment, and Output............................... 49

17. Cost Estimating Steps Followed in the Case Study Validation ............................... 50

18. Legend Representing the Framework Elements .................................................. 52

19. Overview of Model-Based Cost Estimation Framework ....................................... 53

20. Input-Environment-Output Diagram with the Implemented Software ..................... 56

21. SQL Table of Flexible Parameter Mapping ......................................................... 59

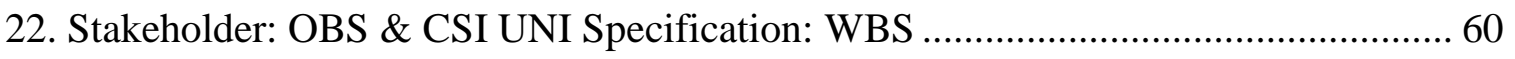


23. Flowchart Outlining the Documentation of Means and Methods............................ 62

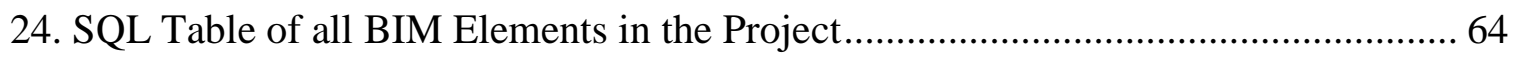

25. Navisworks Add-in Data Model for connecting the BIM Elements to SQL.............. 65

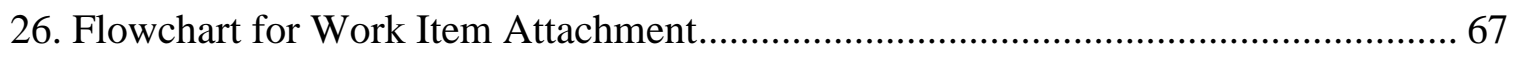

27. Assembly Estimating Feature for Work Item Attachment Step ............................. 68

28. Navisworks Add-in Tab for selecting a BIM Element to Attach Work Items........... 69

29. Flowchart for Completing a Parametric Estimate ................................................. 70

30. SQL Entities for Capturing Subjective Input .................................................. 71

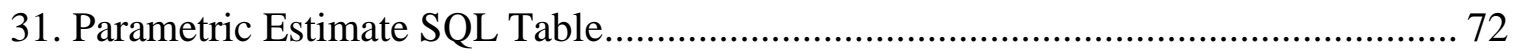

32. Cost Control SQL Table Linking Cost Codes to the Cost Estimate ......................... 75

33. Drone Photograph of YakPity t $^{\mathrm{ty}} u$ Student Housing Project (Cal Poly, 2018) ........... 79

34. Process Diagram of the Cost Estimate Case Study Modules.................................. 82

35. Traditional QTO of SOG Completed using Bluebeam Revu ................................. 83

36. Cost Estimate Spreadsheet produced from the Traditional QTO ............................ 85

37. BIM QTO of SOG performed with the Navisworks "Selection Inspector" ............... 87

38. Traditional Cost Estimate Driven by Quantities from the BIM QTO ...................... 90

39. Conditioned Navisworks File for Completing a Model-Based Cost Estimate ........... 93

40. Work Item Attachment Using the Navisworks Add-in........................................ 94

41. Traditional Cost Estimate Spreadsheet for Comparison purposes........................... 96

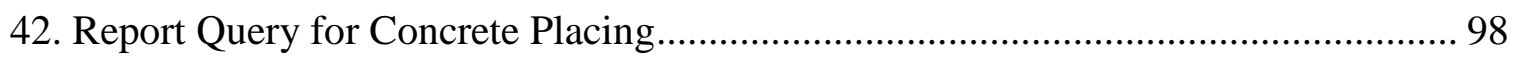




\section{LIST OF ACRONYMS}

$\begin{array}{ll}\text { BIM } & \text { Building Information Modeling } \\ \text { VDC } & \text { Virtual Design and Construction } \\ \text { OBS } & \text { Organizational Breakdown Structure }\end{array}$

WBS Work Breakdown Structure

SOW Scope of Work

MEP Mechanical Electrical and Plumbing

AACE Association for the Advancement of Cost Engineering

ACWP Actual Cost of Work in Place

TCM Total Cost Management

GMP Guaranteed Max Price

LOD Level of Development

IFC Industry Foundation Class

RFI Request for Information

SQL Structured Query Language

BI Business Information

API Application Programming Interface

BEP BIM Execution Plan 


\section{INTRODUCTION}

\subsection{Background}

$\mathrm{BIM}$ is a computer-based process of communicating design intent. BIM is becoming the platform for the management of the entire construction project lifecycle. VDC is the use of models provided by different project stakeholders to pursue construction objectives. It's important to note that VDC is a verb, meaning it is the act of employing information in project-related decision making. Successful VDC involves visualization and analysis of the model to produce decisions. The zenith of BIM and VDC is the return of the master builder concept. Not to an individual, but to one locus of control for the entire project. The BIM model presents elements that spatially organize the project's information. This information is used to plan and execute construction operations using VDC. Proper implementation of BIM and VDC entails that the project's suite of information is wholly accessible within the BIM model. The BIM model then becomes the singular locus of control for the entire construction project.

Many project variables, including the project's estimated cost, are dependent on the parameters stored in BIM elements. The core principle guiding the proposed modelbased cost estimating framework is "no cost estimate information should exist that is inaccessible from, or blind to, the project's BIM models." When this principle is followed, all the cost estimate work items should be driven by the parameters of the BIM model elements. Any design changes to the model element's parameters should automatically be available to the cost estimate work items. Thereby the BIM model environment becomes the locus of control for a project's cost information. Then through VDC, construction cost data is collected in the context of the BIM environment. 


\subsection{Problem Statement}

The existing body of knowledge lacks a concise framework for construction cost estimation using BIM. Current popular BIM cost estimating computation platforms lack a pure BIM model-based method and instead rely on quantity extraction. While these platforms increase speed and efficiency in the quantification process, this is achieved with a loss of accuracy. The current computation platforms extract parameters from BIM elements instead of completing the cost estimate within the spatial context of BIM. This extraction leads to a partial loss of the estimator's ability to conceptualize the impact of the arrangement of the 3D model elements on the project's cost. This loss is detrimental to the spatial context BIM provides, and consequently the accuracy of the cost estimate.

Aside from a loss of accuracy, this data extraction also reduces the efficiency of the cost estimating process. Since the existing tools rely on more than BIM elements, estimators at times manually author additional geometric shapes to host parameters that are not provided in the BIM model. This authoring is not parametric, it will not update when a design change is proposed in the designer's BIM model. These manually defined QTO conditions are not BIM elements, and therefore cannot store additional information or be communicated to other stakeholders. This QTO authoring introduces measurement error and is not directly useful to other project stakeholders. The current body of knowledge employs computation systems that under develop the potential efficiency increase of using BIM elements in cost estimation.

The main limitation within the existing body of knowledge is the absence of an easy to use framework for capturing all parameters that affect the project's cost, within the BIM model-based environment. In current practices, some parameters are manually 
authored as QTO conditions, while other granular parameters are missed. This limitation should be addressed by improving the capabilities of cost estimation from within a BIM environment. Such an improvement departs from the school of thought that relies on quantity extraction for cost estimation. Improvements should increase both the quality and quantity of geometric and cost estimate information available within BIM.

\subsection{Research Objectives}

The objective of this thesis is to develop a framework to complete a construction cost estimate entirely within BIM. An accurate cost estimate must take into consideration all variables and constraints where the quantity is installed within the project. This cannot be accomplished with a quantity extraction, the model-based cost estimate requires the spatial context that is provided by BIM. The proposed framework is intended to capture all costs. To achieve this main objective, the following sub-objectives are carried out:

1. Conduct interviews with cost estimating professionals.

2. Complete a literature review that sufficiently analyzes BIM, VDC, and other influences on BIM model-based construction cost estimation.

3. Prepare a succinct methodology that lays out a roadmap for the modelbased cost estimation framework.

4. Develop a Framework for model-based cost estimation that incorporates these four sequential modules:

- Module 1: Establish cost estimate requirements.

○ Module 2: Plan and structure the cost estimate.

○ Module 3: Conduct quantification and costing.

- Module 4: Refine historical cost data from within BIM. 
5. Complete a case study to evaluate the proposed framework against the existing body of knowledge.

\subsection{Thesis Organization}

This thesis begins with a literature review (Chapter 2) that develops the eight limitations in detail. These limitations are analyzed in the methodology (Chapter 3). The methodology outlines the development process of the thesis. This process is pursued to create a framework for model-based cost estimation (Chapter 4). This framework is tested against two other cost estimate methods to create a case study comparison (Chapter 5). The conclusion examines results and identifies any prevailing limitations (Chapter 6). 


\section{LITERATURE REVIEW}

\subsection{Overview}

Through a detailed literature review, this chapter builds an understanding of the

limitations in the construction industry which hinder adoption of parametric BIM modelbased construction cost estimation. This literature review analyzes BIM and VDC, cost

estimation, contract structures, construction phase cost control, and the industrial manufacturing industry's successful adoption of parametric cost estimation.

\subsection{Introduction to BIM}

This section defines BIM and VDC. It explores the increasing involvement of the general contractor in the design process and examines how BIM and VDC have enabled increased participation by the construction contractor in the design process. The actual mechanics and functionality of BIM and VDC are further explored in Sections 2.5 through 2.7 .

\subsubsection{Definition of BIM}

BIM is a 3D model-based process of representing design intent in building construction. The models contain data representing the physical and functional characteristics of the project. This data is associated with discrete digital elements contained in the model. BIM has grown in popularity as construction projects become increasingly complex (Autodesk, 2018). It is a system that clearly communicates the designer's intent. Clear communication allows many stakeholders to coordinate and improve the productivity of construction. Clear communication of design intent through BIM promises to improve productivity in construction (Turner and Townsend, 2018). 
BIM tools include a litany of software platforms allowing the combination of different stakeholder's data in a spatial environment. A BIM model is built of 3D elements. They are discrete objects, each of which has a unique identifier known as an object ID. Unique object ID's allow BIM users to clearly select an element. Object ID's are also a tool for referencing relationships to other objects. Parameters of model elements store data. These parameters allow stakeholders to communicate information. So, BIM is a form of spatial organization with a litany of software interpretations (ADEB-VBA, 2015). Since BIM can host so much data, one interest in the industry is building cost estimate information into the definition of BIM elements. However, BIM is not presently popular for use in cost estimation. In a 2010 survey, spatial design coordination was the most common task to leverage BIM. Spatial design coordination allows project teams to "detect clashes" or identify where multiple model elements occupy the same 3D space. Clash detection involves 3D data, which BIM visually represents. Meanwhile, the cost is an additional dimension of data. This additional dimension is currently not well interpreted through BIM. This is in part why cost estimation ranked fourteenth of twenty-five options in the survey of BIM uses (Kreider, Messner, \& Dubler, 2010).

\subsubsection{Definition of VDC}

VDC is the use of models provided by different project stakeholders to pursue objectives. It's important to note that VDC is a verb, meaning it is the act of employing information in project-related decision making. Successful VDC involves visualization and analysis of the combined model to produce decisions. Producing these visualizations requires a product-organization-process model. An organizational model 
identifies various stakeholders in an organizational breakdown structure (OBS). This is effectively a list of all parties who qualify as project stakeholders. The process model is the work breakdown structure (WBS), or the sequential activities required to complete the work. Since BIM elements can hold additional parameters, they can store data regarding the element's relationship to the OBS and WBS (Stanford Engineering, 2018).

BIM is one of the three sub-models within the product-organization-process model. It represents the finished product as intended by the design team. The organization and process models encompass the elements that construct the models. The construction team evaluates the design intent and applies means and methods to physically produce the model. VDC digitally communicates the organization and process components of a project. VDC synthesizes the information produced by a designer's BIM with the people and processes required to complete the project (Chen, John, \& Cox, 2018).

Employing VDC adds fluidity to the construction process since it is no longer completed in discrete "design-bid-build" stages. Specialty sub-contractors including HVAC-R and plumbing adopted VDC to increase pre-fabrication of piping and ventilation assemblies. Thereby, they can employ lower wage-higher productivity labor to produce products offsite which increase profitability. However, these sub-contractors experience cost overruns in the actual implementation of VDC. Specifically, when design changes are made, these trades must reproduce the VDC plans for their pre-fabricated components. The cost overrun was a product of the additional effort required to update the model (Said \& Reginato, 2018). Model-based cost estimation could reduce the cost of evaluating design changes (Borhani, Dossick, Lee, \& Osburn, 2017). 


\subsubsection{BIM and Construction Cost Estimating}

BIM cost estimation should require estimators to spend less time on QTO and data manipulation and allow more time assessing qualitative components of the cost estimate. Figure 1 quantitively depicts the improvement using Autodesk Revit. QTO consumes over half of an estimator's time. It is a process of measuring existing data, so QTO alone does not add value to a project. Model-based cost estimation affords more time for the estimator to add value to a project with original thought (Hall, 2018).

\begin{tabular}{|c|c|c|c|}
\hline \multirow[b]{2}{*}{ Category } & \multirow[b]{2}{*}{ Contents } & \multicolumn{2}{|c|}{ time [minutes] } \\
\hline & & Manual & Revit \\
\hline Table of rooms & Floor and ceiling composition & 40 & 20 \\
\hline Foundations & Pads, belts, slabs & 125 & 20 \\
\hline Construction phase & Walls, pillars, girders & 420 & 10 \\
\hline Vertical constructions & Masonry, isolation & 450 & 30 \\
\hline Wall surface & Plasters, paints & 330 & 20 \\
\hline Ceiling composition & Ceiling composition & 20 & 15 \\
\hline Floor composition & Floor composition & 40 & 15 \\
\hline Wall composition & Wall composition & 100 & 20 \\
\hline Facade & Facade & 240 & 20 \\
\hline Roof composition & Roof composition & 20 & 5 \\
\hline Balcony composition & Balcony composition & 50 & 15 \\
\hline Groundwork & Excavations, embankments, removal & 120 & - \\
\hline Staircases & Staircases & 60 & - \\
\hline Other construction and work & Cleaning, shining, covering & 70 & 20 \\
\hline Tables for take-offs & & - & 130 \\
\hline Total & & 2085 & 340 \\
\hline
\end{tabular}

Figure 1 QTO Time Savings with BIM (Olsen \& Taylor, 2017)

Figure 1 does not depict the categorical loss of accuracy in BIM QTO. Therefore, the use of BIM in cost estimation is currently limited to conceptual estimates. At early project stages, large contingencies account for uncertainty (AACE RP 17R-97, 2011). The uncertainty and accompanying contingency mitigate the effect of BIM model inaccuracies or omissions on the estimate. Detailed estimates are not performed using BIM today since no consistent framework exists because BIM is not conditioned to represent a cost estimate (Borhani, et al., 2017). 
The framework does not exist partially because the existing software tools are insufficient. BIM-based QTO does not capture enough detail to accurately estimate a project. It yields a bill of materials without any context to the item's complexity or the contractor's definition of the work. Construction estimators are interested in identifying the scope of work (SOW). The SOW involves quantities, as well as people and processes required to complete the work (Stanford Engineering, 2018). A system of model-based estimation must allow estimators to capture these other parameters and associate them with the model generated quantities. (Trimble Navigation Limited, 2014).

BIM's estimating allure is in its structure of storing data. It allows automation in the takeoff process. Specifically, the organization and unique identification of model elements. Model elements are categorized in a hierarchical structure by; 1) category, 2) family, 3) type, and 4) the element. A BIM-based QTO can select all instances in the model by any of these hierarchical steps. A categorical breakdown in this fashion can help estimators select all the elements in a model associated with a specific quantity if the model hierarchy matches the structure of the estimate. BIM is effectively a system for spatially organizing a cost estimate (Golaszewska \& Salamak, 2017).

\subsubsection{VDC and the Contractor's Participation in Design}

In 2007, it was noted that BIM technology promises construction teams the ability to simulate building construction. The teams who employ VDC can gain a competitive advantage by simulating certain complicated activities within a project. Simulation of these activities reduces the risk of changes in the field. This trend is increasing exponentially (AGCA, 2007). 
Since 2007, the number of activities a team can simulate has increased. This trend started with high-risk activities. An example is mechanical, electrical, and plumbing (MEP) coordination. Specifically, in renovations of existing structures. This coordination involves multiple systems which must occupy the same limited interstitial spaces of buildings. Those limited spaces are confined by the existing structure. When coordination is inadequate, MEP systems must be resized causing cost and schedule delays (Farnsworth, Beveridge, Miller, \& Christofferson, 2014) VDC allows teams to avoid these cost and schedule delays.

VDC is a tool for the team to control construction risks during design. MEP coordination is one small subset of risks endured on a project. Worker safety and even variations in labor productivity are risks that VDC is used today to assess. The general contractors ultimately decide if a project will use BIM since they are the link between designer and owner during design, construction, and commissioning. A design team's model is only valuable to the owner if the model was referenced and updated during construction. General contractors are increasingly adopting BIM, thereby influencing the other project stakeholders to adopt BIM as well (Ghaffarianhoseini, et al., 2017).

VDC involves the synthesis of BIM models with external data to optimize the results of a project. A BIM model represents the finished product since it's used to communicate design intent. This leaves the model absent of many social and technical methods necessary to achieve the finished product. VDC adds a broader scope to modeling. It incorporates the design intent but includes the means and even motivations for achieving that finished product. VDC is pertinent to model-based cost estimation 
since the cost is driven by the product, organization, and process models (Kam, Song, \& Senaratna, 2016).

\subsection{Construction Cost Estimation}

This section reviews current methods of cost estimation in construction. A cost estimate is an establishment of the most probable cost for a project. The project must have a defined scope. In construction, this scope is typically delineated by the drawings and specifications (AACE RP 10S-90, 2015). It is important to note that the construction cost estimate is a linear representation of a dynamic system. Managing a cost estimate means managing the influences on the dynamic system (Alzraiee, 2013).

\subsubsection{Cost Estimate Uses}

There are multiple stakeholders who use construction cost estimates, and each seeks different information from the report. The interest in information also varies with the stage of an estimate. The three discrete stages include; 1) cost planning, 2) estimating, and 3) tendering. Cost planning helps stakeholders establish a budget. Estimating informs the design team to make design changes to keep the project on budget. Finally, tendering is employed by the construction team to establish a firm price (Brook, 2017).

\subsubsection{AACE Cost Estimating Standards}

The Association for the Advancement of Cost Engineering (AACE) is an organization that influences standardization in cost estimation. These standards help increase cost estimate reliability. A selection of standards that are prevalent in the context of BIM model-based cost estimation is presented in this sub-section. These standards influence cost estimate reliability and repeatability. 
The AACE outlines prescriptive requirements for the skills and knowledge of cost estimators. This comprehensive list incorporates most characteristics required to complete an accurate estimate. Since these characteristics produce successful estimates, they can guide the development of estimation software. The main skills and knowledge that translate to development of software that facilitates model-based cost estimation includes; 1) clearly identified supporting knowledge, which constitutes all the background data that may be incorporated in a cost estimate 2) total cost management(TCM), which is a structured map that explains each step in a cost estimate and how that estimate figures into the project life cycle. 3) estimate planning, identifies the goal of an estimate and devotes the appropriate resources towards achieving the goal. and 4) performance assessments generate supporting knowledge in the form of historical data. A successful assessment guides future improvement of cost estimate assumptions in similar construction projects (AACE RP 19R-97, 2012).

The AACE provides a comprehensive list of terms relevant to the cost estimating profession. The Actual Cost of Work Performed (ACWP) is the cost an estimate is intended to project. It consists of all the dollars spent to complete an activity. So, in comparison to the cost estimate, a contractor profits when ACWP is less than or equal to the estimated cost for that activity. The construction cost estimators job is to project the ACWP. The construction cost estimate ascertains the ACWP (AACE RP 10S-90, 2015). The reliability of this projection depends in part upon the completeness of the drawings used in the cost estimate. The AACE categorizes estimates based on their class. Each class considers how well the plans define the SOW. It also considers the method used to produce the estimate. The goal of categorization is to establish an expected accuracy 
range. Changing the method of estimation could increase the expected accuracy range (AACE RP 17R-97, 2011).

\begin{tabular}{|c|c|c|c|c|c|}
\hline \multirow[b]{2}{*}{ ESTIMATE CLASS } & \multirow{2}{*}{$\begin{array}{c}\text { Primary } \\
\text { Characteristic } \\
\text { MATURITY LEVEL } \\
\text { OF PROJECT } \\
\text { DEFINITION } \\
\text { DELIVERABLES } \\
\text { Expressed as \% of } \\
\text { complete definition }\end{array}$} & \multicolumn{4}{|c|}{ Secondary Characteristic } \\
\hline & & $\begin{array}{l}\text { END USAGE } \\
\text { Typical purpose of } \\
\text { estimate }\end{array}$ & $\begin{array}{l}\text { METHODOLOGY } \\
\text { Typical estimating } \\
\text { method }\end{array}$ & $\begin{array}{c}\text { EXPECTED } \\
\text { ACCURACY } \\
\text { RANGE } \\
\text { Typical +/- range } \\
\text { relative to index of } 1 \\
\text { (i.e. Class } 1 \text { estimate) } \\
{\left[\begin{array}{l}\text { [a] } \\
\text { (a) }\end{array}\right.}\end{array}$ & $\begin{array}{l}\text { PREPARATION } \\
\text { EFFORT } \\
\text { Typical degree of } \\
\text { effort relative to least } \\
\text { cost index of } 1^{[b]}\end{array}$ \\
\hline Class 5 & $0 \%$ to $2 \%$ & $\begin{array}{l}\text { Screening or } \\
\text { feasibility }\end{array}$ & $\begin{array}{l}\text { Stochastic } \\
\text { (factors and/or } \\
\text { models) or } \\
\text { judgment }\end{array}$ & 4 to 20 & 1 \\
\hline Class 4 & $1 \%$ to $15 \%$ & $\begin{array}{l}\text { Concept study or } \\
\text { feasibility }\end{array}$ & $\begin{array}{l}\text { Primarily } \\
\text { stochastic }\end{array}$ & 3 to 12 & 2 to 4 \\
\hline Class 3 & $10 \%$ to $40 \%$ & $\begin{array}{c}\text { Budget } \\
\text { authorization or } \\
\text { control }\end{array}$ & $\begin{array}{l}\text { Mixed but } \\
\text { primarily } \\
\text { stochastic }\end{array}$ & 2 to 6 & 3 to 10 \\
\hline Class 2 & $30 \%$ to $75 \%$ & $\begin{array}{l}\text { Control or } \\
\text { bid/tender }\end{array}$ & $\begin{array}{c}\text { Primarily } \\
\text { deterministic }\end{array}$ & 1 to 3 & 5 to 20 \\
\hline Class 1 & $65 \%$ to $100 \%$ & $\begin{array}{l}\text { Check estimate } \\
\text { or bid/tender }\end{array}$ & Deterministic & 1 & 10 to 100 \\
\hline
\end{tabular}

Figure 2 AACE Cost Estimate Classification System (AACE RP 17R-97, 2011)

The process of producing a cost estimate is outlined by the AACE. It includes 7 steps of direct effort: 1) establishing the estimate requirements based on the end user, 2) planning the estimate based on the WBS and OBS, 3) establishing cost using the project documents and external sources, 4) assess the risk produced by uncertainty, 5) document the basis of estimate, 6) compare the estimate to historical data, and 7) deliver the estimate to enterprise decisionmakers. This process is described in Figure 3 (AACE RP 19R-97, 2003). 


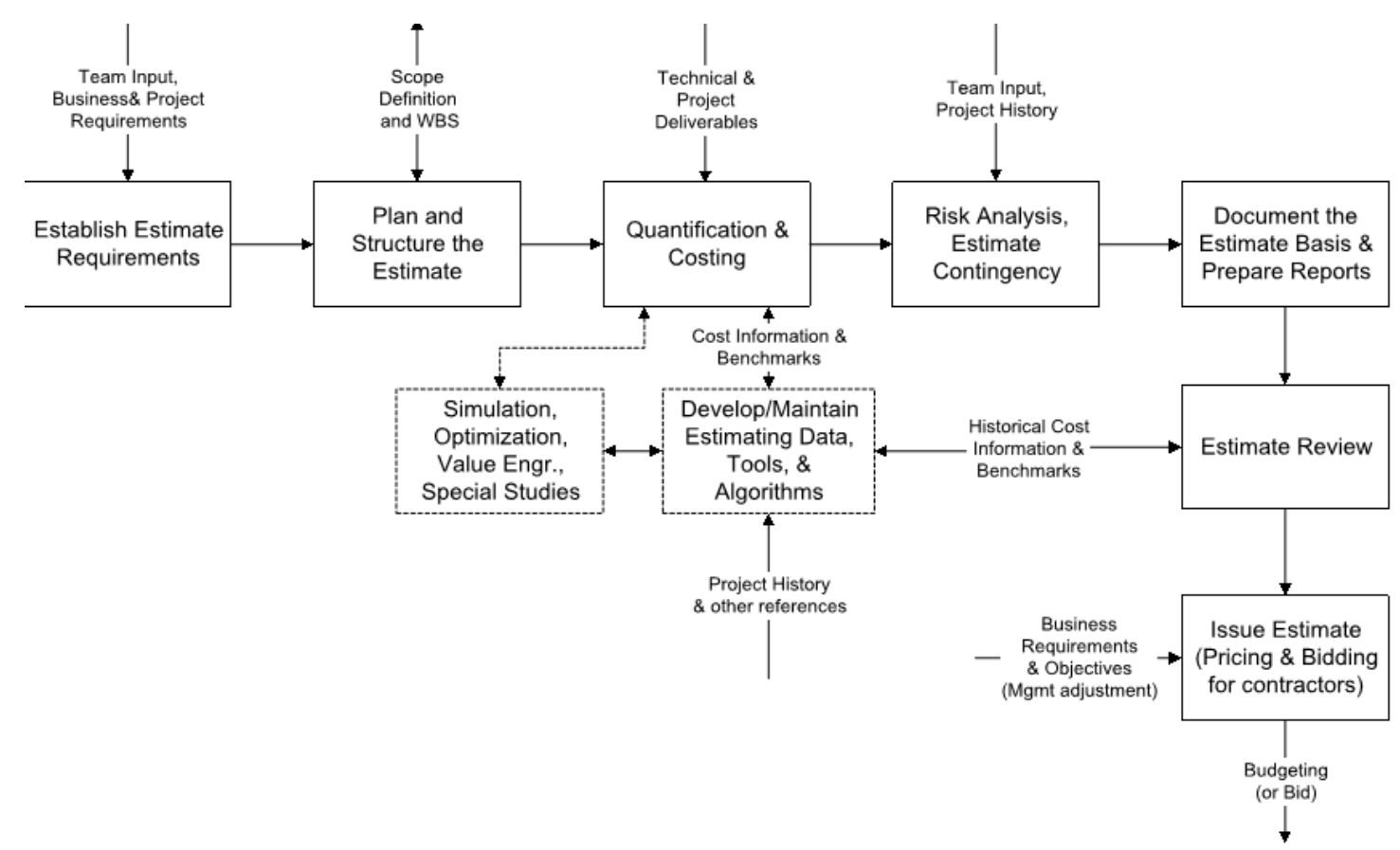

Figure 3 AACE Cost Estimate Process Diagram (AACE RP 19R-97, 2003)

\subsubsection{Traditional QTO and Cost Estimating Method}

The traditional estimating method is defined in this thesis as the use of $2 \mathrm{D}$ (paper or PDF) drawings for QTO and Excel for producing the estimate. This is the most common procedure used to produce detailed cost estimates. The seven steps are described in detail in the following list:

1. In the traditional method, step 1 consists of communication external to the estimate. Email correspondence and meetings between estimators and designers guide the requirements of the estimate. This information is not attached to the contract documents or the cost estimate.

2. In step 2, the $\mathrm{GC}$ would review the plans and specifications to define the entire SOW. Estimators read the plans and specifications to visualize project requirements. Once visualized, the estimator can categorize each requirement by WBS. 
3. During step 3, the estimators(s) measure quantities and categorize them by the WBS. Measurements are made by drawing shapes on the 2D plans to capture lengths, areas, and volumes of the work-in-place (AACE RP 34R05, 2014). The estimator manually asserted where each condition occurred, and there is no link between the quantity and the corresponding specification section (Chen, Lu, Peng, Rowlinson, \& Huang, 2015).

4. In step 4, the estimators assess the estimate's uncertainty. The two types of risk are epistemic, knowledge-based, and aleatory, "roll of the dice" (Der Kiureghian, 2009). An example of epistemic risk is information the estimator does not have time to review in the contract documents. An aleatory risk is an uncertainty in manually produced quantities. Historical average data is used to mitigate each risk (AACE RP 19R-97, 2003).

5. In step 5, estimators prepare a basis of estimate. During steps 1-4, the estimator(s) take mental or physical notes of any unique conditions or possible external impacts on the project. They also produce a project narrative. This qualitative information is combined typically into a word document (AACE RP 10S-90, 2015).

6. During step 6, the estimators compare benchmarks to similar projects. These benchmarks include price per floor area, the price per unit, or price per occupant. They may drill into a specific WBS section to compare benchmarks of that section. Examples of this include the cost of plumbing per occupant or the price of air conditioning per building volume. The purpose of this review is to identify any significant variances with 
historical data. Then the estimators must justify the variance or correct major mistakes.

7. The GC produces a cost report for other project stakeholders. This report must be manually produced by manipulating the individual estimate line items (Brook, 2017).

Estimators who collaborate must manually coordinate scopes through communication methods detached from the estimate i.e. email or physical meetings. Upon completion, the estimators must manually review each other's work to confirm the entire SOW is captured exactly once. Work-sharing allows multiple BIM users to work on the same file simultaneously. It has enabled improved collaboration and quicker project delivery. The iterative nature of computers combined with the ability to easily collaborate through work-sharing has improved the design process (Autodesk, 2018). BIM should be leveraged to do the same for construction cost estimation.

\subsubsection{Current BIM QTO Systems}

This section examines the current body of knowledge pertaining to BIM QTO and its accompanying computation platforms. All existing BIM cost estimating platforms rely on information external to the BIM model. The models supplied by the design team lack “consistent quality". Up to half of the data for QTO may be absent from the BIM model (Olsen \& Taylor, 2017). The current BIM QTO systems attempt to map designer's objects straight into an estimate ledger (Lawrence, Pottinger, Staub-French, \& Nepal, 2014). This mapping process is inconsistent since "Error-free classification is beyond state of the art" (Wu \& Zhang, 2018). In model-based cost estimation, there is a reliable and repeatable method for producing a cost estimate from a BIM model, the current 
systems are not reliable or repeatable (Borhani, et al., 2017). It is worth categorizing the BIM QTO systems as 2D/3D or 3D only. A 3D system can only quantify what the design team has authored in their BIM model. A 2D/3D system allows estimators to author additional quantities. A 2D/3D system can achieve greater estimating accuracy by adding more information to the model in the form of QTO conditions (Sattineni \& Bradford, 2011).

Figure 4 depicts the survey popularity of BIM software for all uses in industry. This is the justification for the literature review's focus on Autodesk Assemble and Navisworks for BIM-based cost estimation. As seen in Figure 4, 24 software platforms were used by at least one professional in this study for BIM applications.

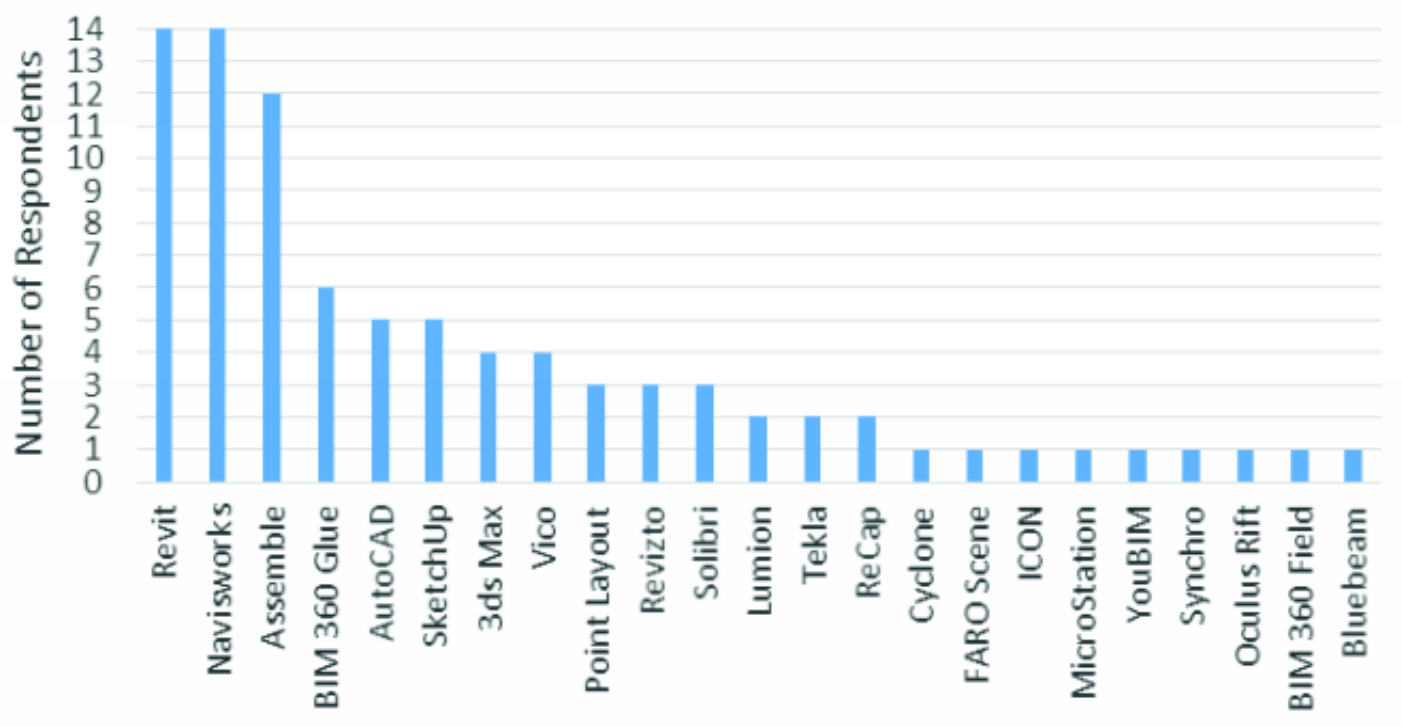

Figure 4 Software Popularity (Lawrence, et al., 2014)

Navisworks is a project review software. It can review models and data produced by multiple stakeholders in a single aggregate model (Figure 5). Navisworks can read over 60 native file formats, so it is popular for its interoperability. The native Navisworks file is up to 80 percent smaller than the source formats, this helps immensely with sharing 
and collaboration. Because of these characteristics, its most popular use is in "clash detection" and not cost estimation (Dodds \& Johnson, 2011).

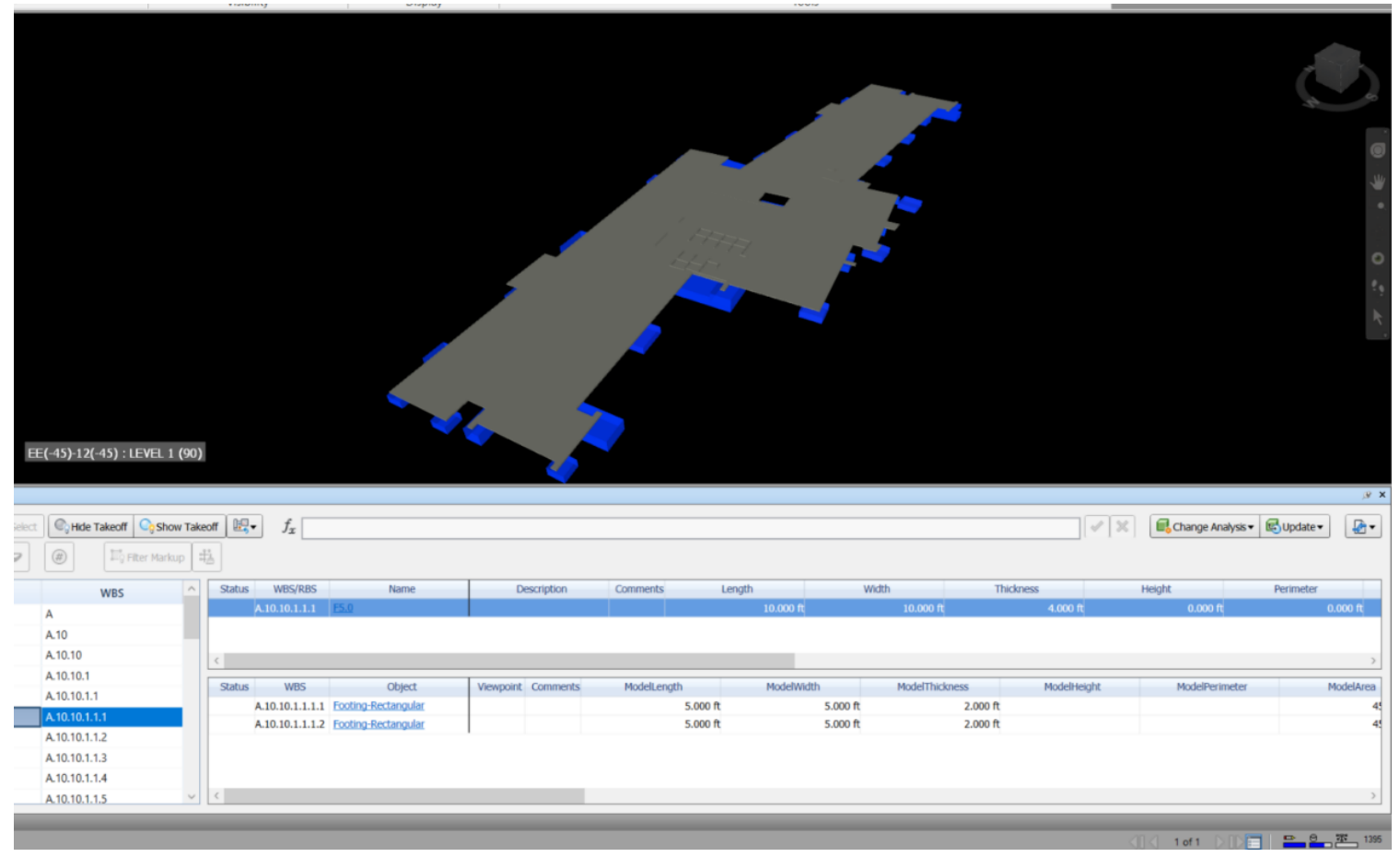

Figure 5 Navisworks QTO of Spread Footings, Highlighted Blue

Navisworks is not popular for cost estimation. It is not BIM authoring software, meaning the object parameters in Navisworks are strictly produced by the native software and original author. The accuracy of extracted cost estimate parameters depends on the modeling standards dictated by the design team (Monteiro \& Martins, 2013). Figure 5 depicts the designer-authored length, width, and thickness parameters in the QTO. In order to produce a complete QTO, any gaps in the SOW must be manually taken off in a $2 \mathrm{D}$ view. This process incorporates $2 \mathrm{D}$ QTO, similar to the traditional method.

Assemble is the most used 3D BIM QTO software package (Olsen \& Taylor, 2017). It reads BIM model elements directly from the native Revit file (Figure 6). Interoperability is limited since it can only read from some Autodesk formats. However, the user interface is simple to use, and the platform is web-based, both characteristics 
make it popular for QTO. It enables conditioning and querying BIM data to other estimating platforms by way of a CSV export (Autodesk, 2018). This platform is more limited by gaps in the SOW. There are no features allowing authoring of additional elements. So, it is typically not used at the bid-tendering phase of cost estimation. At this phase, the AACE cost estimate class is low, meaning that the acceptable cost contingencies are low. This means that a bid-tender cost estimate should more closely project the ACWP for the project.
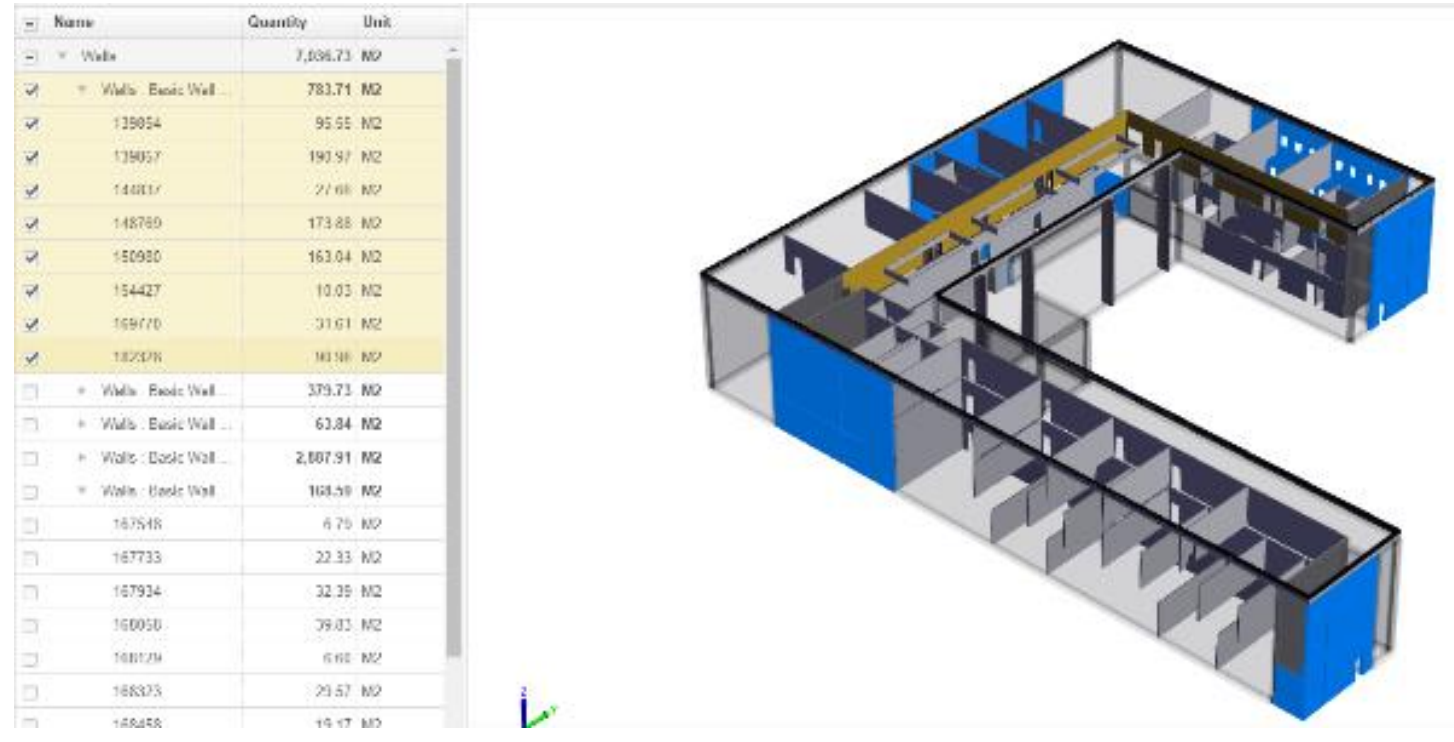

Figure 6 Assemble QTO of Masonry Walls, Highlighted Blue

The fact that Assemble is limited to reading from Revit increases its accuracy by rigid mapping in comparison to other BIM QTO platforms. Since Revit has a distinct data structure, the mapping between Revit and Assemble is fixed. Therefore, there are no data losses when information is transferred from Revit to Assemble. These two do not communicate using the IFC framework. They are both products administered by Autodesk that use proprietary data mapping. 


\subsection{Construction Contracts}

This section reviews various popular contract delivery methods employed in construction to identify each delivery method's impact on model-based estimation. The type of construction contract dictates how and when BIM authoring is funded. From the cost estimating perspective, it is preferable for BIM funding to be provided early and by the client. This funding strategy is favored by collaborative contract delivery methods.

\subsubsection{Delivery Methods \& Cost Estimation}

In design-bid-build, the owner establishes a contract with the construction team. This contract obligates them to provide the finished product for their bid price. Cost estimators in this delivery method establish a bid for delivering the product per the plans and specifications provided by the owner (Fernández-Solís \& Chugh, 2018). Meanwhile in design-build, the owner contracts with a single firm for design and construction services. The costs and scope of the design-build contract are determined by the team with a guaranteed max price (GMP). A GMP limits the financial risk of the owner but provides flexibility to the project delivery team. A fixed price bid would require $100 \%$ complete design documents, which are not available (Burnham \& Nagata, 2016).

Bridging is a blend of the two previous approaches and involves two separate design entities. The first team is hired by the owner to produce bridging documents. The second design team is hired by the construction team in the same fashion as a designbuild contract. The owner can dictate quality or functionality through the bridging documents while the construction team can adapt those documents for constructability. Then they produce the final plans and model which they finally build. This blend offers the flexibility of design-build while the product is defined by the owner (Fernández-Solís 
\& Chugh, 2018). In this method, the cost estimate is a blend of both parties too. The owner establishes a preliminary budget with the bridging documents, then estimators project the price to deliver the project their team designed (Burnham \& Nagata, 2016).

\subsubsection{Warranted Model Accuracy}

In design-bid-build, the plans and specifications constitute the entire scope of work. Models are provided "for information purposes only" as an omission from the model could be argued as a limitation to the SOW. Model-based cost estimation in design-bid-build would be completely driven by the construction team who would also have to produce the model from $2 \mathrm{D}$ drawings and compensate for that cost in the bid. This repetitive process still saved time in controlling cost during construction. So, modelbased estimation in design-bid-build is possible (Zhao \& Wang, 2014), but the additional cost is a great loss if the bid is not won.

In design-build, no model is provided by the owner. The team dictates the design and BIM authoring requirements to stakeholders. One requirement is a BIM model level of detail that is enough to produce a cost estimate. The team is compensated to produce the design, so they can invest resources in model-based cost estimation and be compensated through design fees paid by the owner. The team produces and thus dictates the BIM model's warranted accuracy (AIA, 2007).

Bridging produces two separate document sets; the bridging documents and construction documents. This contract structure has the same warranted model accuracy as design-build. The construction team ultimately governs the level of detail and quality of construction documents and model. The owner can influence this method early by 
producing a detailed bridging model. However, it's ultimately the construction model that defines the scope of work (Fernández-Solís \& Chugh, 2018).

\subsection{Complications in BIM for Model-Based Cost Estimation}

A BIM model's purpose is to represent design intent, which does not communicate cost by default. This section examines BIM's limitations that negatively impact its potential to produce reliable cost estimates. The underlying theme is inconsistencies in information and software tools (Olsen \& Taylor, 2017).

\subsubsection{Ontology of Model Elements}

The general term ontology is a component in the study of philosophy. It examines the concept of what objects exist and their categorization. Its goal is ascertaining an objective reality. Ontology in BIM is the term used to describe the formal and explicit specification of model elements. It seeks to rigidly categorize BIM elements by their family, category, type, and ultimately cost. An ontology does not allow modifications of BIM element definitions by the design team. A successful ontology requires a singular library of model elements which is accessible to all who use the software (Sabol, 2008). An ontology also requires that modifications to a model element do not change its definition. Any stakeholder who has access to a model can produce a model element. Therefore, any stakeholder with model access can modify the parameters and the resulting meaning of a model element. This introduces uncertainty in the definitions of model elements. An ontology is meant to eliminate subjectivity in the process of estimating. Figure 7 depicts the underlying ontological framework for BIM-based cost estimation of tile flooring (Lee, Kim, \& Uy, 2014). 

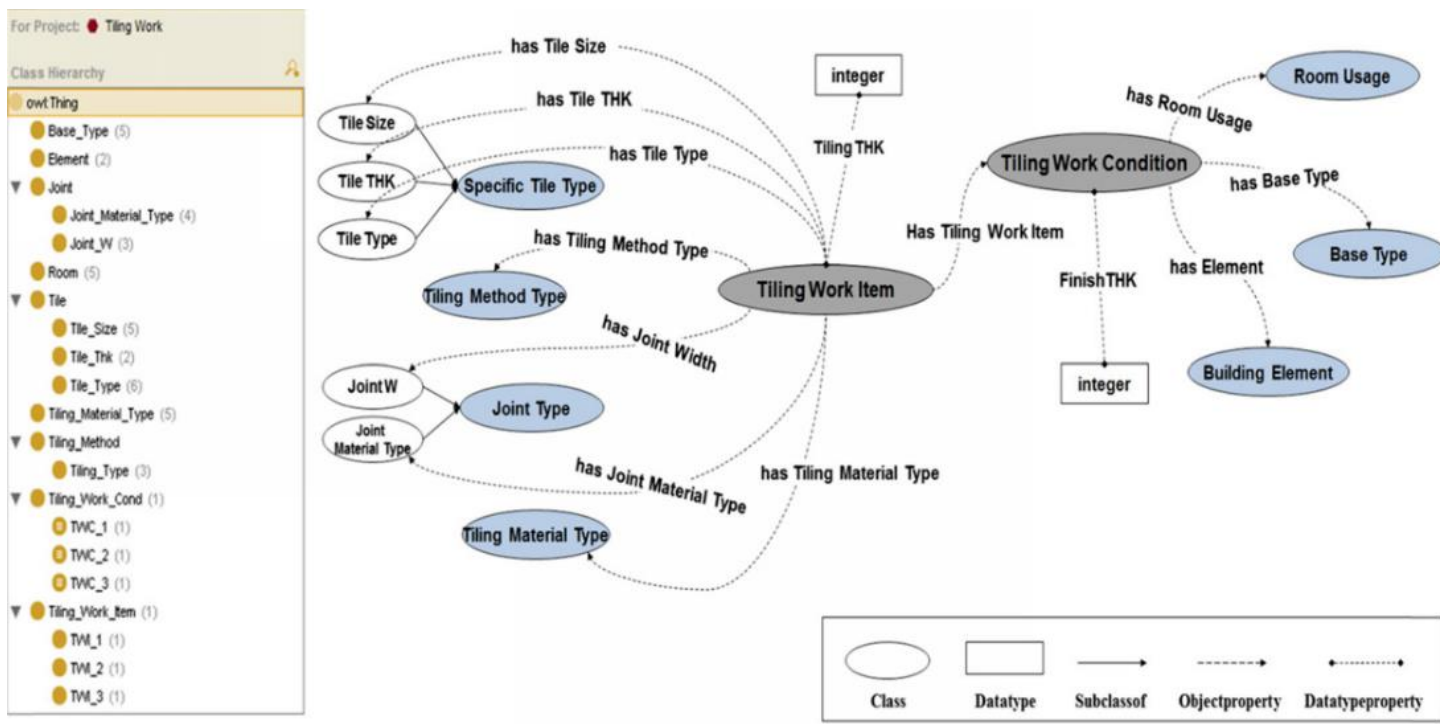

Figure 7 Ontological Cost Estimation Framework (Lee, Kim, \& Uy, 2014)

BIM cannot be compressed into an ontology (Chen, John, \& Cox, 2018). Without an ontology, the model based estimating process must involve manual categorization of model elements. The model-based cost estimation process cannot be automated since the designers do not have the intent of communicating cost directly (Monteiro \& Martins, 2013). Under the current object-oriented domain, a second hierarchy must be produced exclusively for cost estimating. Since classes defined in different domains cannot share parameters, the cost estimate class must be produced by manual manipulation (Niknam \& Karshenas, 2015). The manual process does not have to be tedious. Digital models contain tools for manipulating data with much greater ease than $2 \mathrm{D}$ paper drawings (Trimble Navigation Limited, 2014).

A philosophy more appropriate for BIM is creating a flexible mapping between a designer's model and cost estimation data. This flexible map method still involves an ontology, but it is developed on a project basis. Each project team involves different stakeholders, who ultimately communicate in varied fashions. The ontological definitions should be set at the project level (Franco, Mahdi, \& Abaza, 2015). Figure 8 depicts an 
ontological map produced for a spread footing. Figure 8 suggests there is a shared ontology between the construction team and designers. In this situation, the designers are producing BIM models with the intent of communicating cost. Since they do not have complete knowledge of how the contractor will complete the construction project, they cannot fully define the cost of construction. The designer's main goal in BIM is to communicate the design intent of the construction project. The estimators can produce a flexible map in the absence of a shared ontology (Niknam \& Karshenas, 2015).

The flexible map system does not eliminate input from estimators as true automation or ontology would. Instead, this tool gives estimators the efficiency to focus their efforts on tasks more complicated than the quantity takeoff and organization of cost estimate. Flexible mapping uses a data structure that points estimator input to existing objects in BIM. These pointers reuse the parameters of the BIM objects in the cost estimate (Lawrence, et al., 2014). 


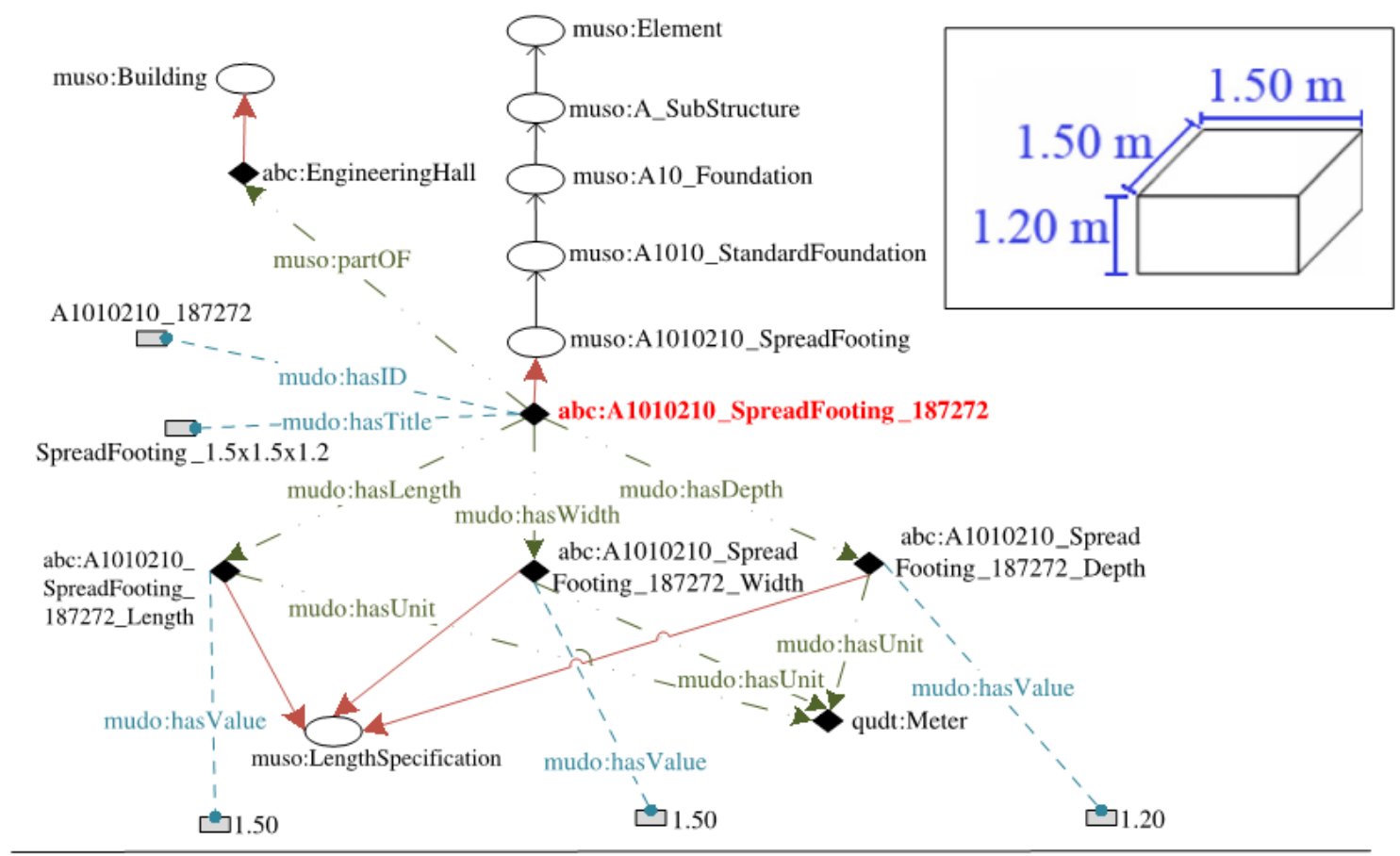

@ prefix muso: http://www.marquette.edu/building_model_shared_ontology\# @ prefix mudo: http://www.marquette.edu/building_model_design_ontology\# @ prefix abc: http://www.ABC_DesignCompany .com\#

@ prefix qudt: http://qudt.org/vocab/unit\#

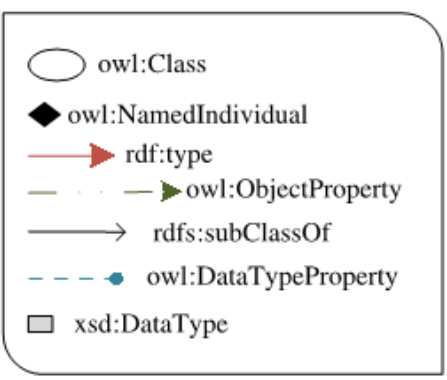

Figure 8 BIM Knowledge-Base Ontological Map (Niknam \& Karshenas, 2015)

A flexible map affords estimators the framework to document subjectivity and standardize it rather than eliminating it in a rigid ontology. An estimator requires months of training on automated QTO software before it yields an improvement in efficiency. This growth in efficiency is marred by the estimator's distrust of automation (Sattineni \& Bradford, 2011). Meanwhile, a flexible map is simply a tool to document the assumptions that veteran estimators already employ (Wu \& Zhang, 2018). 


\subsubsection{Model Level of Development}

The model quality is the key indicator of the simulation's performance. One aspect of model quality is the detail to which elements are represented; this is commonly referred to as Level of Development (LOD). AIA Document E203-2013 sets industry standards for LOD (Borrmann, Konig, Koch, \& Beetz, 2018). A graphical representation of that standard LOD classification is presented in Figure 9.

\section{LEVEL of DEVELOPMENT \\ LOD 100 LOD 200 LOD 300 LOD 400 LOD 500}
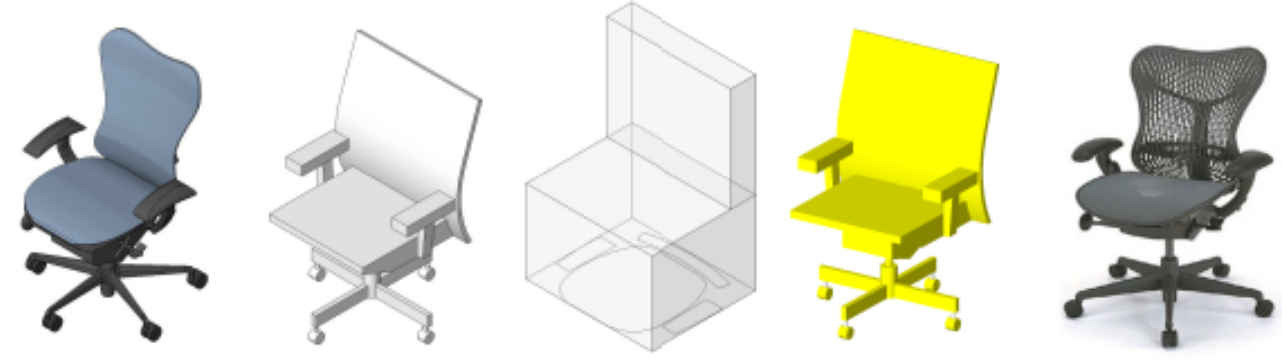

Concept (Presentation)
\begin{tabular}{|l|}
\hline DESCRIPTION: \\
Office Chair \\
Arms, Wheels \\
WIDTH: \\
DEPTH: \\
HEIGHT: \\
MANUFACTURER: \\
Herman Miller, Inc. \\
MODEL: \\
Mirra \\
LOD: \\
100 \\
\hline
\end{tabular}

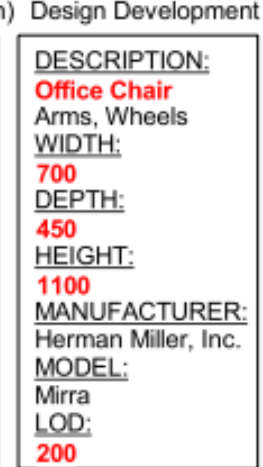

Documentation
\begin{tabular}{|l|}
\hline DESCRIPTION: \\
Office Chair \\
Arms, Wheels \\
WIDTH: \\
\hline 700 \\
DEPTH: \\
450 \\
HEIGHT: \\
1100 \\
MANUFACTURER: \\
Herman Miller, Inc. \\
MODEL: \\
Mirra \\
LOD: \\
300 \\
\hline
\end{tabular}

Construction
\begin{tabular}{|l|}
\hline DESCRIPTION: \\
Office Chair \\
Arms, Wheels \\
WIDTH: \\
685 \\
DEPTH: \\
430 \\
HEIGHT: \\
1085 \\
MANUFACTURER: \\
Herman Miller, Inc \\
MODEL: \\
Mirra \\
LOD: \\
400 \\
\hline
\end{tabular}

Facilities Management
\begin{tabular}{|l|}
\hline DESCRIPTION: \\
Office Chair \\
Arms, Wheels \\
WIDTH: \\
685 \\
DEPTH: \\
430 \\
HEIGHT: \\
1085 \\
MANUFACTURER: \\
Herman Miller, Inc \\
MODEL: \\
Mirra \\
PURCHASE DATE: \\
01/02/2013 \\
\hline
\end{tabular}

Figure 9 Model LOD (McPhee, 2013)

LOD is currently proportional to the level of effort a designer spends in representing the work. So, to achieve a high level of detail, design teams must devote considerable modeling resources. This resource devotion is cost prohibitive to completing a model that closely represents all activities in a project. Therefore, BIM efforts typically focus on specific high-risk activities which achieve high reward for low modeling effort (Chen, et al., 2015). 


\subsubsection{Interoperability of Software and Data}

Interoperability is the exchange data between applications to avoid data re-entry or recycling. Interoperable data remains usable when transferred between programs. Interoperability, strongly connected to an ontology, is analogous to the structure of the sentence, while ontology is the meaning of words in that sentence. Interoperability leads to increased collaboration amongst stakeholders who utilize various software platforms (Wu \& Zhang, 2018).

The BIM user must consider interoperability when selecting software applications (Azhar, 2011). Certain software combinations will require macros, programs, or other "links" to semi-automatically transcribe data from one data structure to the other software which requires this intermediate manipulation is weakly interoperable (Wu \& Zhang, 2018). The additional resources spent to transcribe data reduces stakeholder buy-in to BIM-based project management (Ma, Xiong, Olawumi, Dong, \& Chan, 2018).

The ISO-registered industry foundation classes (IFC) were introduced to improve software interoperability. This data structure should produce a "one-to-many" information flow. The IFC allows parameters of a model element produced by one stakeholder to be re-interpreted for use by others. However, this re-interpretation still requires subjective human input. An IFC object representing a wall could be drawn using IfcWallStandardCase, IfcSlab, or Ifcbeam and visually present the same result. Thus, successful IFC interoperability is also driven by an ontology. Those who model walls must always use the correct IFC class to eliminate the need for re-interpretation. The IFC provides only a data structure and not standards on data within the structure $(\mathrm{Wu} \&$ Zhang, 2018). 


\subsubsection{Data Recycling}

Data recycling is a trend in the construction industry. It is the process of each stakeholder taking information and transcribing it into their own language (Figure 10). The current practice of manually parsing and collating data in spreadsheets is an enormous overhead to the industry. Since multiple stakeholders interact in construction projects, data recycling is common (Fulford \& Standing, 2013).

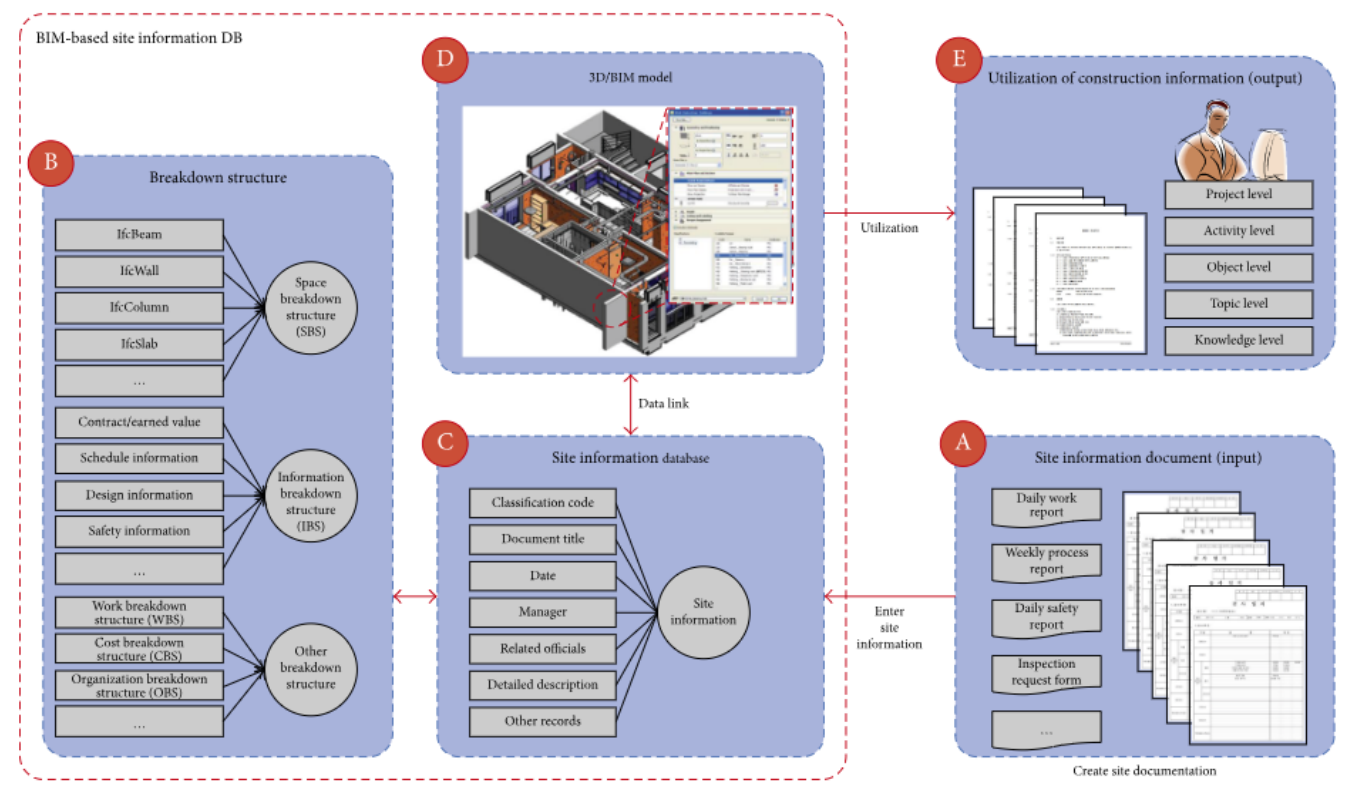

Figure 10 BIM Based Site Information Management (Lee, Park, \& Song, 2018)

Data recycling is detrimental because it increases error and is an effort that by itself does not add value to a project (Fulford \& Standing, 2013). Error is potentially introduced at each manual data transaction. In the above example, both the architect and engineer must manually transfer the current version file with the proper measurement scale. This process by itself does not add any value to the project. Value in construction is attained through activities that bring the project closer to completion (Chan, Scott, \& Chan, 2004). 


\subsection{Costs External to the Model Elements}

BIM can represent a host of data spatially by linking that data to a $3 \mathrm{D}$ element within the BIM model. Geometric parameters are automatically generated and stored in BIM elements since they are required to define the 3D model. These parameters also partially define the quantities of work items in cost estimation. However, additional information is required to complete the cost estimate. This section examines cost estimating information that is not stored in BIM elements automatically that should be considered to produce a reliable model-based cost estimate.

\subsubsection{Means and Methods of Construction}

Construction means and methods are activities employed to complete the project and not an element of the finished product. Since they are not the design intent, they are not documented in construction drawings or a designer's BIM model. However, both design and construction are acts of communication (Lobel, 2008). The GC completes plans a plan to build details then confirms them through submittals or requests for information (RFI). Thereby, model elements are not authored solely by the designer. The GC employs expert knowledge to determine means and methods (Lobel, 2008).

Defining the means and methods of construction involve a cognitive process of understanding the project's design intent. Scaffolding is an example of this, it is produced from a cognitive understanding that workers must access the exterior of a multi-story building. BIM is employed to plan, design, and represent scaffolding. The BIM-based approach allows other stakeholders to view, understand, and add input to means and methods the construction team selects to build the product (Kim, Cho, \& Kim, 2018). 
This digital documentation allows graphical communication the construction teams cognitive understanding of the design intent.

A design's constructability is driven by the means used to communicate between design and construction. The construction team is responsible for translating this information into a series of logical procedures to produce the finished product. RFI's and submittals are examples of communicating this cognitive process. BIM introduces a new platform to both produce and interprets RFI's and submittals. RFI's are a tool the GC uses when it cannot discern or produce the documented design intent (Lobel, 2008). Education overemphasizes the model authoring aspect of BIM. There is a poor conception that what can be modeled can be built. The construction teams that successfully adapt BIM for their projects should emphasize the people and process arms of over technology and information. Therefore, people who learn to translate a model to into a physical product, or produce means and methods of construction, are more likely to successfully employ BIM (Chen, John, \& Cox, 2018).

\subsubsection{Multiple Quantities Driven by an Element}

A BIM element requires multiple work items to produce them physically. A wall assembly contains studs, insulation, and drywall. These items are physically separate but are lumped into a BIM model element. As much as twenty-five percent of the total cost is a result of these inferred quantities. One method for addressing additional work items is applying a waste factor or contingency. At the conceptual estimate level, contingencies are high (AACE RP 17R-97, 2011). These high contingencies conceal the effect of missing information by appending a factor to the bill of quantities. These factors are 
organic and not quantitative, they are produced by a subjective understanding of the model's accuracy (Olsen \& Taylor, 2017).

A more accurate approach for capturing additional work items is driving a multitude from the same BIM element. In other cost estimating systems, this requires the quantity to be produced multiple times. Using the stud wall assembly example, a separate selection in the BIM model would be made to define studs, drywall, and insulation. This is the "many-to-many" approach previously discussed (Wu \& Zhang, 2018). To simplify this, standard assemblies are adopted. The new problem is standardization requires adherence to a rigid definition (Lee, Kim, \& Uy, 2014). These standard cost estimating assemblies are difficult to use in custom situations. A more effective approach maps multiple estimate line items to a single BIM quantity (Figure 11). The difference is each component can be customized and the parameters driven by geometry in the BIM model.

\begin{tabular}{|c|c|c|c|c|c|c|c|c|c|c|c|c|}
\hline \multicolumn{13}{|c|}{ Assembly Takeoff } \\
\hline \multicolumn{2}{|c|}{ MAQ } & \multicolumn{4}{|c|}{ Interior - $47 / 8 "$ Partition (1-hr) } & Assembly & \multicolumn{5}{|c|}{ 0932- Wall - 5 Studs Interior } & Q \\
\hline & & \multicolumn{2}{|c|}{ Property } & Value & Unit & & \multicolumn{2}{|c|}{ Variable } & Value & Unit & Mapping & $\Delta$ \\
\hline & \multicolumn{3}{|c|}{ Count } & 13 & & \multicolumn{3}{|c|}{ Quantity } & 1 & & & \\
\hline & & \multicolumn{2}{|c|}{ TypeName } & Interior - $47 / 8 "$ Par... & & \multicolumn{3}{|c|}{ Length LF } & 226.947 & $\mathrm{ft}$ & Length $(\mathrm{ft})$ & \\
\hline & & \multicolumn{2}{|c|}{ Width } & 0.406 & $\mathrm{ft}$ & \multicolumn{3}{|c|}{ Ht. of Framing LF } & 15.5 & $\mathrm{ft}$ & & \\
\hline & \multirow{2}{*}{\multicolumn{3}{|c|}{ UnconnectedHeight }} & 15.5 & $\mathrm{ft}$ & \multicolumn{3}{|c|}{ Wall Doubled Fra... } & No & Y/N & Unconne... & \\
\hline & & & & 10.0 & rc & \multicolumn{3}{|c|}{ Stud Spacing IN } & 16 & in & & \\
\hline 5 & & \multicolumn{2}{|c|}{ Area } & 3107.05 & sq ft & \multicolumn{3}{|c|}{ Interior Stud Size } & 358 & in & & \\
\hline 2. & & \multicolumn{2}{|c|}{ Length } & 226.947 & $\mathrm{ft}$ & \multicolumn{3}{|c|}{ Interior Stud G... } & 25 & ga & & \\
\hline$\Sigma$ & & & lume & 46.753 & cu yd & \# Doors & Needin & g... & 0.000 & ea & & \\
\hline & & & & & & Door Fra & ame Stu & d... & 20 & ga & & $\nabla$ \\
\hline Galc & culation & & & & & $\mathrm{S} 1 \mathrm{mog}$ & & & & & $1 \%$ & $\infty$ \\
\hline & Phase & Item & Desc & ription & & Quantity & Unit & Loc & ation & Bid Item & Estimator & $\Delta$ \\
\hline$\square$ & 9120.010 & 10 & Labo & Interior Studs To Deck & & 226.947 & If & & & & & $\square$ \\
\hline$\square$ & 9127.010 & 30 & Labo & r Hang GWB Interior & & 0 & sf & & & & & \\
\hline$\square$ & 9132.010 & 10 & Labo & r GWB Finish All Steps & & 0 & sf & & & & & \\
\hline$\square$ & 9130.010 & 35 & Pins & \& Loads $1 / 2^{\prime \prime}$ & & 227 & ea & & & & & \\
\hline$\square$ & 9130.010 & 40 & Pins & \& Loads 3/4" & & 227 & ea & & & & & \\
\hline$\square$ & 9130.010 & 65 & Drill F & Pt Screw $7 / 16^{\prime \prime}$ & & 688 & ea & & & & & - \\
\hline 11 & & & & & & & & & & & • & \\
\hline $\mathrm{Ad}$ & just Producti & ity & 0 & $\%$ X $\checkmark$ Replace Exis & ing Estim & & Takec & & Cancel & Clos & Help (F & \\
\hline Quar & ntity: $0 \mathrm{sf}$ & & & Cost: $\$ 1,11$ & 5.54 & & & & & & & \\
\hline
\end{tabular}

Figure 11 BIM-Based Cost-Estimation Employing Flexible Mapping (Lawrence, et al., 2014) 
Often unnoticed are the multiple types of mappings an estimator uses to describe a work item. Figure 11 displays a "one-to-many" parameter mapping (Wu \& Zhang, 2018). This is what most BIM-based cost estimating software's emphasize. It solely analyzes geometric object properties. The other maps are more often produced subjectively with the cost estimator's own knowledge. They are proxies, aggregated conditions, and spatial conditions. It is useful to understand each map since design changes and updates to the model affect each differently. Another key feature of all types of mappings is their re-usability. When these cost estimating maps are recorded into a database, they should be used for subsequent cost estimates with similar BIM elements. Figure 12 presents an example of a flexible mapping framework (Lawrence, et al., 2014). A proxy map is used by estimators to price work based on historically related parameters. An example is a baseboard quantity based on the gross floor area of a lecture theater. The mapped items are the gross floor area and the definition of a lecture theater. In this example, a lump sum price was provided. The lump sum allowance does not suggest certainty in the quantity of millwork. The proxy map is useful when the plans are incomplete, but an estimator subjectively understands the relationship from historical data. Meanwhile, aggregated and spatial conditions abstractly represent different effects on productivity. Aggregated conditions measure the compound effect of repetition since productivity improves as the crew learns from each instance of practice. Spatial conditions are a subjective measure of how the geometry will affect productivity. For example, a curved concrete wall costs more to produce than a comparable straight wall. The complicated curves require special formwork and attention to detail. Aggregate and 
spatial conditions are important to estimate since their impact can vary total construction cost considerably (Lawrence, et al., 2014).

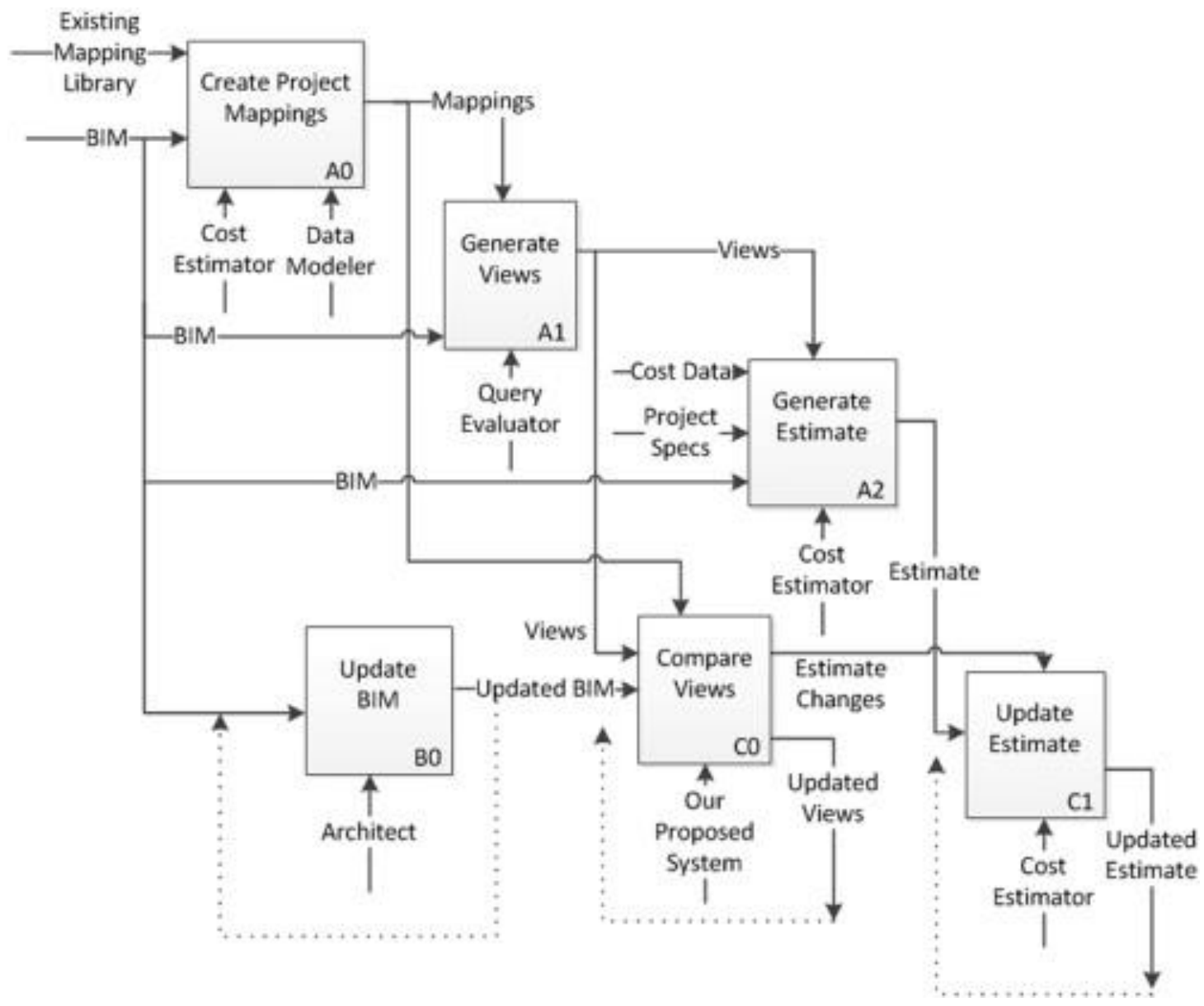

Figure 12 A Flexible Mapping Process to Update an Existing Cost Estimate (Lawrence, et al, 2014) 


\subsection{Construction Cost Control}

This section reviews construction cost control and its relationship to BIM modelbased cost estimation. Cost control is a process to monitor the project's budget against a benchmark. Since the cost estimate is a benchmark, a BIM model-based cost estimate should be tailored for use as a benchmark in cost control. Such a system should associate historical cost data with geometric properties of BIM objects.

\subsubsection{VDC Project Controls}

Project control involves monitoring the resources invested in an activity and correcting procedures to meet the targeted resource amounts. Earned value is the percentage of an activity that is completed. So, a $\$ 100$ activity that is $60 \%$ complete has an earned value of $\$ 60$. However, an activity that has consumed $60 \%$ of its duration has not necessarily earned $\$ 60$. Earned value management is a progress control system. It considers the activity completion alongside the schedule duration. It involves capturing the scope, schedule, and resources of the project. Earned value management enables a comparison of earned value to the actual cost of the work completed. Earned value management is one process that establishes investment versus work complete, thereby providing a metric to control a project (AACE RP 10S-90, 2015).

Today, VDC is occasionally employed to control certain project metrics. In a 2014 case study titled "A Comparison of Using Traditional Cost Estimating Software and BIM for Construction Cost Control” (Zhao \& Wang, 2014), both VDC and traditional methods were utilized to control a project. Including training on the new software, the BIM-based method took 74 hours to complete the QTO and cost estimate. Meanwhile, the traditional took 114 hours to complete the same QTO and cost estimate. Though 
quicker, this exercise revealed that BIM currently lacks a library of elements and properties to document estimate assumptions and infer parameter to modify the estimated cost.

Project control involves monitoring a complex web of variables and managing those variables to produce information for stakeholder decision making. VDC is excellent for the spatial organization of variables, Figure 13 below displays the spatial organization of a project schedule. While a system like this is a powerful cost control tool, it is not widely adopted today. One reason for this is manually updating a BIM model is tedious and error-prone. Therefore, the model remains static since synchronizing it with the ongoing building process is too cumbersome and the pace of construction is dynamic. A future VDC solution to this limitation is connecting model elements to parameters already measured on-site (Chen, et al., 2015).

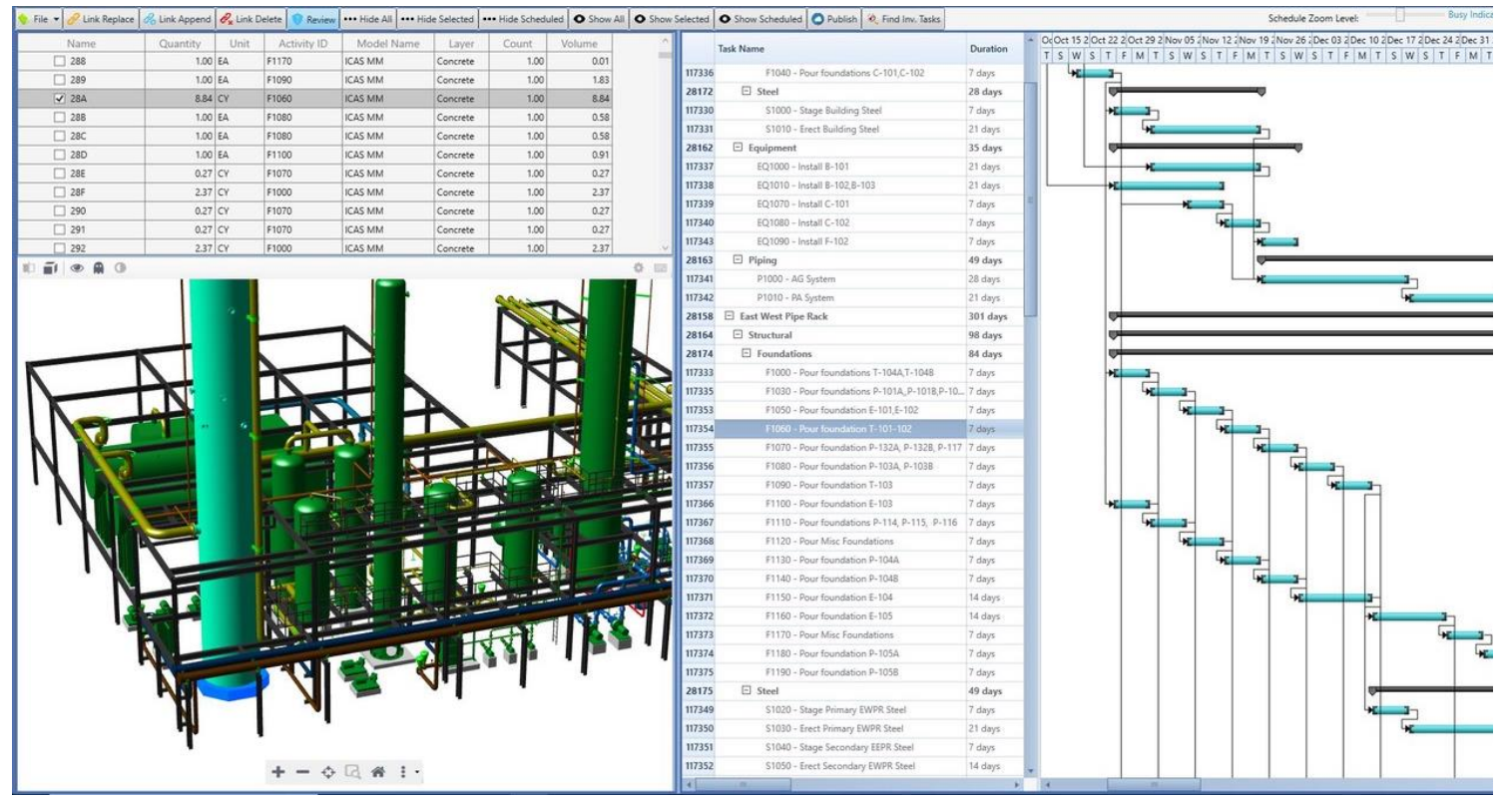

Figure 13 P6 and Assemble used in Model-Based Project Control (Scroggins, 2018) 


\subsubsection{Cost Codes for Construction Activities}

Cost codes associate the actual effort of resources with a given activity. The AACE prescribes standards for cost codes since they are a metric for controlling a project. A central theme is the standardization of codes between estimators and project management. Cost codes are a tool for communication and therefore require a dictionary or standard library. Two usages of cost codes worth highlighting are providing a means to correlate work-in-place to the budget and categorizing past performance. VDC provides a means for defining a cost code dictionary. The two highlighted usages will provide data to improve estimate accuracy (AACE RP 20R-98, 2003).

\subsubsection{Historical Data Reporting}

Historical data constitutes most of the cost basis for construction cost estimating. A proposed system for organizing this information involves indexing and storing the cost for specific BIM elements in a database. This proposed system allows future users of the database to reference these BIM elements with consistent work items for generally diverse projects. The link that enables building this database is controlling a project and feeding the data back to the initial database (USA PN US08357417, 1999). Proper collection and management of historical data allow estimators to build an operable database. This can be easily referenced by professionals in the firm handling similar decisions. BIM is great for organizing spatial data; however, it is rarely utilized to organize a historical database. One method of assimilating historical data, collecting labor productivity with timecards, was the lowest ranked use of BIM in a survey of GCs (Farnsworth, et al., 2014). 
Cost estimating is just one activity that would benefit from a spatially organized historical database. This detailed information can be used in court to support claims to damages resulting from other stakeholders. If other stakeholders introduce factors that impact labor productivity on the project and this is supported with historical data, then the construction team can be compensated for lost productivity (McDonald, et al., 2004).

\subsection{Industrial Manufacturing Perspective on Cost Estimation}

This section evaluates the industrial manufacturing industry's parametric cost estimation tools. This industry produces small parts similar to scaled-down construction projects. It has successfully implemented a parametric model-based cost estimation framework. This system functions by parametric assignment of cost to the geometric features of manufactured parts.

\subsubsection{Qualitative Versus Quantitative Cost Estimate Techniques}

The framework used by manufacturing professionals to assign a cost to the production of a part can be widened to the breadth of a building. The key difference is the scale. In construction, the focus is an entire project and not an individual part. Therefore, the same level of effort cannot be expended as it would be cost and schedule prohibitive. Qualitative cost estimation is primarily a comparative analysis of the current project and past results for projects with similar characteristics (Niazi, et al., 2005). Such an estimate is based on the buildings intended use, location, the ratio of area to the perimeter, and other global variables that affect the order of magnitude of the price. This type of estimate is useful for determining feasibility since it is not resource intensive (AACE RP 10S-90, 2015). 
A more developed version of qualitative cost estimation is pricing the major building systems separately. In industrial manufacturing, this is described as case-based reasoning, which attempts to make use of historical data that closely matches the attributes of a new design. Meanwhile, quantitative analysis is based on a detailed understanding of the cost to provide each item within the scope of work. Quantitative costs are calculated using an analytical function representing different parameters. Use of this method is typically limited to the final phase in design since it requires a complete comprehension of the design. Parametric models express cost as a function of constituent variables. Constituent variables become clearer with increased design development (Niazi, et al, 2005). Quantitative analysis is better suited for a well-defined design while qualitative methods can be more useful in early project stages. Each method has a different level of cost certainty (AACE RP 17R-97, 2011).

\subsubsection{The Activity Based Costing Method}

In the manufacturing industry, the activity-based costing method (ABC) is used to accumulate product cost. As applied to BIM-based estimation, accumulation involves determining all work items required to physically produce a given BIM model element. In construction, the output is the work-in-place, work items that install the work-in-place, and associated costs are derived from pricing the work items (Qian \& Ben-Arieh, 2008). The underlying mathematical equation of the $\mathrm{ABC}$ model is linear and simple. It sums all parameters multiplied by the corresponding unit price. It is possible to obtain an accurate and quick estimation of design and development costs of one part (Qian \& Ben-Arieh, 2008). BIM model elements are analogous to parts. Incorporating more parameters in the QTO linearizes and thus simplifies the elements related to cost. 
The same ABC method can sum non-linear parameters. An example of a nonlinear parameter is the frequency at which a line item or model element appears in the project. As more objects appear in the project the cost decreases, but it never reaches zero. A common example of this phenomenon is the cycle time of producing concrete decks in vertical construction. As the crew becomes more familiar with that deck layout, the cycle time decreases then eventually reaches a lower limit (Antunes, et al., 2018).

\subsection{Summary of Identified Limitations}

BIM QTO alone is insufficient for detailed cost estimation. The spatial context required to increase accuracy is lost when the quantities are exported from BIM. The estimators must manually quantify gaps in the SOW since BIM QTO only captures the cost of the finished product. BIM element definitions are "flexible"; therefore, a rigid ontology cannot be established. Due to the flexible definitions of BIM elements, they must be mapped by conditioning the BIM model. BIM QTO allows changes in the design to smoothly propagate to the estimate and improve cost estimating efficiency. BIM QTO should be utilized as a step-in model-based cost estimation to address these limitations.

Model-based cost estimation is the complete incorporation of cost estimate information into the BIM model. Such a system requires a succinct framework to facilitate its adoption. The model-based estimate should be tailored for use in project cost control to refine future cost estimate assumptions. Detailed $\mathrm{ABC}$ yields parametric definitions of cost for mass-produced parts, this process should be applied to construction. Manually authoring gaps to the SOW is an opportunity for the GC to communicate means and methods which may encourage adoption of this process as it reduces mistakes. 
A successful framework for model-based construction cost estimation will implement improvements to the eight limitations listed below:

1. The framework should be easy to use and concise.

2. The estimators should be able to incorporate their subjective opinion and tribal knowledge into the model-based cost estimate.

3. Construction contracts should be refined to warrant the accuracy and completeness of a BIM model that is used in the framework.

4. The model-based estimate should be completed parametrically, by referencing only the parameters available in the BIM environment

5. Using VDC cost control and a cost code tethering structure, construction phase production data should be available for estimate data refinement.

6. The means and methods of construction that are defined by the contractor should be modeled in the BIM environment. The parameters of these elements should be used to estimate the cost of the means and methods of construction.

7. The project team should employ flexible mapping procedures to link their data sources together and reduce data recycling.

8. The project team should use a succinct software suite that is interoperable with the software or other project stakeholders. 


\section{METHODOLOGY}

\subsection{Overview}

This chapter details the methodology employed to develop a framework and a system for model-based construction cost estimation. The Methodology outline is illustrated in Figure 14.

Phase I: Initiation and Literature Review

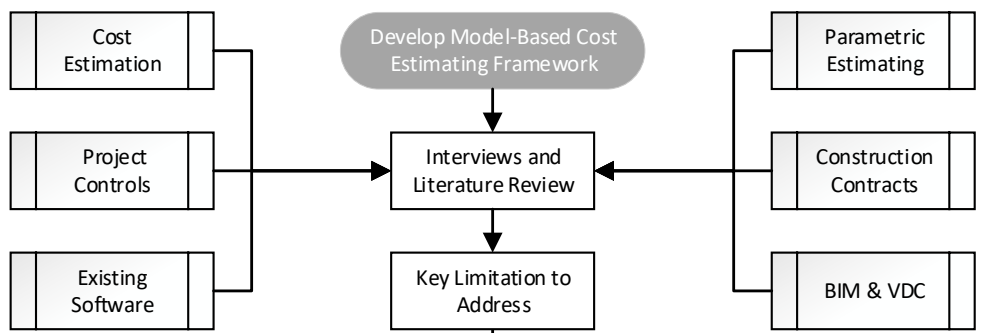

Phase II: Plan Framework Components

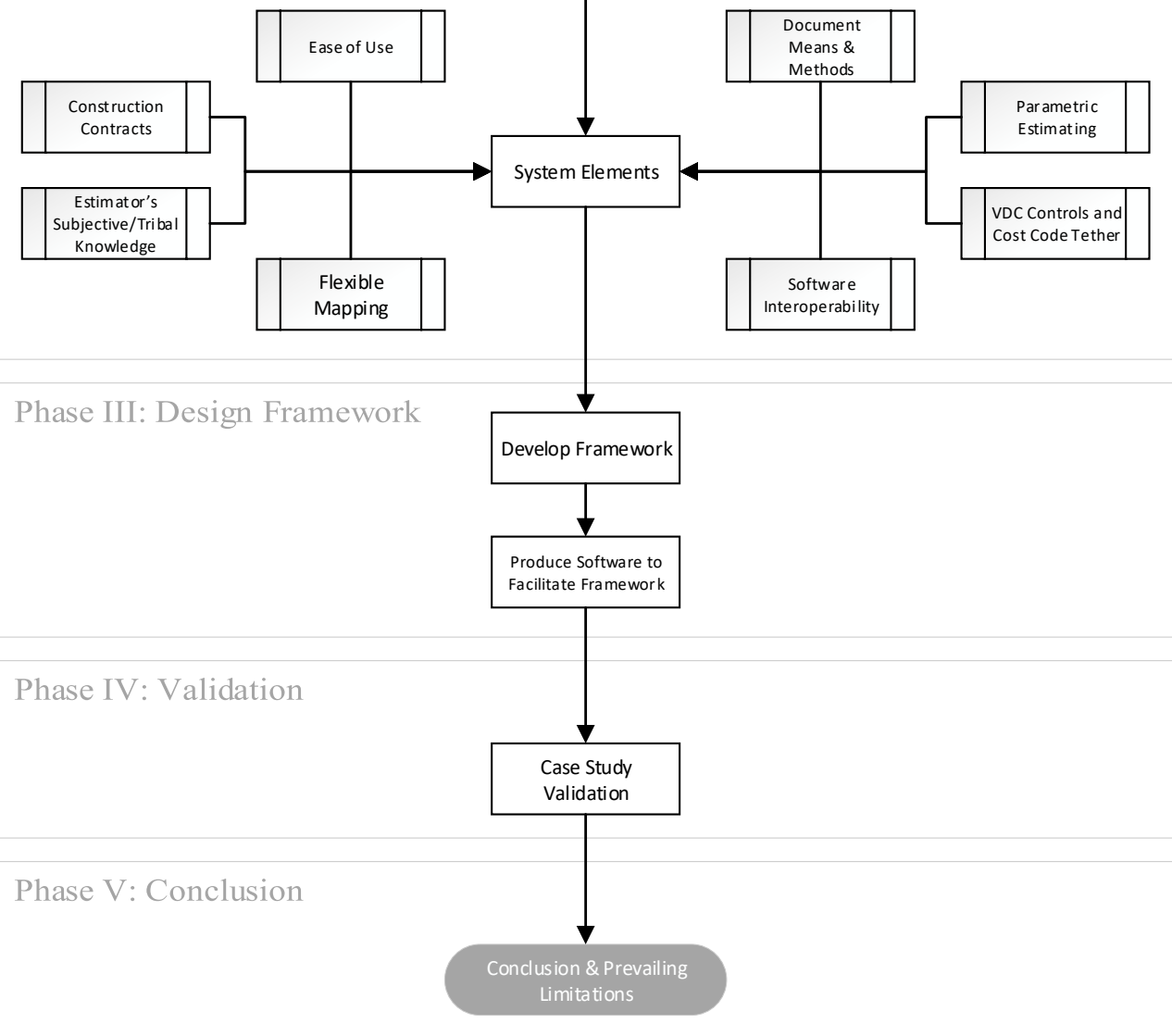

Figure 14 Methodology Overview 


\subsection{Phase I: Initiation and Literature Review}

The literature review was conducted in Chapter 2 to identify current limitations to using BIM in cost estimation. Eight limitations within the existing body of knowledge were identified. While there are more than eight total limitations, these were selected such that improving them should yield a resulting framework preferable to the traditional method of cost estimation. Table 1 maps the eight limitations to the corresponding literature review subchapter(s). The table is sorted by a subjective assessment of importance, with the most important component, ease of use, appearing first.

\section{Table 1 Map of Limitations and Corresponding Literature Review Sections}

\begin{tabular}{|c|c|}
\hline Limitation & Literature Review Section \\
\hline \multirow{3}{*}{ Ease of Use } & 2.2.3 BIM and Construction Cost Estimating \\
\hline & 2.3.1 Cost Estimate Uses \\
\hline & 2.3.2 AACE Estimating Standards \\
\hline \multirow{2}{*}{ Estimator's Subjective Opinion } & 2.3.3 Traditional QTO and Estimating Method \\
\hline & 2.3.4 Current BIM QTO Systems \\
\hline \multirow{3}{*}{ Construction Contracts } & 2.2.4 VDC and the Contractor's Participation in Design \\
\hline & 2.4.1 Delivery Methods and Cost Estimation \\
\hline & 2.4.2 Warranted Model Accuracy \\
\hline \multirow{3}{*}{ Parametric Estimating } & 2.6.2 Multiple Quantities Driven by an Element \\
\hline & 2.8.1 Qualitative Versus Quantitative Cost Estimate Techniques \\
\hline & 2.8.2 The Activity Based Costing Method \\
\hline \multirow{3}{*}{ VDC Cost Control } & 2.7.1 VDC Project Controls \\
\hline & 2.7.2 Cost Codes for Construction Activities \\
\hline & 2.7.3 Historical Data Reporting \\
\hline Author Means and Methods & 2.6.1 Means and Methods of Construction \\
\hline \multirow{2}{*}{ Flexible Mapping } & 2.5.1 Ontology of Model Elements \\
\hline & 2.5.2 Model Level of Development \\
\hline \multirow{4}{*}{ Software Interoperability } & 2.2.1 Definition of BIM \\
\hline & 2.2.2 Definition of VDC \\
\hline & 2.5.3 Interoperability of Software and Data \\
\hline & 2.5.4 Data Recycling \\
\hline
\end{tabular}




\subsubsection{Ease of Use}

Ease of use is prioritized in this methodology. This is primarily to encourage adoption. Ease of use should make this framework preferable to the traditional method. The second reason lies in achieving reliability and repeatability. A simple framework is more likely to produce results with less variation. As mentioned previously, other stakeholders are equally interested in a cost estimating framework's ease of use. This methodology considers three categories of questions other stakeholders mays ask. These three levels are 1) Reporting "how much does it cost", 2) Querying "how much does this particular feature cost" 3) Alteration "what would change if we did something different". The framework should produce a cost estimate that can answer all three questions, unlike the traditional method.

\subsubsection{Estimator's Subjective Opinion of a Work Item's Cost}

Addressing this limitation involves the documentation of subjective opinion within BIM. The purpose of documenting it is for analysis during and after construction. The documented information provides a comparison opportunity between the parameters of estimated and actual cost to complete.

\subsubsection{Construction Contracts}

A major issue for detailed cost estimation using BIM is the contractually warranted model accuracy. This subject ties into the existing practice of defining a model LOD, but it includes two sub-requirements. They are the quality and quantity of BIM model elements. There is cost uncertainty associated with both in BIM models and LOD is not enough alone to address this. The scope of this research proposes only warranting the accuracy and not the completeness of any BIM model elements. Completeness is the 
responsibility of the contractor; with vague plans, they have the freedom to innovate. Accuracy of information guarantees that any reference made to the parameters of the BIM elements by the estimators is accurate. Future research should investigate the effect of quantity of BIM elements upon cost estimate accuracy.

\subsubsection{Parametric Estimating}

Parametric estimating is the process of linking multiple work items to a single BIM model element and interlinking multiple parameters to a single work item. The key advantages are 1) these work items do not need to be authored in BIM and 2) the parameters can be evaluated once actual project cost data are available. It provides more information with less BIM authoring. It allows assumptions about work items to be made early then confirmed or denied when a more complete model is available. In the early design stage, the database of potential work items associated with a BIM element acts as a checklist. This checklist feature should reduce the variance in estimated cost between design document iterations.

\subsubsection{VDC Cost Control}

A plethora of cost data is produced during construction operations. Collecting it tethered to the BIM model elements allows for better audit and data mining capabilities. This feature allows estimators to control costs and forecast the cost to complete during construction while also refining production data for use in future estimates. Current practices do not involve estimators during the construction phase. 


\subsubsection{Means and Methods}

Identifying the optimal construction approach (means and methods) is an integral part of the cost estimating process. The estimators make decisions about what the construction team will do to produce the work in place, dependent upon the available resources. These choices bind the construction team to a budget that allocates only those resource. A ladder, man lift, or scaffolding are all examples of means and methods that can be employed to work on a building's exterior. So, documenting the decision on selected construction approach in the model 1) allows the cost of alternatives to be easily evaluated and 2) communicates the decision to other estimate stakeholders.

\subsubsection{Flexible Mapping}

Flexible mapping is interrelating two existing data sets, like cost and BIM element parameters, with a recorded map. This is contrary to the current practice of extracting BIM element parameters and importing them to a cost estimating environment. It is rooted in how cost estimates are completed today with quantity extraction. This extraction is a manual one-time process that must be repeated with each design iteration. Flexible mapping allows the quantity links to be reused in subsequent design iterations. Addressing the flexible mapping limitation should 1) reduce the menial tasks that estimators perform and 2) decrease the cost of estimating design changes. The flexible map should allow parameters stored in BIM elements produced by the design team to flow through to the proper cost estimate work items. 


\subsubsection{Software Interoperability}

The software interoperability limitation is the inability of computation platforms to succinctly communicate data to each other. The industry today manually recycles data to remedy this issue. The simplest solution requires that the team use a specific software package. Therefore, this framework is built on popular Autodesk and Microsoft software including Revit, Navisworks, SQL Server, Excel, and Power BI.

\subsection{Phase II: Plan Framework Components}

The planning phase began with an analysis of the eight limitations identified in the literature review, see Section 2.9 Summary of Identified Limitations. The analysis revealed that three computation tools in addition to BIM, Business Intelligence (BI), C\#, and SQL, were required to address the eight limitations. SQL was chosen to manage and query a large set of interrelated tables of data. Meanwhile, C\# was implemented to correlate rows in a manageable and queryable database with BIM elements through Navisworks. BI is a platform that easily queries and reports data from SQL. It is implemented to allow different stakeholders with varying levels of access to the same database. These three computation platforms should enable ease of use in the framework. They are described in more detail in Sections 3.3.1 and 3.3.2. With these two computation tools in mind, the framework was conceptually outlined to define its skeleton. This outlining process considered the steps of the AACE Cost Estimating Process (AACE RP 19R-97, 2003). Steps One through Three are directly taken from the AACE RP. Step four was inspired by the AACE RP and adapted, which should improve 
the cost estimating database over time. The results of this phase in the thesis are summarized in the roadmap (Figure 15).

\subsubsection{Structured Query Language and Business Intelligence}

The Structured Query Language (SQL) powers a database and enables computations to be performed within it. This enables both the storage of historical cost estimate data and the computations that use this data with BIM element parameters. Computation is supported by pre-defined and custom wrote functions for specific columns in a table. Another key feature is that it can support a host of interrelated tables. This allows the association of cost estimate information with the construction schedule, suppliers, subcontractors, BIM authoring software, and past cost estimates. SQL is the background architecture that allows all parameters influencing the project's cost to be available in the model-based cost estimate. Business Intelligence (BI) is a process for analyzing SQL data. It enables visual analysis of cost data alongside the various other cost estimate influences. This process can return all the costs associated with a specific BIM element, floor level, sub-trade, subcontractor, etc. It is a tool that enables the visualization of SQL data.

\subsubsection{Navisworks Application Programming Interface Add-in}

The Navisworks add-in is written using the Autodesk application programming interface (API). It is written in the $\mathrm{C} \#$ programming language and contains namespaces for reading and writing data to an SQL database. Since SQL is a database and computation platform, $\mathrm{C \#}$ must only handle the input and output transaction from the database to Navisworks. 


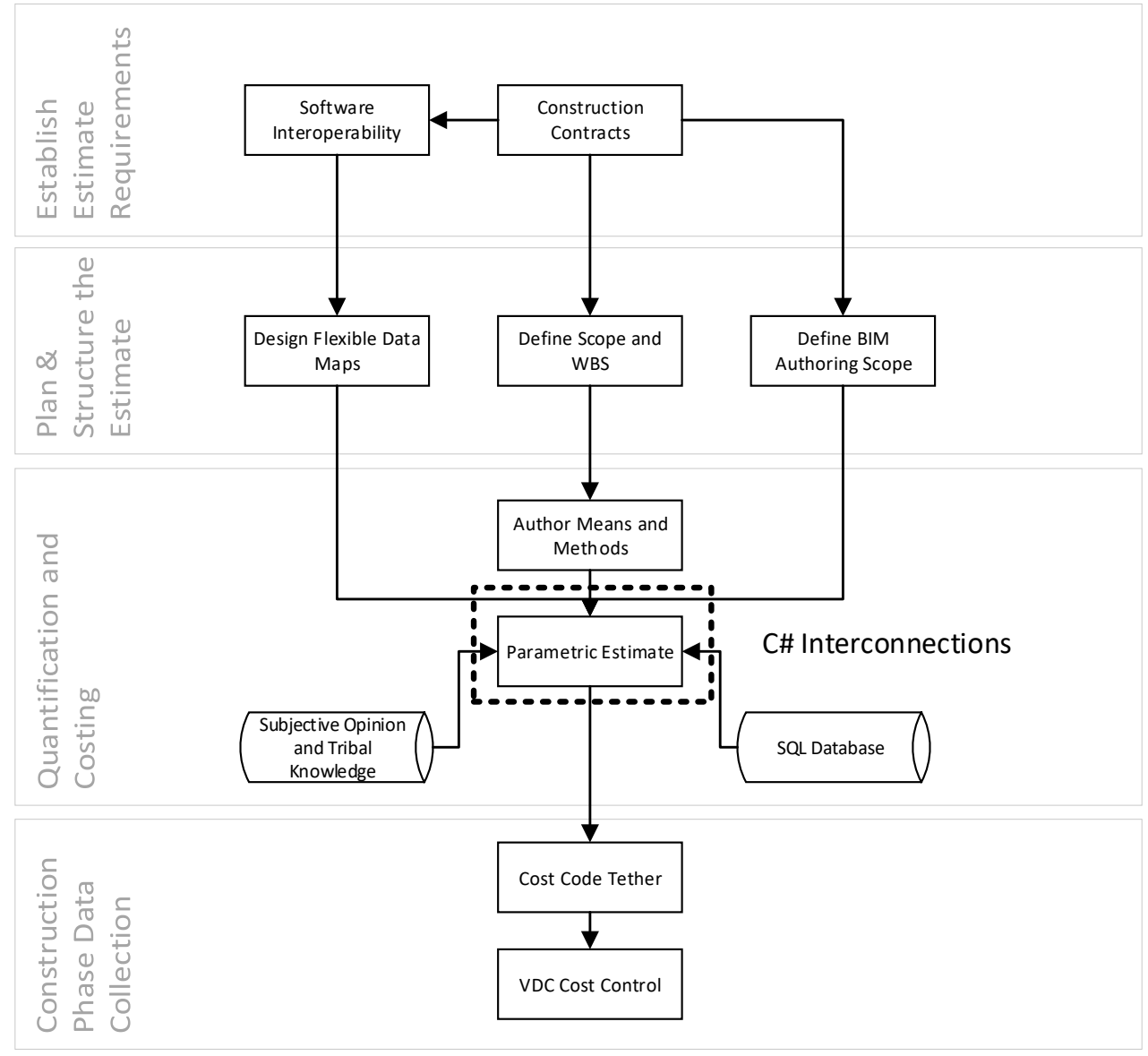

Figure 15 Conceptual Roadmap of Model-Based Cost Estimating System

\subsection{Phase III: Develop Framework}

This phase formulated the framework for model-based cost estimation.

Development of the framework initially considered the system's input and output. Input in this context is any information or BIM model that a stakeholder produces that influences the cost of the construction work. This information is either in a BIM model format or another non-object-oriented format. So, this information is either initially stored internal to a BIM model or external to it. The desired output is any cost estimate information and an audit trail for quality control. That information is presented in a suite of reports which are provided for different purposes to different stakeholders. The 
framework is a set of processes which conditions then intakes this information to produce reports. The system's skeleton is presented in Figure 16.

Given the input and output requirements, a database should be implemented to map information not in BIM such as the price per square foot for paint, to the information and parameters that are already associated with BIM elements, such as the area of all gypsum board walls. the Structured Query Language (SQL) was selected for the database implementation. This language supports queries, an audit trail, and interoperability with the specified BIM authoring and VDC review software. The SQL database exists parallel to the BIM models. Using an add-in built into Navisworks, data transactions are made that send BIM parameters to a SQL table. This add-in then records the associations made by the cost estimator of BIM elements to work item. Computations are performed in the data environment based on these associations which return a column of cost data. Finally, this data is returned from the database into the BIM environment and the BI report platform. The proposed Navisworks add-in connects the BIM Environment to the Data Environment shown in Figure 16.

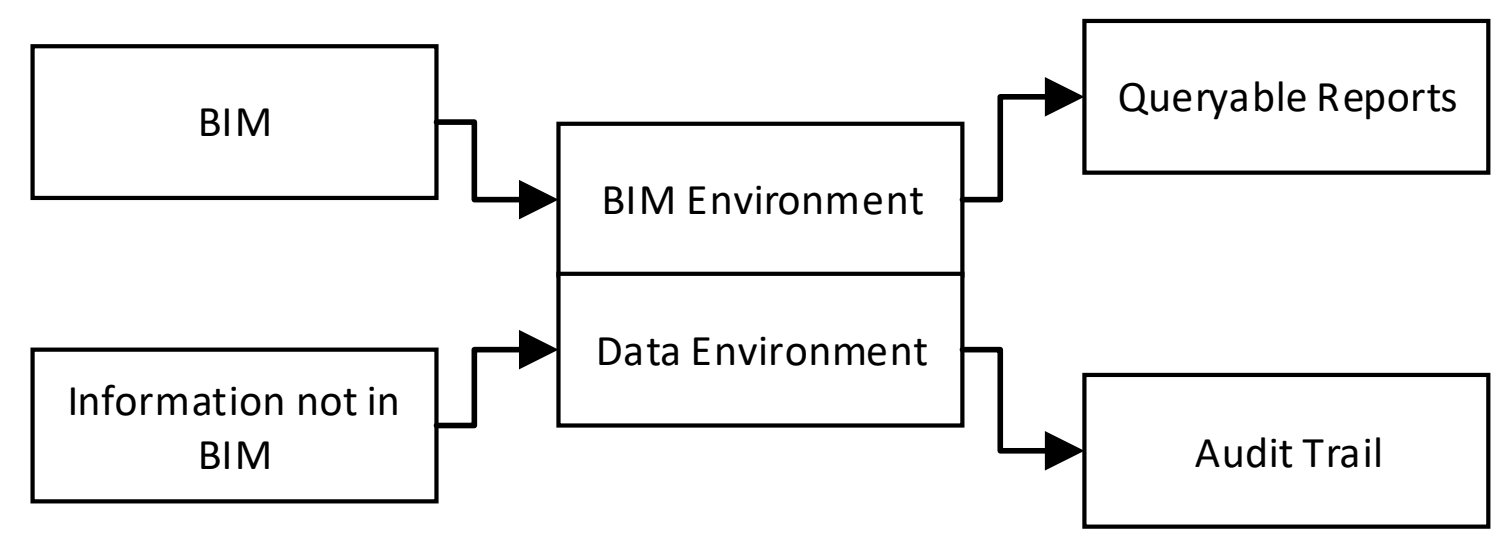

Figure 16 Skeleton of the Framework's Input, Environment, and Output 


\subsection{Phase IV: Validation}

The validation phase applied the framework to a real case study construction project. The studied project employed the design-build delivery method and its BIM model had the LOD for model-based co-ordination. The first three modules in the framework were followed to complete three separate estimate reports. Three cost estimate reports were created following the traditional method, the BIM QTO method, and the model-based cost estimating framework respectively. Each cost estimate was completed using the project drawings, specs, and BIM model (except for the traditional method). All three of the cases employed the process outlined in Figure 17. The estimate reports are presented and analyzed.

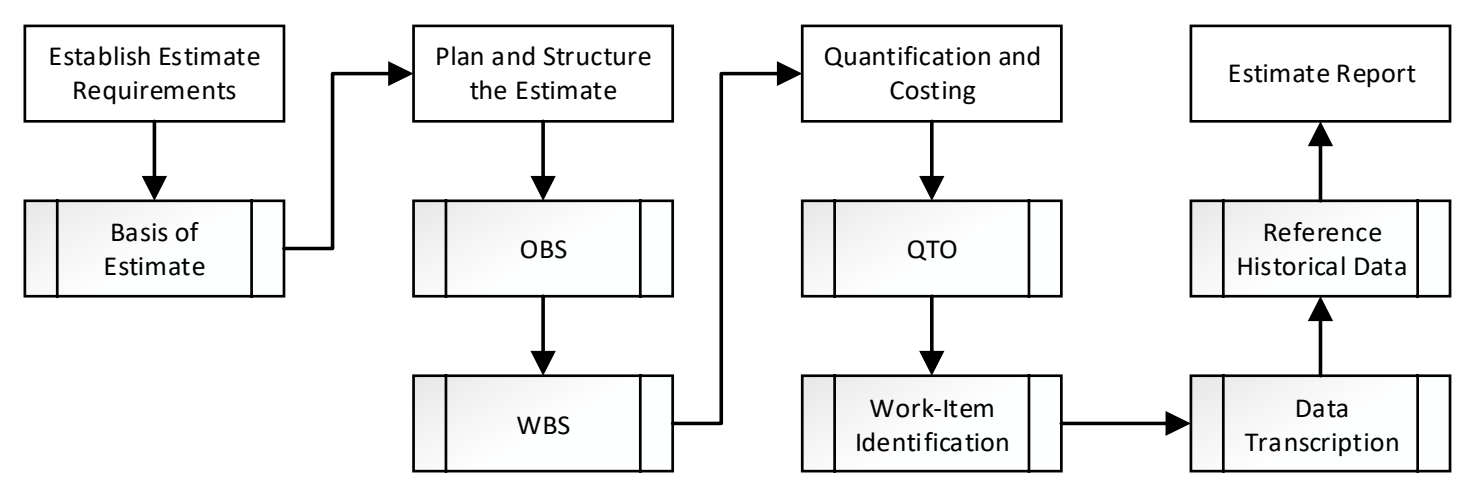

Figure 17 Cost Estimating Steps Followed in the Case Study Validation

\subsection{Phase V: Conclusions and Recommendations}

A summary is presented in the conclusions and recommendations Chapter that covers the framework, case study implementation, and results. The challenges encountered during the model-based estimating case study and lessons learned are also presented. The prevailing limitations are those that were identified in the literature review but not addressed in the framework. These should be the focus of future works. 


\subsection{Summary}

This chapter presented the methodology employed to develop and propose the following framework. The literature review conducted in Phase I indicated the current limitations to model-based cost estimation. The planning in Phase II identified eight limitations to the existing body of knowledge that the proposed framework should improve. The design in Phase III synthesized these eight limitations into a single methodology to develop a framework for model-based cost estimation. Phase IV was intended to validate the framework, it was a case study of a real, completed, construction project. Then Phase V presented the findings from the research along with other limitations that were outside the scope of this thesis. 


\section{MODEL-BASED COST ESTIMATING FRAMEWORK}

\subsection{Overview}

The framework proposed in this thesis is a formulaic process for completing a model-based cost estimate. The four modules in this framework are 1) establish the estimate requirements, 2) plan and structure the estimate, 3) quantification and costing, and 4) construction phase data collection. The modules are supported by a purpose-built Navisworks add-in. It facilitates interoperability between Navisworks, Excel, SQL, Revit, and Power BI. The framework's goal is to fully define the cost impacts of the product, organization, and process models of a construction project from within a BIM environment.

This framework also features validation of the historical cost estimate data with data collection during construction operations. This data collection occurs after the cost estimate is completed, and only affects future estimates. Module four addresses the framework's second feature, improvement of historical data. This second feature is possible since modules one through three establish a model-based estimating environment that is conducive to collecting historical data.

A legend (Figure 18) is presented below describing the framework's steps. The entire framework is presented in a diagrammatic overview (Figure 19). This overview is divided into four modules. Each process and requirement in Figure 19 has a dedicated subsection explaining its function in detail.

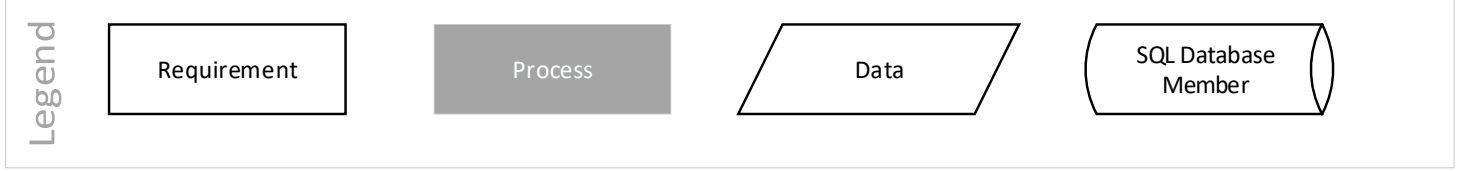

Figure 18 Legend Representing the Framework Elements 


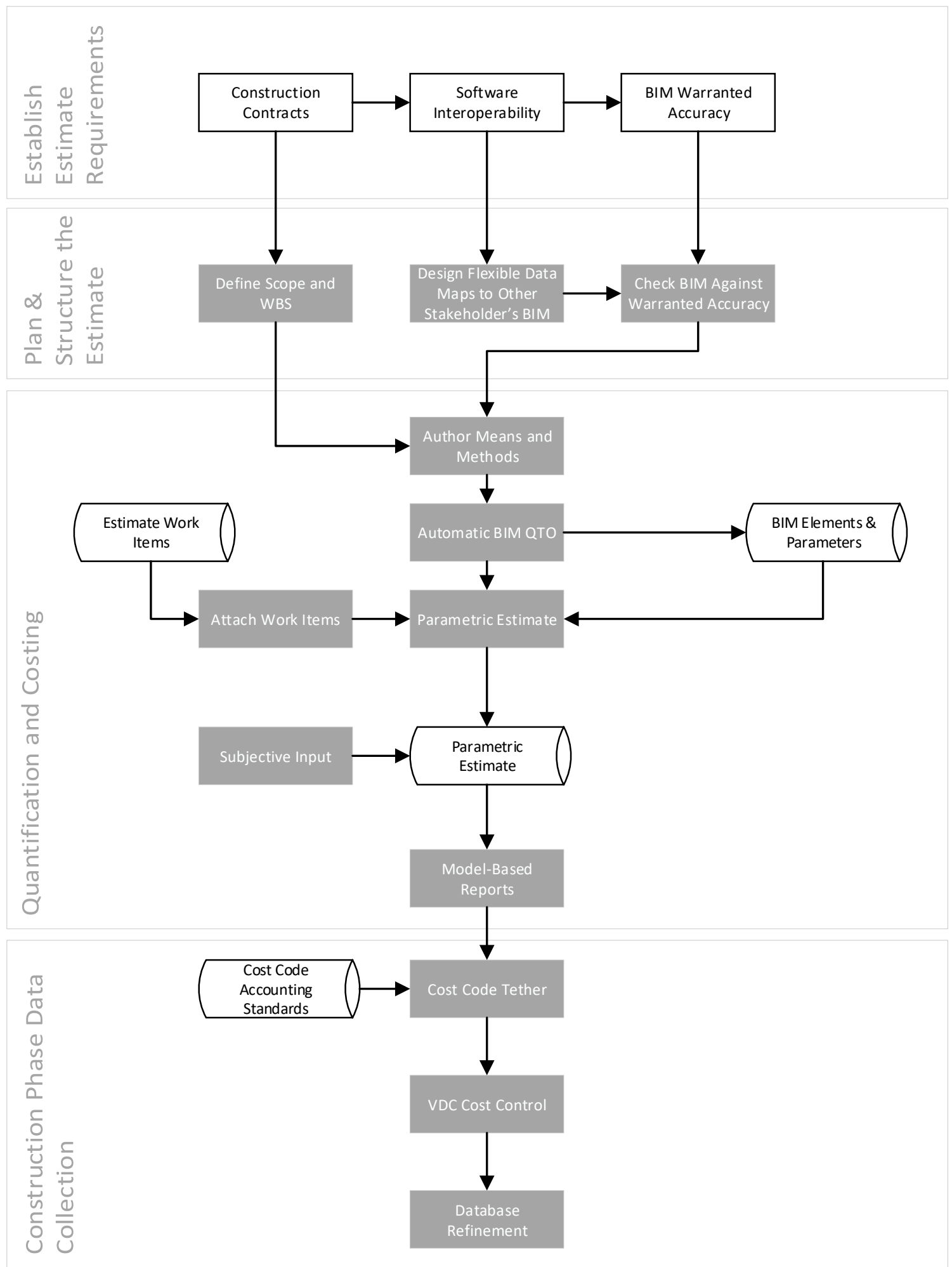

Figure 19 Overview of Model-Based Cost Estimation Framework 


\subsection{Establish Estimate Requirements}

The estimate requirements must be established prior to any BIM authoring by stakeholders. The purpose of these requirements is to establish a BIM model that can produce a reliable cost estimate. Repeatability is achieved by flexible data mapping. The flexible map allows parameters stored in BIM elements produced by the design team to flow through to the proper cost estimate work items. This module sets the requirements for reliability and repeatability, which prepares the stakeholders' models for conditioning.

\subsubsection{Construction Contracts: BIM Execution Plan}

This framework proposes that construction contracts should contain specific language regarding software interoperability and BIM warranted accuracy, denoted as the BIM Execution Plan (BEP). A BEP ensures software interoperability which reduces the need to recycle data previously produced by other stakeholders. This framework uses Autodesk Revit for all BIM authoring, so the BEP should specify that this is the required modeling software for the design team to use. If they are unable to meet this requirement, then the software should be capable of communicating its data with Revit through a software link. However, the scope of this framework is limited to one software link that facilitates communication with Revit only. A BEP's warranted accuracy ensures that the BIM elements presented by the design team contain accurate information like location, size, and function. This could be achieved in part by specifying a LOD for design models. But the BEP must also incorporate quantity and quality control tasks performed automatically by a computation platform or manually by the cost estimators. In this research, all quantity and quality control efforts were manual. 


\subsubsection{Software Interoperability}

There are two levels of software interoperability, intrastakeholder versus interstakeholder. Inter-stakeholder interoperability is defined by the contracts created between the design team members and the contractor performing the cost estimate. The requirement is that the software communicates through links as specified in the construction contracts sub-section. This framework uses C\# to bridge a software's data to a SQL database. That data link is reading Revit instances from within Navisworks. So, the software links can either connect the designer's data into a Revit model or directly into the SQL database through C\#. This type of interoperability is intended to reduce data recycling between the project stakeholders. This interoperability requirement is defined in the contracts between the contractor and other stakeholders who author BIM models.

At the intra-stakeholder level, software interoperability is achieved with the estimators sticking to Autodesk Revit for authoring and Navisworks for estimating. This setup allows estimators to take advantage of Revit's Switchback feature for Navisworks. This feature allows estimators to author means and methods while completing the estimate. While the BIM authoring takes place in Revit, Switchback allows this process to start and end in Navisworks. This feature allows the entire estimate to be completed with Navisworks as the singular locus of control. It initiates the switch into and out of Revit and achieves intra-stakeholder interoperability.

Figure 20 presents the suite of software used in the proposed framework. Other software combinations can produce the same model-based cost estimate. However, each combination would require its own purpose-built data connection and software add-in. The framework limited the scope of software to a single combination so that 
interoperability could be guaranteed. Autodesk Revit is the BIM authoring application since it is the most popular in the industry. Likewise, Autodesk Navisworks is specified as the VDC model BIM viewing software, since it is the second most popular in the industry (Olsen \& Taylor, 2017). SQL Server Management Studio is employed to map in all information that does not originate in BIM. The data environment is a locally hosted SQL server. The purpose-built add-in connects the BIM and data environments together with a data bridge. Through this bridge, BIM elements and their parameters are available alongside historical cost estimate data. All reports, including the audit trail, are presented in Microsoft Power BI. This platform allows all stakeholders to access the BIM and cost data without disclosure of proprietary cost information.

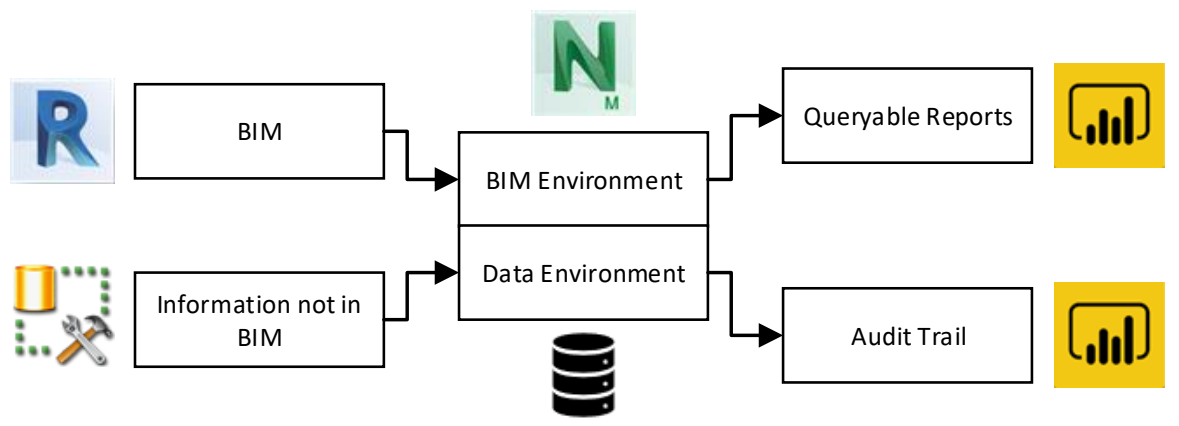

Figure 20 Input-Environment-Output Diagram with the Implemented Software

\subsubsection{Check BIM Against Warranted Accuracy}

This framework requires that construction contracts specify the quality and quantity of BIM elements produced by the design team and the contractor. The complete agreement constituted the BIM authoring SOW. This is a step beyond current LOD standards which dictate some components of quality. The information quality that the designer must warrant includes category, family, type, length, width, height, area, volume, and position. The entire list includes any parameter that the estimate will directly reference. 
Complete quantity is conceptually described as showing all BIM elements to completely define the generic mass of the building. If a building element occupies that space, then the model should have a BIM element in that location. This is so that the estimator can attach work-items and parameters to the mass. The actual contractually warranted model quality and quantity were not evaluated since it is beyond the scope of this thesis. Future works should evaluate the cost estimating risk associated with a specific level of BIM model quality and quantity.

\subsection{Plan and Structure the Estimate}

This module conditions the stakeholders' models for the cost estimate and prepares many forms of information for association with BIM elements. In this module, a separate model is authored to host parameters for the contractor's means and methods of construction. The complete set of designer and estimator authored BIM elements serve as the hosts for all cost estimate information. The information required prior to the cost estimate is the division of the SOW. It's required in this order so that during the work item attachment in module three, the estimator can also assign the work item to a specific stakeholder. Therefore, the estimators divide the SOW by OBS and WBS.

\subsubsection{Design Flexible Data Maps to Other Stakeholders' BIM Models}

The framework's flexible data maps connect the designers' BIM to the contractor's estimate structure. They are designed in Navisworks and are recorded into an SQL table. These data maps can be used between design iterations and between projects. Therefore, the data maps reduce the wasteful recycling of data. Using the Navisworks add-in, the maps are created in a two-step process. First, the estimator visually filters to all unique BIM Category-Family-Type combinations in Navisworks. This visual filtering 
is assisted by the search sets feature in Navisworks. Second, the estimator selects each element that represents a unique combination and drags that element to a corresponding estimate type. This second step records the assignment of the designer's category-familytype combination into an estimate type SQL table (Figure 21).

The structure for flexibly mapping cost estimate data is built in a SQL database. This database has 36 entities or tables that are inter-related. Figure 21 presents an example of three entities from within this database. Each attribute within the entity represents a column in the table. PK (primary key) indicates that the attribute forms the entity's unique identifier. FK (foreign key) indicates that the attribute is referencing the primary key of another (foreign) entity. Using this data structure, creating a crew, adding members to it, and even defining new members are all activities that the estimator can complete within the Navisworks add-in environment. The estimator does not have to learn SQL to use this database.

The entries within the parenthesis present an example for parameter mapping of a slab on grade BIM element (Figure 21). The "ParameterMap" entity contains abstract parameters, operations, and a resulting assembly parameter. The assembly parameter is used in the cost estimating process while the abstract parameters and operation maps to the unique type. The example takes any BIM element from the Structural Model that is a 4" thick concrete slab on grade and creates an area assembly parameter by applying the mathematical operation to the concrete length and width parameters of the unique type BIM element instance. The "ParameterMap" abstract length and width parameters specify which "UniqueType" concrete parameters to use. This system flexibly maps BIM parameters to cost estimate assembly parameters with an abstract reference. 


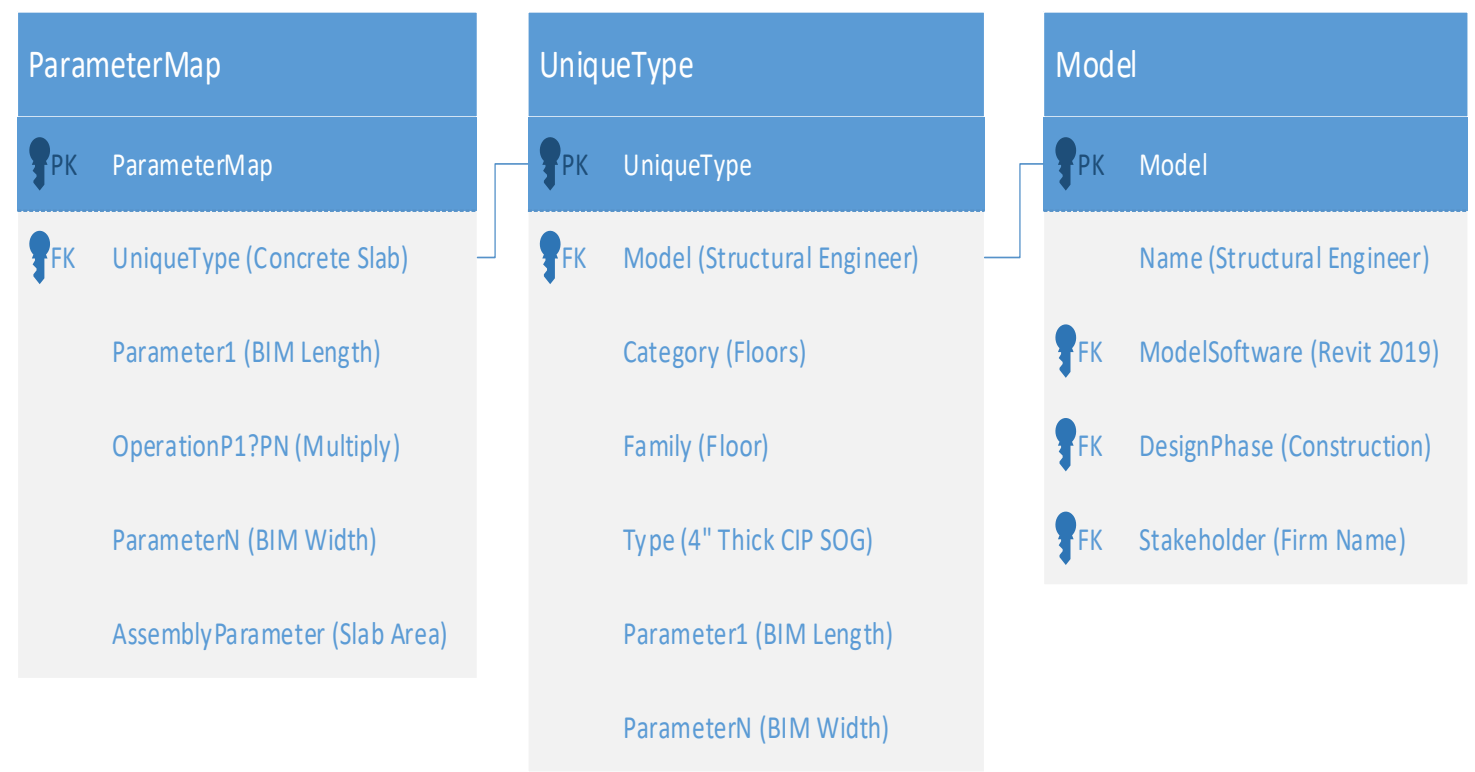

Figure 21 SQL Table of Flexible Parameter Mapping

\subsubsection{Define $O B S$ and $W B S$}

Planning the cost estimate involves the estimators assigning the SOW to subcontractors or self-perform groups, physical resources that will complete the work. This step must be taken after the flexible maps are defined. It is performed in the Navisworks add-in and involves assigning groups of work-items with the same CSI or Uniformat division to a specific contract entity. Such division of labor is supported by the Scope of Work (SOW) SQL entity Figure 22. The foreign key relationships allow a single SOW to be assigned each to a stakeholder, i.e. a concrete sub-contractor completing the cast-inplace foundations per the example within the parenthesis. This table enables flexible mapping of the CSI and UNI Format divisions to each project stakeholder. With this system, it should be easy to assign the same subcontract stakeholder the cast in place concrete floor scope (CSI 03-30-00 \& UNI A.10.10) along with the concrete flatwork scope (CSI 32-12-00 \& UNI G.20.30) within the BIM environment. 


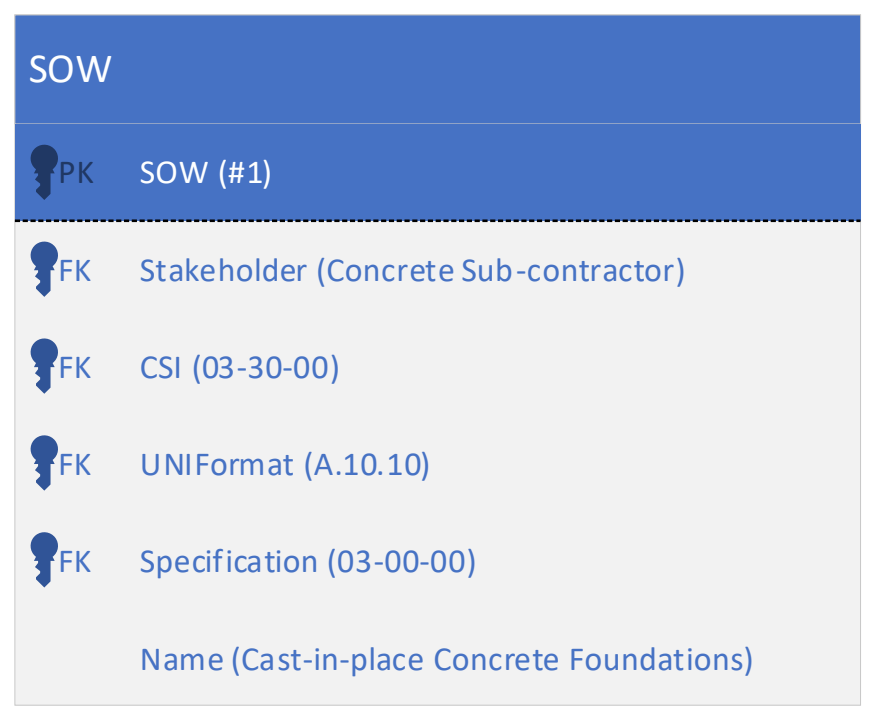

Figure 22 Stakeholder: OBS \& CSI UNI Specification: WBS

\subsection{Quantification and Costing}

Parametric estimating is the primary limitation addressed in the quantification and costing module. It involves linking existing and new BIM parameters to estimator created work items. Each BIM element hosts a set of work items. These work items are driven by the BIM parameters that are children of the hosting BIM element. The quantification and costing module produces new cost information in the context of the conditioned BIM model. The output of this step is the model-based cost estimate.

\subsubsection{Author Means and Methods}

The estimators coordinate with the construction operations group to define the means and methods of construction. Traditionally, this is done with communications external to the cost estimate platform. Diminishing the audit trail for decisions. This framework instead proposes authoring the means and methods within the model environment since the environment functions as the cost estimate platform. Once the means and methods are defined in BIM, the estimators can use these BIM elements to 
host the work items associated with that mean or method. The cost of the work items is driven using the BIM element parameters.

This should be the only step where the estimator undertakes BIM authoring if the contractual BIM warranted accuracy is met. The framework prescribes that the finished building volume is accurately represented by the design team's BIM models. Section 4.3.2 outlines the BIM model's warranted accuracy requirement. So, if the design team is delivering models that meet the requirement, then the estimators need not complete any additional BIM modeling to produce the cost estimate for the work-in-place. However, means and methods occupy additional 3D space beyond the work-in-place. Means and methods of construction are not work-in-place, they need additional parameters not available in the design team's models to be estimated within the model-based environment. These additional parameters are provided by BIM elements authored by the estimators.

Figure 23 outlines the BIM authoring process that the estimator completes when the design team has submitted their models for cost estimation. First, the estimator opens Revit from within Navisworks, using the Autodesk switchback feature. The estimator then links in the design team's models to use as a background or guide for placing BIM elements. Once the estimator identifies a mean or method, it can be attached as a work item to the existing design team's BIM models, or if that work item requires custom parameters to estimate its cost. If the work item does not require custom parameters, then no new BIM element is authored. Otherwise, the estimator checks the existing custom Revit families for an instance to host that work item. The estimator must create a new reusable family if one is not available. Then the estimator places the BIM element in the 
new Revit BIM model. Once the BIM element is authored, the estimator switches back to Navisworks to attach one or more work items to that BIM element. At the end of this step, every BIM element required to complete the cost estimate should be authored.

Therefore, every parameter that is required in the cost estimate should be available within the BIM model.

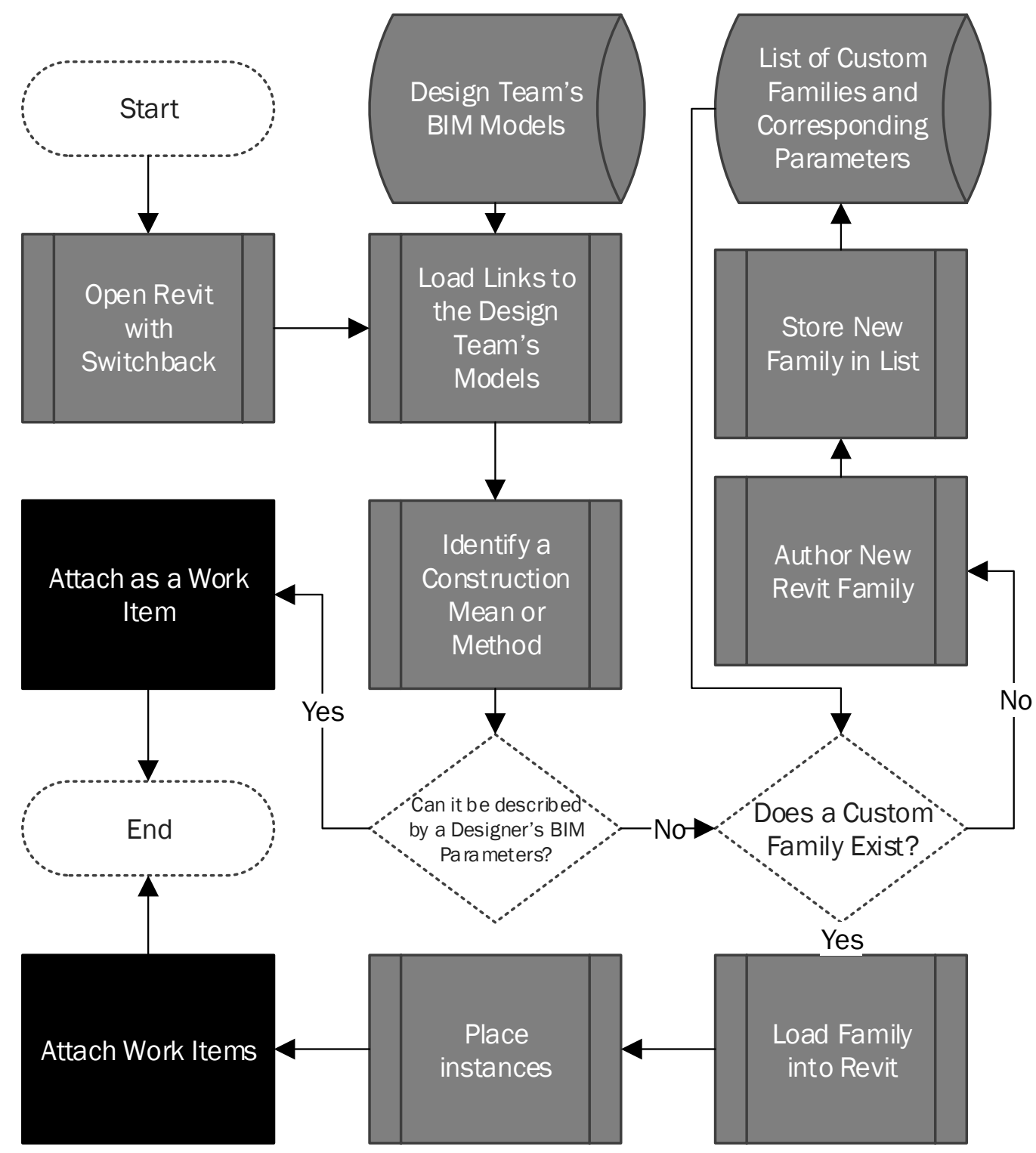

Figure 23 Flowchart Outlining the Documentation of Means and Methods 


\subsubsection{Automatic QTO of BIM Elements}

The process followed up until this point should yield a set of BIM models that define all the spatial parameters of the project when combined. This step of the framework prescribes that these models be appended into a single Navisworks file set (filetype .nwf). It includes the designer's intent and the estimator's means and methods. This single Navisworks file contains all project BIM elements and spatial parameters. The add-in can then complete an automatic recording of all the BIM elements in the model. It will create an SQL table whose primary key is the element Id and model Id. The other columns will host all the element's parameters. Each row in this table contains one BIM element an all its associated parameters. This is like a QTO except the table does not have any work items stored directly in it. This table instead acts as a checklist, it includes all BIM elements that should have associated work-items before the estimate is complete. This is the data table that the add-in will read from when the estimator is performing the model-based cost estimate. Figure 24 shows a diagram of this table. The first three columns are Element ID, Model ID, and Model name. Then there is an additional column for each parameter used. Examples of these parameters include length, width, height, area. This table effectively transfers all the BIM information required to complete the estimate out of the BIM model. 

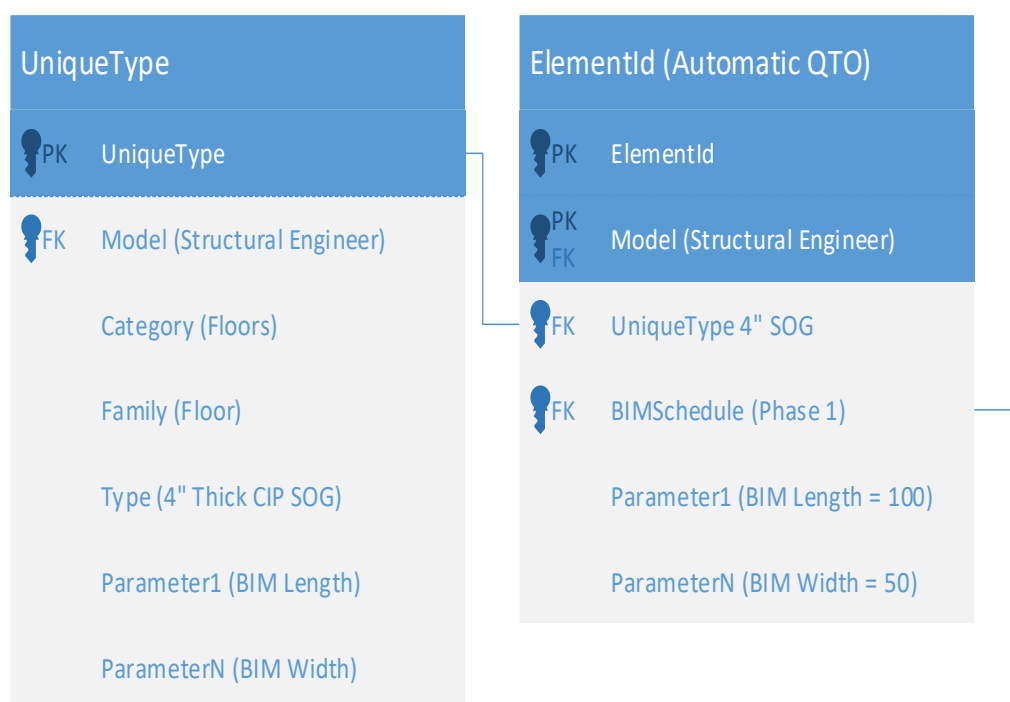

\section{BIMSchedule}

BIMSchedule

Name (Phase 1)

StartDate $(4 / 1 / 2018)$

EndDate (5/1/2018)

Figure 24 SQL Table of all BIM Elements in the Project

The automatic QTO process is facilitated with a Navisworks Add-in. This add-in enables the flow of BIM data into and cost estimate data out of SQL. Data flows through the add-in utilizing a SQL connection and SQL data model (Figure 25). The connection is simply a reference to the hosting location of the SQL server. The data model is a C\# based emulation of the actual SQL database. It contains 36 classes, each emulating one of the 36 database entities. The C\# class shown in Figure 25 is the data model emulation of the "Element Id" SQL entity. The class name is "Element Id", matching the name of the entity in the database. The entity has a foreign key relationship to the "ParamEstimate" entity, (Figure 31) so it contains a hash set that refers to the "ParamEstimate" C\# class. ElementID, Model, UniqueType, BIMSchedule, and AssemblyParameter are all entries in the SQL database and are therefore variables in the C\# data model class. This data model serves as a bridge for extracting information from BIM then writing it into the SQL database. 


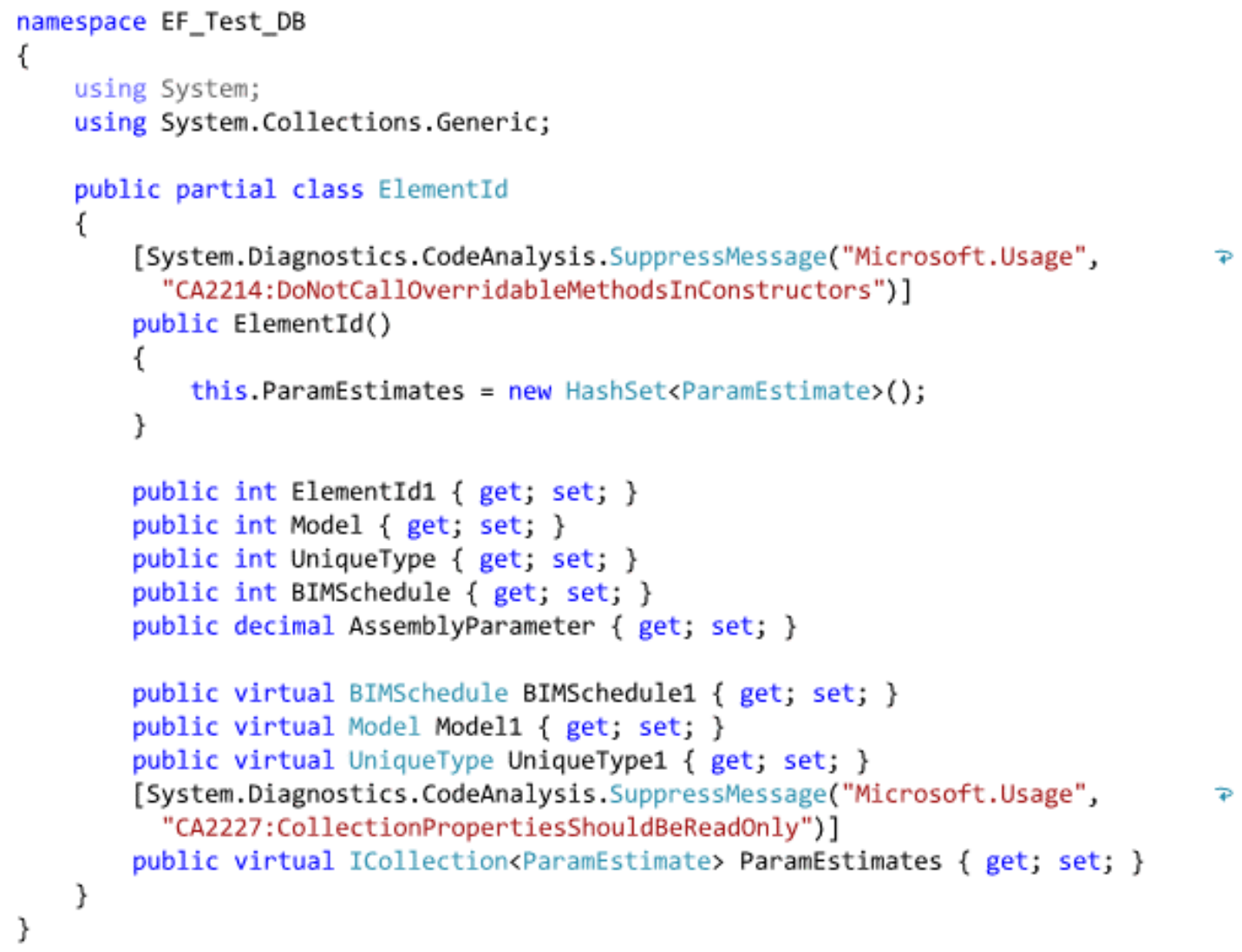

Figure 25 Navisworks Add-in Data Model for connecting the BIM Elements to SQL

\subsubsection{Attach Work Items}

The following two framework steps, work item attachment, and parametric estimate, are completed consecutively for each attached work item. This is a departure from the traditional method, where the entire QTO is completed then the entire estimate is completed. In this framework, the cost estimation of a work item happens immediately after its quantification. This is an important difference because it allows the estimator to capture the context and the knowledge that is gathered during quantification then immediately incorporate it in the cost estimate.

When the work item attachment step begins, all required reference information should be linked into the model-based environment. Now the estimators establish the 
quantity of work for the entire project. This quantification process is similar to the traditional QTO in which estimators examine the model to determine the quantity of work. Except in this framework, information is flowing into the BIM model instead of out. This is why the framework contains the keyword "model-based", the work item attachment is completed in the context of the BIM model.

The first activity in the work item attachment step (Figure 26) is selecting a BIM element within the Navisworks model. When this is done, the add-in reads the selection and queries the SQL database. It returns a list of all potential work items that are premapped to that element's BIM hierarchy. If the estimator finds the desired work item in that filtered list, then the process continues. Otherwise, the estimator may need to define a new mapping, or even define a new work item. The estimator should strive to utilize existing work items because a newly created work item will have no historical data automatically associated with it from past projects. The estimator has now either found or defined the work item that should be attached to the BIM element. Next, the estimator chooses whether this work item belongs to an assembly. If it stands alone, then the work item attachment process is complete. If it is within an assembly, then the estimator can choose or define a new assembly. Once the assembly is selected or defined, the estimator completes the work item attachment step by clicking a button and moving on to the parametric estimate step. This step took place within the Navisworks add-in. Once the estimator clicked the button to move on, the work item attachment record was recorded into the work item SQL table. This record is externally available to the power BI reporting software. 


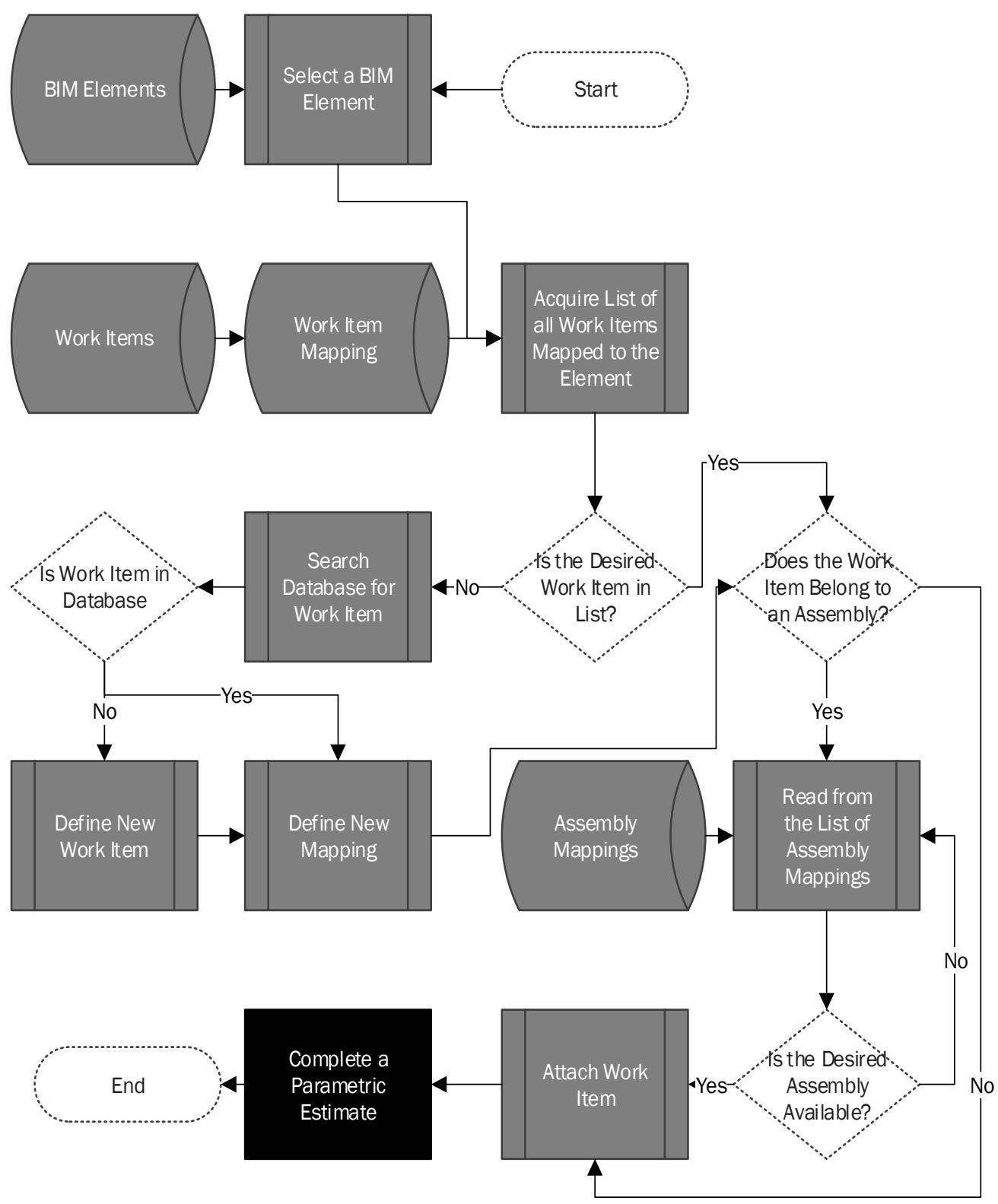

Figure 26 Flowchart for Work Item Attachment

The work item attachment step includes a feature that enables the use of estimating assemblies. This feature is intended to reduce redundancy, errors, and increase efficiency in the work item attachment process. It utilizes an entity (table) in the database that is dedicated to mapping assemblies (Figure 27). The "Assembly" table simply stores a list of work items polymorphically. The "Assembly_WorkItem" table enables a one-to- 
many relationship of one assembly containing multiple work items of each type (labor, material, and equipment). It also allows multiple scopes of work to be estimated in a single assembly. This platform leverages the repeatability of assembly estimating alongside the detailed cost estimate produced by a work item level estimate.

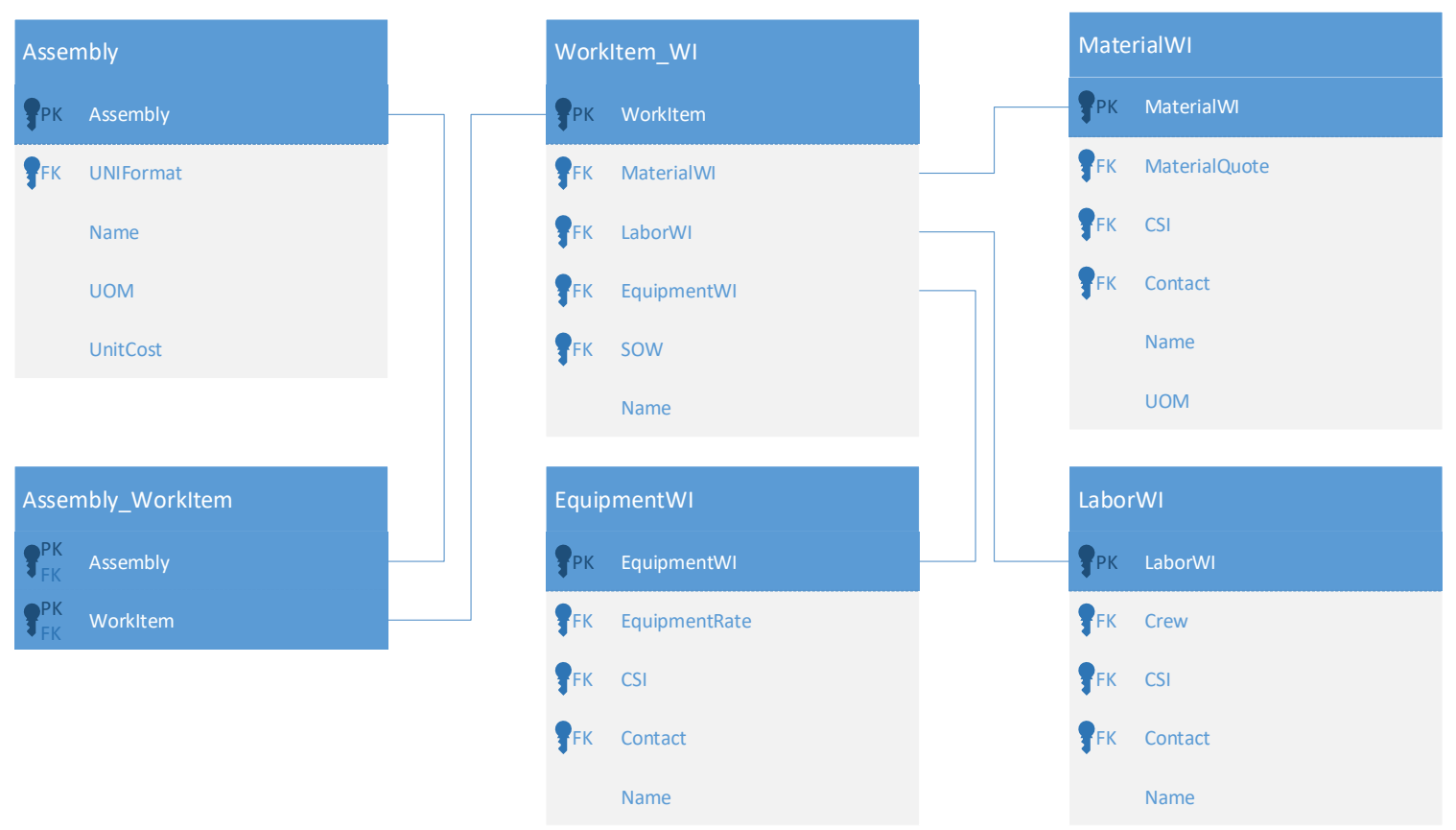

Figure 27 Assembly Estimating Feature for Work Item Attachment Step

The next user feature is work item attachment (Figure 28). This is what allows the user to transfer BIM data into SQL. When the estimator selects an element, the add-in reads that element's unique Element Id, "Type Name" in Figure 28. Per section 4.4.2, the Element Id is already in SQL. Therefore, the BIM parameters for that element are available in SQL. Once selected, the estimator finds and attaches the desired work item in a list that is filtered by the type of object selected. The assembly parameter for this work item is driven by the parameter mapping specified in the param estimate SQL entity Figure 31. Selecting the element allows the estimator to complete a SQL based cost estimate while using BIM as a visual aide. 


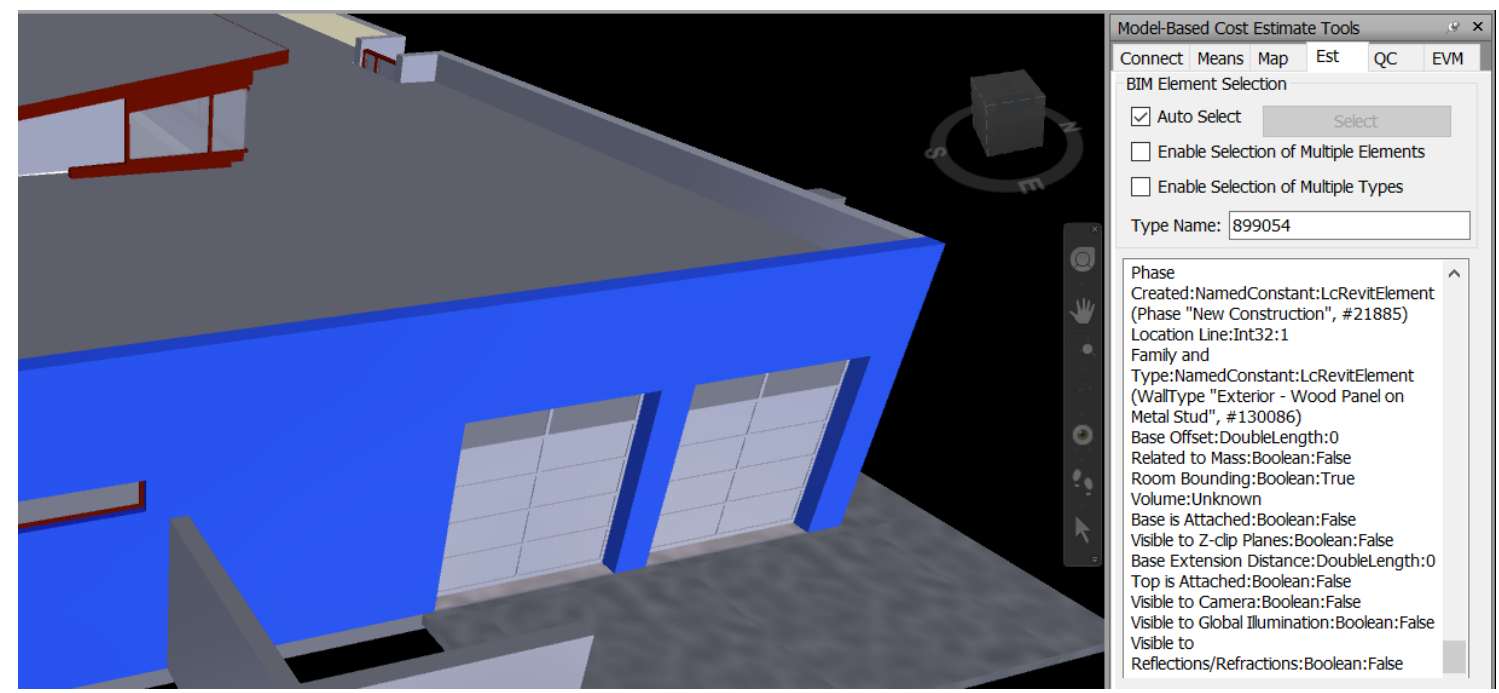

Figure 28 Navisworks Add-in Tab for selecting a BIM Element to Attach Work Items

\subsubsection{Parametric Estimate}

A parametric estimate is completed twice. The first is automatically after work item attachment. The second incorporates subjective estimator input. As mentioned in section 4.4.3, the initial parametric estimate is completed automatically with work item attachment. The work item mappings were pre-defined, and the BIM parameters were automatically transferred from BIM to SQL. The second parametric estimate is manually completed when the estimator reviews the model and incorporates subjective input.

Figure 29 depicts the second parametric estimate. To begin, the estimator selects a BIM element. If it has no attached work items, then the estimator will be instructed to either attach work items or remove the element. Next, if no parameter mapping was initially defined the estimator will define a new parameter mapping. Once this is complete, the add-in will allow the estimator to incorporate subjective input. 


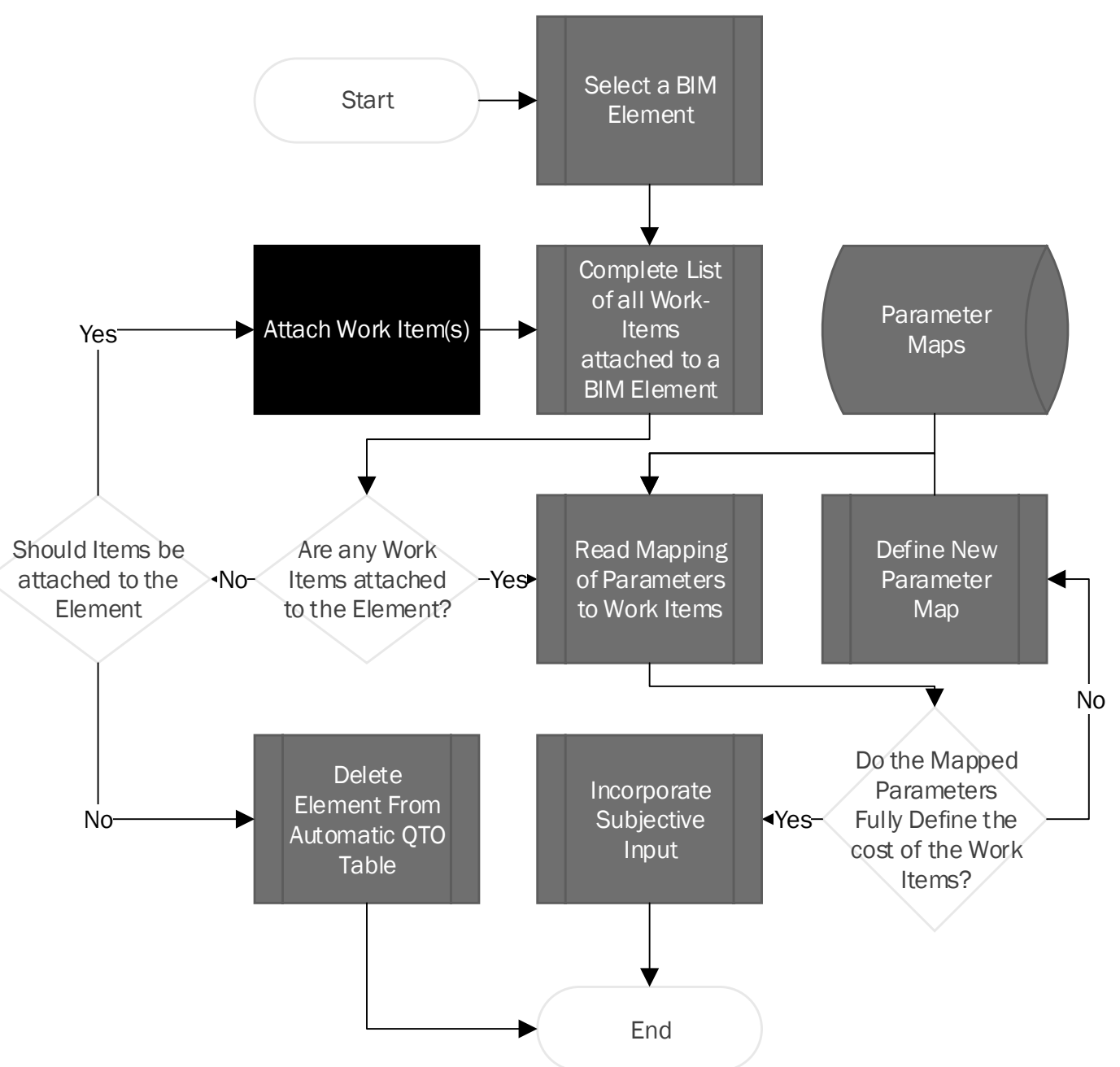

Figure 29 Flowchart for Completing a Parametric Estimate

Subjective input is incorporated into the SQL data structure using the three entities (tables) presented in Figure 30. The two entities that modify the collection of work items for a BIM element are "Complexity" and "Waste". The first modifies the time to complete a work item based on perceived complexity or difficulty. This modifier impacts the cost of labor and equipment. Meanwhile, "Waste" represents the perceived material that should be required in addition to the net quantity. It impacts the cost of the material. Aside from adjusting the estimated cost, these factors could flow into the schedule or bill of materials used by other project stakeholders. The third entity in the input table is the "Contact" entity, and it refers to the table that stores the contact 
information for the estimator who established this subjective input. This enables an audit trail that ties estimating decisions back to the estimator. This structure enables the input of subjective opinion that is reinforced with an audit trail.

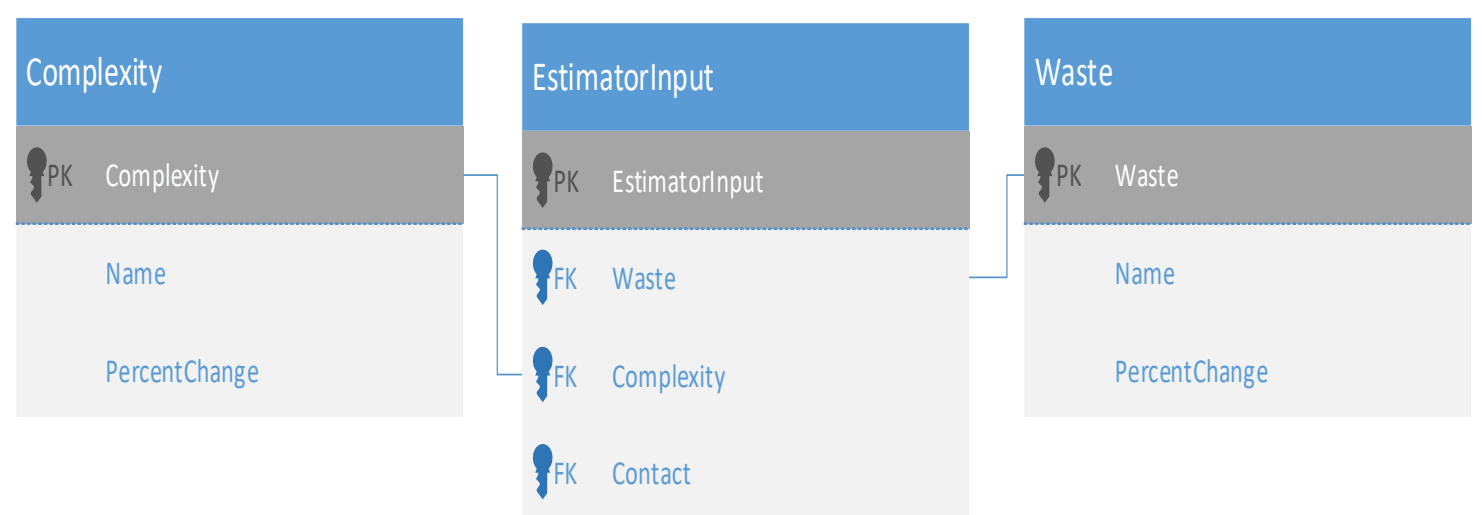

Figure 30 SQL Entities for Capturing Subjective Input

The final parametric estimate entity is presented in Figure 31. It is an amalgamation of the many SQL groups that were described above. Amalgamation in this context means that the table contains many (seven) foreign key relationships. The seven foreign keys reference rows of data in seven other tables. It includes a reference to the cost estimate data for all concrete slab on grade objects. It also includes a reference to the Element Id, spatially identifying the BIM element referenced, along with the model and detail(s) that apply to that element. Finally, it contains references to the modifiers that the estimator can manually define base on subjective knowledge. The two entities that are not foreign key relationships present the total estimated cost, and the estimated cost prior to the input of subjective opinion. This table is at the center of the SQL data structure (see appendix). 


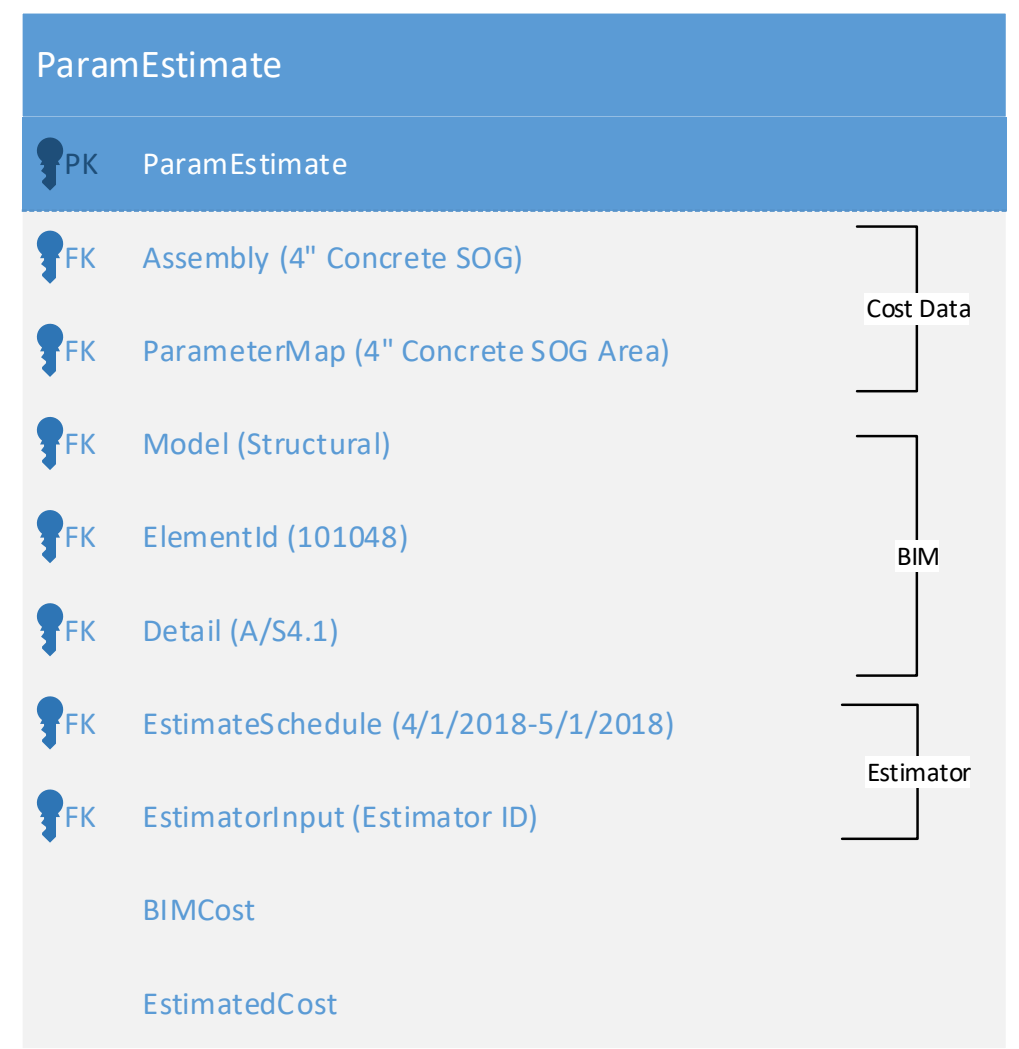

Figure 31 Parametric Estimate SQL Table

\subsubsection{Model-Based Reports}

There are two types of reports produced by this framework as mentioned in Figure 20. One presents cost estimate data while the second presents an audit trail. The main feature added in these reports is the ability to query the underlying data. The data is contextually linked to BIM elements. Through the audit trail, other stakeholders can review the assumptions made in the cost estimating process. The cost estimate reports are enhanced by queries. Queries can either filter BIM elements by cost or costs by BIM element. Furthermore, any data brought into the model in the conditioning is accessible to these queries. The estimator can find the cost for a scope of work, or for every element on a building level without doing additional takeoff or estimate manipulation. The queryable 
reports allow multiple stakeholders to consume the same estimate data. This adaptability reduces the recycling of data in the estimate reporting process.

An audit trail establishes a record of the assumptions made in the cost estimating process. Other stakeholders can review the audit trail reports to answer specific questions that would otherwise be communicated through conversation. Example uses of the audit trail reports include ascertaining which estimator made which set of assumptions, determining the impact of assumptions on the estimated cost, and understanding how complexity is subjectively defined. Answers to these reporting questions alongside historical cost data refinement should improve future cost estimate assumptions.

\subsection{Model-Based Historical Cost Data Refinement}

The key limitation addressed in this module is VDC cost control. This final module in the framework is the crux for the successful implementation of model-based cost estimation. This section should produce revelations tying productivity and cost to model geometry, product specifications, and other BIM element parameters. The revelation of these relationships, in the context of BIM elements, should further improve the performance of model-based cost estimation.

\subsubsection{Cost Code Tether}

The premise of this step is to associate a set of estimate work items with a specific cost code. The field uses accounting cost codes to budget their work, pay employees, and track progress. Currently, these codes are set by the accounting department and field personnel. So, there is some disconnect between the estimate and field personnel's cost breakdown structure. In the proposed framework, these codes are set and managed by the estimators. If an issue arises and the field needs another cost code to bill, then the 
estimators should be the ones to create a new cost code. the estimators remain involved while construction is in progress to map estimate information to production data.

At the end of module three, the estimators created cost reports and an audit trail driven by the data model amalgamated with the BIM model. This complete cost model included a list of work items with associated material, labor, and equipment costs. These work items were also associated with specific BIM elements in the model. The first step in module four ties estimated quantities and durations to the actual construction cost. The real cost is collected with cost codes, which are filled out by the field construction personnel. When these cost codes are tied to work items, the actual cost can be compared side by side with the estimated cost. Furthermore, this tether connects the cost codes to the BIM elements and their associated parameters. This gives cost codes a 3D spatial organization structure. So, once the work items are tethered to a cost code, historical accounting data is available in the model-based environment. This allows the estimating to review the accuracy of their estimate at the end of construction.

Implementation of this cost code tether is achieved within SQL. Figure 31 in section 4.4.4 shows the "ParametricEstimate" SQL Entity. This entity is linked to the "CostCode" entity by way of the "CostCode_ParametricEstimate" entity, both shown in Figure 32. This setup allows multiple work items to be associated with the same cost code. This is an example of a "one to many" relationship that is enabled by the SQL language. This affords the estimators flexibility to assign their estimate items to cost code. The relational structure also allows the relationship to be established after the estimate is complete. I.e. the estimators do not need to assign each work item to a cost 
code simultaneously. They can instead wait until the estimate is complete before mapping collaborating with the project management team.

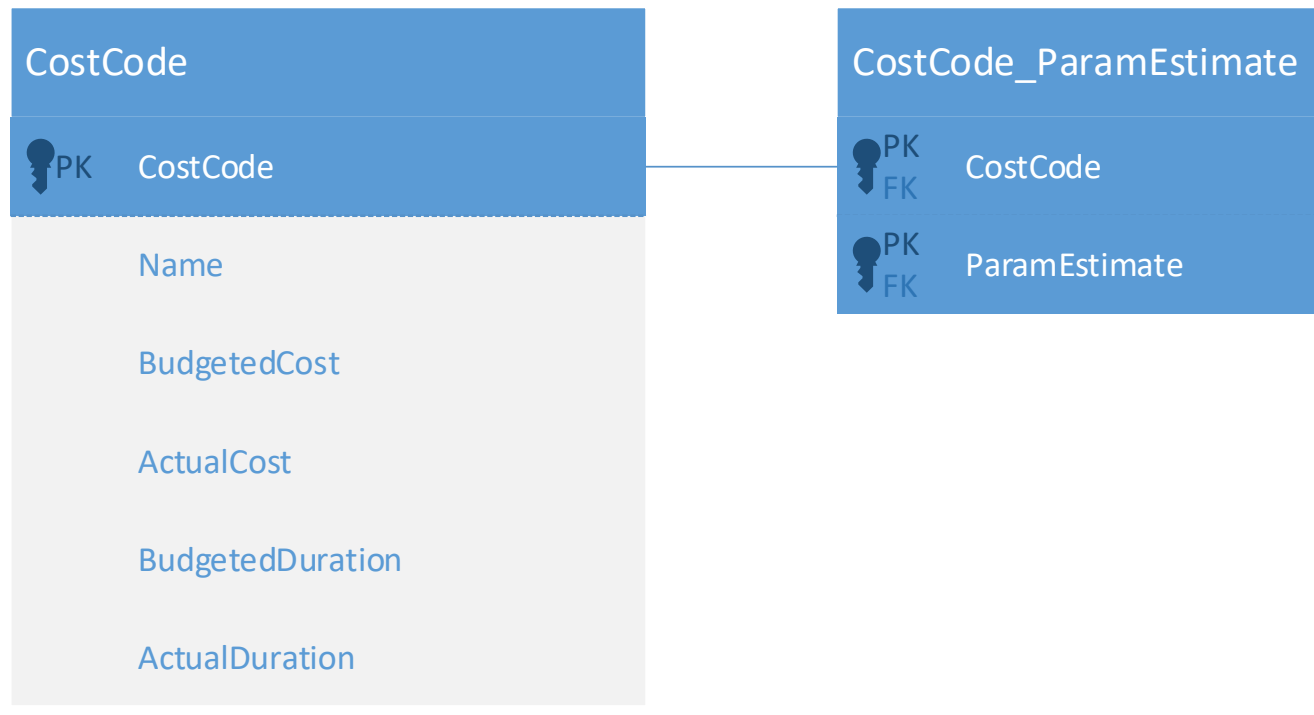

Figure 32 Cost Control SQL Table Linking Cost Codes to the Cost Estimate

\subsubsection{VDC Cost Control}

The VDC cost control step entails capturing production data using the modelbased environment as an aide. In step one of this module, the estimators tethered production cost codes to the work items that they estimated. Then by association, the BIM model elements are related to the accounting cost codes. So, a BIM user can select an Element in the model-based environment to query all the cost codes associated with that BIM element. This step in module four proposes using this feature to collect production data during the construction phase that is within the context of BIM elements.

One implementation of this idea is to create a model-based time card system. The critical advantage of this form of cost control is associating production with both cost codes and BIM elements. This concept is best explained with an example. Take the concrete columns on the ground floor of a building. Installing and stripping the formwork for these columns would be accounted for with a single cost code (Roy, 2018). This 
means that a crew can report their production rate for formwork of all columns on the ground floor. When these numbers are reviewed in the production report, only an aggregate average for all columns is available. However, when this data collection is done within the context of the model these production rates are discrete for each BIM element. The production report can then evaluate the differences in production rates by each individual column. This feature should help the estimators analyze the BIM element parameters alongside the reported production. This analysis should lead to an understanding of which BIM element parameters affect production rates.

\subsubsection{Historical Data Refinement}

The final step in the framework is to analyze the collected data and refine the production rates that are stored in the work item SQL database. As the framework is repeated on additional projects, the accuracy of the work-item database should evolve. The first cost estimates would be completed with a database derived from traditional cost estimates and production reports. Current production reports are blind to the element properties for which a certain production rate was achieved. The database evolution should be driven by the increase in granularity of the production reporting process. The model-based data is associated with BIM elements and can, therefore, access element properties. The project team should be able to gather more data in the context of the BIM model without adding additional responsibilities for the field team to handle.

\subsection{Summary}

This chapter detailed the steps within the four modules of the model-based cost estimating framework. The first module prepared the project team to handle the BIM model conditioning process. These preparations enable accessibility of all the project's 
data required for a cost estimate from within the BIM model. The second module conditioned the BIM models that would be used in the quantification and costing process. This conditioning process established the estimate structure in the context of the BIM model. The third module established the project's cost within the BIM model environment. The estimators added work items that were hosted and driven by the BIM elements and their parameters. The fourth module leveraged the model conditioning and cost estimation to refine the construction phase data collection process. The production data captured in this framework is contextually linked to the work items and host BIM elements. This fourth module allows database refinement that should evolve the accuracy of future model-based cost estimates. 


\section{IMPLEMENTATION}

\subsection{Overview}

The proposed cost estimation framework was tested against a real construction project. A case study comparison was made between the traditional, BIM QTO, and model-based cost estimating methods. The case study's scope is limited to a single twelve thousand square foot structural concrete slab on grade (SOG). This element is the foundation slab of building 4E in the YakPityuty $u$ student housing project at Cal Poly in San Luis Obispo. The three cost estimates of that element were performed in the following order, 1) a traditional QTO and Excel-based cost estimate, 2) a BIM QTO and Excel-based cost estimate, and 3) a model-based cost estimate. The SOG was selected for this study since it is a single element with multiple attached work items. The physical element is the 3D mass of the slab, it is represented in BIM as a single BIM element of the category: floors, family: floor, and type: 4" concrete SOG. This element was selected to exemplify the work item attachment feature of the model-based cost estimation method.

\subsection{Project Background}

The YakPity $u^{y} u$ Student Housing project is a residential community on the Cal Poly campus adjacent to Grand Avenue in San Luis Obispo, California. It consists of seven three to five-story residence halls with 1,475 beds, commercial retail space, and an adjacent four-story parking garage. An aerial photograph of the project near completion is presented in Figure 33. 


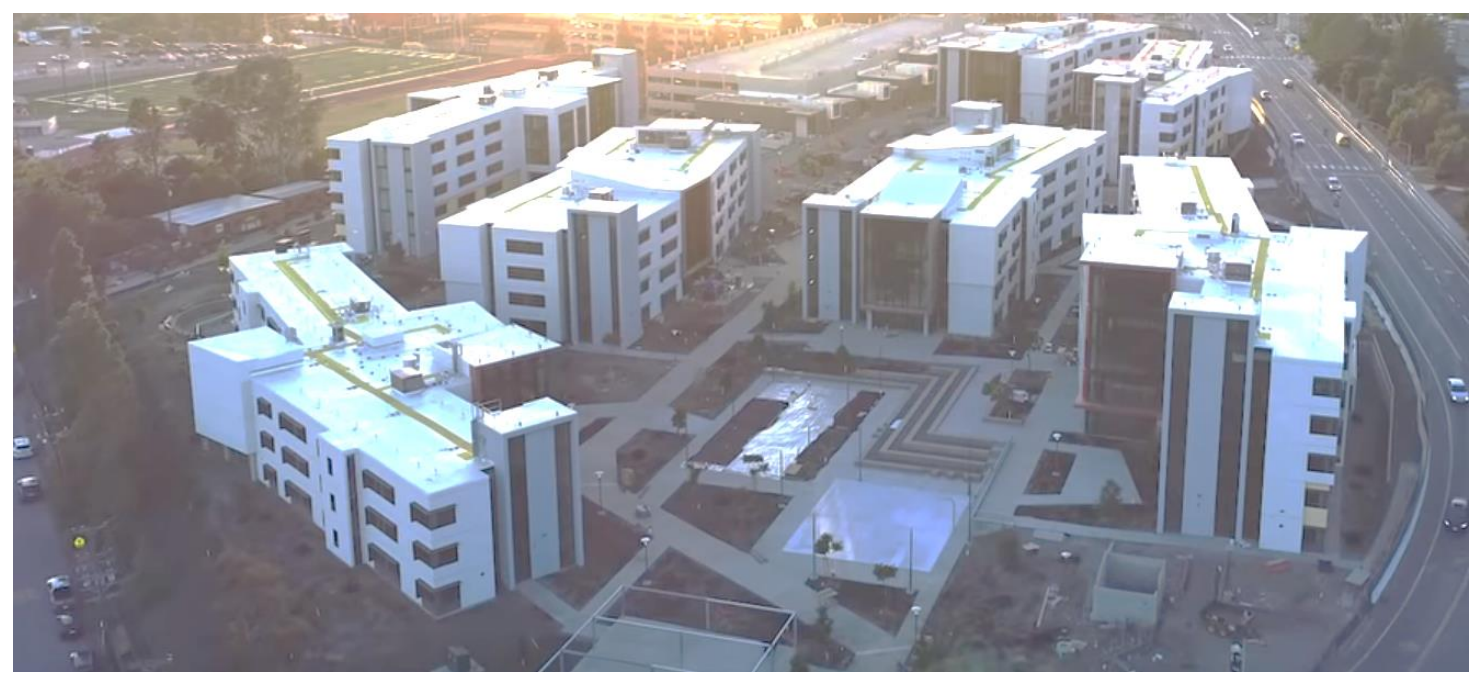

Figure 33 Drone Photograph of YakPity utyu Student Housing Project (Cal Poly, 2018)

The subject building of this study is a three-story residence hall, it is the leftmost building in Figure 33. It is constructed of cast-in-place concrete with a metal stud wall enclosure. The foundation system is comprised of a four-inch-thick SOG and spread footings that rest on bedrock, which is only a few feet below the surface. The gravity system consists of round and square reinforced concrete columns. These columns support the deck, which is pre-stressed cast-in-place concrete. The lateral force resisting system is comprised of orthogonal concrete shear walls.

Each residence hall viewed from the plan perspective has an outline of two rectangles slightly angled offset from one another. This large perimeter to surface area ratio lead to under-estimation of the floor to floor cycle times for slab, column, and suspended slab construction. The project team does not know how the important cost estimating lesson from this overrun will be communicated to other estimators in the company (Tuttle, 2018). Though it was not evaluated in the case study, VDC cost control, proposed in this thesis, should provide a means to transfer such information. 
The contractor who completed this design-build project employed the traditional method of cost estimation. Their cost estimate results are not discussed in this study since their cost data is proprietary and kept secret for competitive purposes. The contractor did, however, perform model coordination and clash detection using VDC. BIM models existed that were authored by the design team in 2014 and 2015 . These models had quantity and quality of information that was sufficient to perform the case study. The contractor provided these models for the case study. These models were not conditioned or purposed for cost estimation by the contractor, so this conditioning was performed in the case study.

The plans and specifications used in the traditional method were acquired from The University's Prolog software platform. The University also provided records of daily production logs and photographs. These were reviewed prior to completing the three cost estimates. These background data were meant to provide the context of the means and methods for the estimator. Interviews with project stakeholders were also conducted. The interviewees included the Cal Poly Director of facilities (Arronson, 2018), the general contractor's construction superintendent (Tuttle, 2018), and a project manager from The University's third-party construction manager (Wyatt, 2018). These interviews helped build a strong context of the project for completing the case study.

\subsection{Traditional Cost Estimate Method}

The traditional method of cost estimation consists of multiple modules conducted in different environments. In this case study, the first step was a review of the plans, specifications, and project documentation to establish the estimate requirements. This entailed writing a basis of estimate, prescribed by the AACE. The basis of estimate is a 
deliverable that defines the scope of the project. Any person with capital project experience should be able to use the basis of estimate to understand and assess the cost estimate (AACE RP 10S-90, 2015). In this case study, the overview and introduction sections of Chapter 5 serve as the basis of estimate. The cost estimate scope is defined as all work-items required to install the SOG to building 4E in California Polytechnic State University's Yak?ityuty $u$ Student Housing project. This first module establishes cost estimate requirements, was described in a word document environment, separate from the QTO and estimate environments.

The second module is planning and structuring the estimate. This involves defining the OBS and the WBS. Note that these two are the organization and process models within the product-organization-process model of VDC (Stanford Engineering, 2018). The OBS simply defined that a contractor's organization was assigned the complete installation scope for the SOG. The WBS broke the install into four work packages including 1) earthwork, 2) formwork, 3) pouring concrete, and 4) finishing concrete. Both of these breakdown structures were defined in the Excel estimating environment using a blank estimating template. These definitions of OBS and WBS are documented in environments separate from modules one and three.

The third module consisted of the quantification and costing efforts by the estimator. This began with 1) a QTO using the structural foundation PDF plan and corresponding details, 2) identification of the required work-items based on the QTO parameters, the OBS, and the WBS, 3) transcription of the QTO parameters to the Excel environment, and 4) references to historical labor, material, and equipment data regarding prices and production rates. The finished product of the quantification and costing 
module is the Excel cost estimate report presented at the end of this section. Figure 34 displays the breakdown of the three modules that were described above.

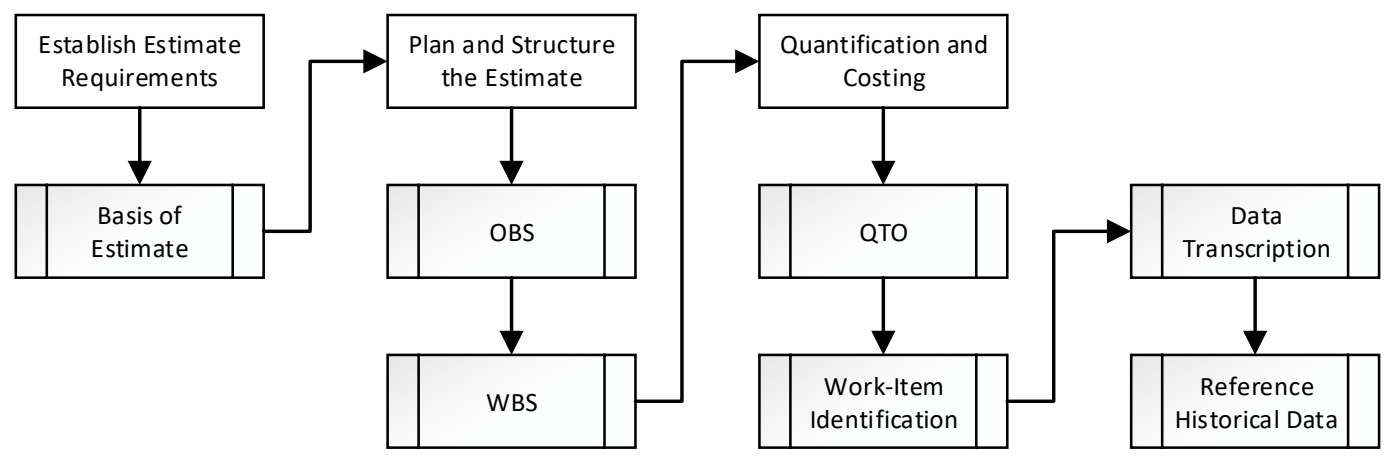

Figure 34 Process Diagram of the Cost Estimate Case Study Modules

The QTO is presented in Figure 35. The following paragraphs describe how the manual QTO was performed. The need to describe in words the steps followed by the estimator exemplifies that the audit trail could be improved. None of the times or steps mentioned below are automatically measured by the QTO software platform. This information would not be available without communicating with the estimator. The audit trail was only created when these paragraphs were written.

The case study only presents the time spent on quantification from the project documents. It does not present the time that the estimator spent on creating the QTO conditions since they may be recycled between jobs. It also excludes any time taken by the estimator to read and understand the plans. The case study assumes this is all completed in modules one and two.

The area of the SOG itself was measured from the PDF drawing. It took approximately 1.5 minutes to perform the 56 clicks to measure the SOG, shown in dark red. Another 1.25 minutes and 56 clicks to measure the SOG perimeter, the pink outline of the shape. The control joints were quantified next. This process was subjective because the joints were not explicitly defined in the plan. The condition was quantified using a 
simple linear measurement, the locations of the actual control joints were approximated based on the SOG's geometry. The control joint QTO took 0.75 minutes. The slab step was also quantified using a linear measurement. It was clearly located on the drawing and not subjectively defined. The QTO took 0.5 minutes. The sloped SOG was an additional area measurement taken atop the SOG condition. This condition was explicitly defined in the drawings, and the QTO took 0.5 minutes. The complete QTO took approximately 4.5 minutes. All measurements were derived from designer authored geometry.

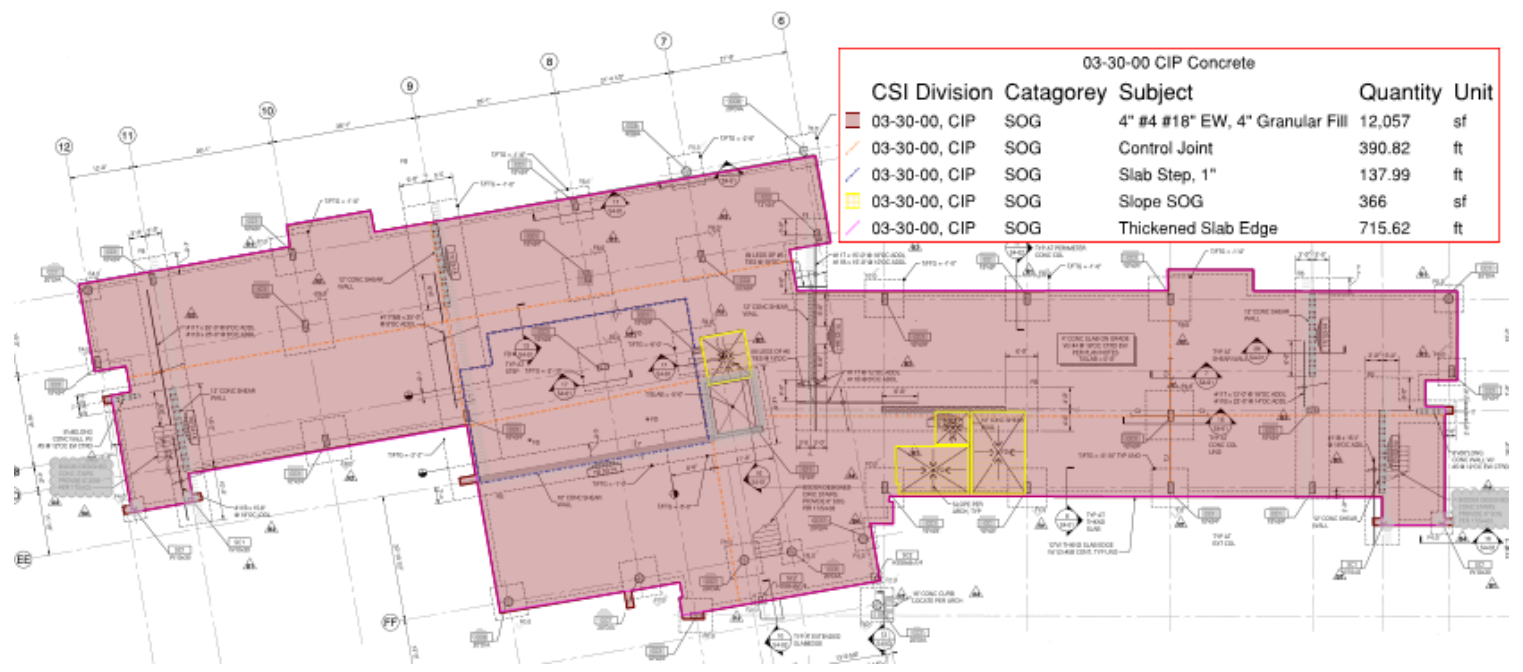

Figure 35 Traditional QTO of SOG Completed using Bluebeam Revu

Table 2 presents the results of the traditional QTO. Bluebeam Revu was the software used to perform the QTO. Those values closely match the BIM quantities since Revu has a feature to snap to Autodesk Objects. Revu was in effect measuring the same parameters that are available in BIM. The PDF software was reading the geometry that spatially defines the element's property, but it was not able to access that property directly. This process is data recycling, which was identified in the literature review. Some of the parameters that are measured in the QTO are already available in BIM. Furthermore, this manual QTO itself is not used by other stakeholders. The resulting 
quantities are used, but the QTO sheets themselves are not useful. It is data solely conditioned for the estimator. In the model-based cost estimating framework, any authored BIM elements are available to other stakeholders when the estimate is complete.

Table 2 SOG Quantities Established from the Traditional QTO

\begin{tabular}{cllll}
\hline CSI Division & \multicolumn{1}{c}{ Subject } & Category & $\begin{array}{l}\text { Primary } \\
\text { Quantity }\end{array}$ & $\begin{array}{c}\text { Secondary } \\
\text { Quantity }\end{array}$ \\
\hline 03-30-00, CIP & 4" \#4 \#18" EW, 4" Granular Fill & SOG & $748.6 \mathrm{ft}$ & $12057 \mathrm{ft}^{\wedge} 2$ \\
03-30-00, CIP & Thickened Slab Edge & SOG & $748.6 \mathrm{ft}$ & \\
03-30-00, CIP & Control Joint & SOG & $390.8 \mathrm{ft}$ & \\
03-30-00, CIP & Slab Step, 1" & SOG & $138.0 \mathrm{ft}$ & \\
03-30-00, CIP & Sloped SOG & SOG & $150.9 \mathrm{ft}$ & $366 \mathrm{ft}^{\wedge} 2$ \\
\hline
\end{tabular}

The cost estimate prepared using Microsoft Excel estimate (Figure 36) was completed following the traditional QTO. In the Excel format, each workbook row is an activity. Each activity has a placeholder for material, labor, and equipment work items. Meaning a single line item can contain as many as three work-items. The orange highlighted cells are all transcribed from the QTO report (Table 2). These were added in "one to one" relationships. This means that one and only one activity directly represents the QTO work item. All tan highlighted cells were database references or "one-to-many" quantity references. In the Quantity row, the "one-to-many" references are produced from a formula that is driven by an orange quantity. The database references define the cost and production rate of a work item. These references are contained within the Unit/HR and Unit Cost columns. They are equations that were manually linked to other Excel workbook pages. The complete estimate process was completed in 17 minutes. 
Project Name: Building 4E SHS

Date: $1 / 25 / 2019$

Estimator: Michael Clark
Quantity from Relationship

Quantity from QTQ
Total Conc Volume: $177 \mathrm{CY}$ Sales Tax Rate: $\mathbf{7 . 7 5 \%}$

$\$ 820.21 \mathrm{CY}$

\begin{tabular}{c|c|}
\cline { 2 - 3 } & \multicolumn{2}{c}{ LABDR } \\
Unit of & Units Hourly
\end{tabular}

\section{* Description}

Quantity

EABTHWORK:

finegrade @ subgrade

1-skiploader whox blade

gravel under slab

1-skiploader whox blade

1-tandem roller

purchase gravel materia

sand fill under slab

1-skid-steer loader

1-telebelt [operated hourly rate]

1-telebelt [charge for volume of $\mathrm{mt}$ )

purchase sand material

Vapor Barrier "Type 8 BBR Dura-

Skrim"

\begin{tabular}{c|c} 
Unit of & Units \\
Measure & IHR
\end{tabular}

Rate

Total

MATERIAL

EQUIPMENT

TOTAL

Unit

Total

ITEM

\begin{tabular}{|c|c|c|cc|c} 
& & $\$$ & - & $\$$ & - \\
\hline SF & 500 & $\$ 141.00$ & $\$$ & 3.401 & \\
\hline DAY & & $\$-$ & $\$$ & - & \\
\hline
\end{tabular}

\begin{tabular}{|c|c|c|}
\hline $\mathrm{CY}$ & 12.0 & $\$ 141.00$ \\
\hline
\end{tabular}

DAY

DAY

\begin{tabular}{l|ll|ll} 
& $\$-$ & $\$$ & - & $\$$
\end{tabular}

FORVWWDRK.

slab edge, 12"H (off subgrade)

C.J bulkhead, $\mathrm{H}=51 / 2$

38" $\times 24$ " smooth dowels @ C.

hang form @ slab depression, $\mathrm{H}<12$

\# hang form @slab depression, $\mathrm{H}<12$ "

21

\# CDNCBETE WORK.

\# concrete 4,000psi

$\#$

\# FINISH. CLIRE \& MISC

\# set screeds

\# place, trowel finish \& cur

\# 1-8' ride-on trowel

\# Sloped Slab

\section{SLAB DN GRADE TQTAL}

33,201

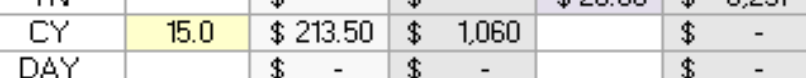

$\$ 26.00 \$ 6.257$

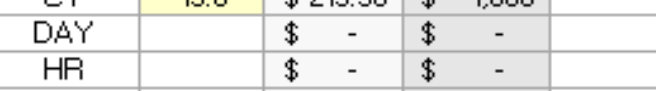

$\mathrm{CY}$

8
74
104

TN

700

$\$$

$\$$

(2)

$\$-$

$\$ \quad-$

$\$ 400.00 \$ 1,600 \$ 1,600$

$\$ 400.00 \$ 800 \$ \$ 1,749$

$\$ 350.00 \$ 700 \$ \$ 700$

$\$-\$ 6,257$

$\$ 400.00 \quad \$ \quad 400 \quad \$ \quad 400$

$\$ 220.00 \$ 1.760 \$ \$ 1,760$

$\$ 2.35 \quad \$ \quad 175 \quad \$ \quad 175$

\begin{tabular}{|llll}
$\$$ & - & $\$$ & 2,471 \\
\hline & - & $\$$ & 3,353
\end{tabular}

Figure 36 Cost Estimate Spreadsheet produced from the Traditional QTO 
Figure 36 does not show that the estimator began with a blank spreadsheet template. Each line item was manually added in the work-item identification step. The estimator referenced the drawings, specifications, and prior tribal knowledge to establish what were the work-items. There was no singular checklist referenced to build out the contents of the estimate. Instead, the estimator had to manage various sources of information and amalgamate them into the spreadsheet. This amalgamation diminishes the audit trail of the estimate. Any stakeholder that reviews the estimate would have to ask the estimator to justify decisions since there is no database storing their justification. It is also not easy to use the system. It takes time and more thought to recycle information from other data sources.

\subsection{BIM QTO and Excel Estimate}

The BIM QTO was completed following the same three modules presented in Figure 34. The results of module one and two are the same for the traditional method. The basis of estimate, OBS, and WBS are all defined external to the BIM model. Therefore, none of the data defined in any of these modules is available in the BIM QTO. The tool employed to complete the QTO was Autodesk Navisworks' selection inspector feature. The inspector was set to the parameters shown at the bottom of Figure 37. The indicated parameters were manually filtered from the list of over 50 available BIM element parameters. The filtered parameters that were usable in the estimate were thickness, volume, area, and perimeter. The category, family, and type parameters are all additional data that describe the functional characteristics of the BIM element. To 
complete the QTO, the SOG was selected as shown and a report of that selection's parameters was exported to an Excel sheet (Table 3).

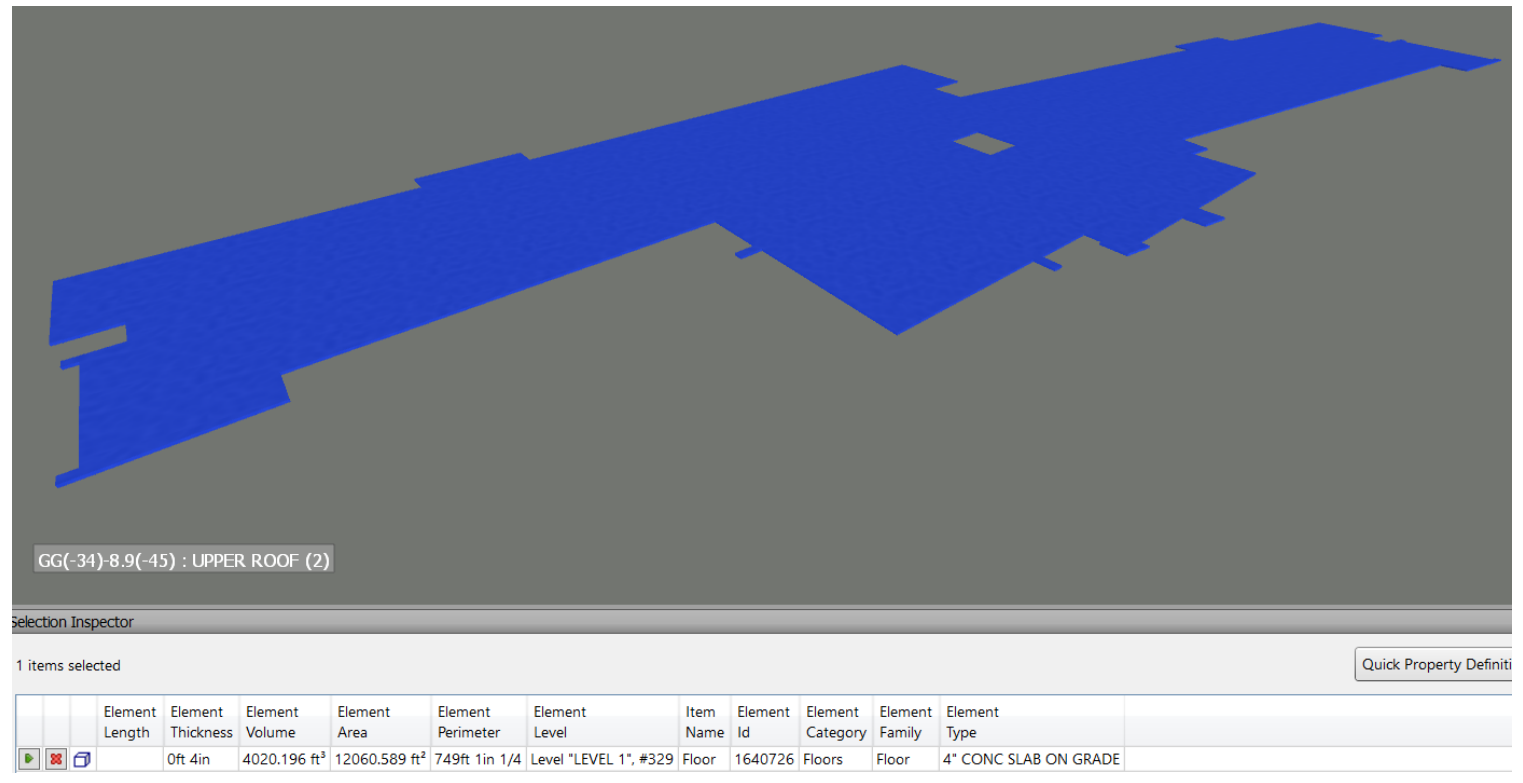

Figure 37 BIM QTO of SOG performed with the Navisworks "Selection Inspector"

The BIM QTO process was completed in one click. This process is simply a data extraction. The parameters were created when the design team authored the BIM elements. The extraction process must use the organization hierarchy as defined by the designer that authored the model. This case study only evaluated a single BIM element, so the organizational hierarchy had no impact on the QTO. The BIM model parameters are presented in Table 3. The BIM QT saved the 4.5 minutes that were expended by the estimator in the traditional method.

The BIM QTO process also reduced errors in measuring the parameters that drive the cost of an activity. In this process, these parameters are wholly defined by the design team. Therefore, there is no transcription or measurement error introduced by the estimator when performing the QTO. Any errors in the values of the "one-to-one" quantities were produced by the design team. While it is still possible for the estimator to 
incorrectly map the parameters to an activity, the frequency of measurement errors while generating the parameters was eliminated.

Table 3 BIM QTO Parameters Exported using the Navisworks Selection Inspector

\begin{tabular}{ll}
\hline Element Parameter & Parameter Value \\
\hline Element Thickness & Oft 4 in \\
Element Volume & $4020.196 \mathrm{ft}^{3}$ \\
Element Area & $12060.589 \mathrm{ft}^{2}$ \\
Element Perimeter & $749 \mathrm{ft} 1$ in $1 / 4$ \\
Element Level & Level "LEVEL 1", \#329 \\
Item Name & Floor \\
Element Id & 1640726 \\
Element Category & Floors \\
Element Family & Floor \\
Element Type & $4 "$ CONC SLAB ON GRADE \\
\hline
\end{tabular}

The parameters in Table 3 were then mapped to quantities in the Excel estimate Figure 38. The Excel format where each workbook row is an activity matches the traditional method. So this is analogous to the data transcription step encountered in the traditional method. The estimator must first identify the activities in the Excel estimate sheet. Then the estimator can define the parameters of those activities by referencing the parameters of the BIM QTO.

The blue highlighted cells in Figure 38 are all transcribed from the QTO parameters report (Table 3). These activities were added in "one to one" relationships, meaning that one and only one activity has the BIM QTO value. This is referred to as the "Primary Quantity". All tan highlighted cells were database references or "one-to-many" quantity references. The parametric relationships in the tan cells are driven by the Primary Quantity. The red cells represent activities that were not captured in the BIM QTO. There's no BIM Element with a Primary Quantity to describe them and they could 
not be driven by another Primary Quantity. This results in a $\$ 12,901$ or $12 \%$ discrepancy in the estimated cost versus the traditional method.

This case study presented a true BIM QTO, limited to the model itself. Therefore, the cost estimate parameters were limited to the BIM model provided by the designer. The estimator could not define any custom parameters to drive the red activities in Figure 38. This case study did not present an evaluation of a mixed system, which uses a combination of the traditional and BIM QTO methods. It was excluded since it is similar to the model-based cost estimating framework except QTO conditions are authored instead of BIM elements. The model-based process instead creates BIM-based conditions. These BIM conditions can host more parameters in addition to the parameter required to estimate an activity. 
Project Name: Building 4E SHS

Date: 1/25/2019

Estimator: Michael Clark

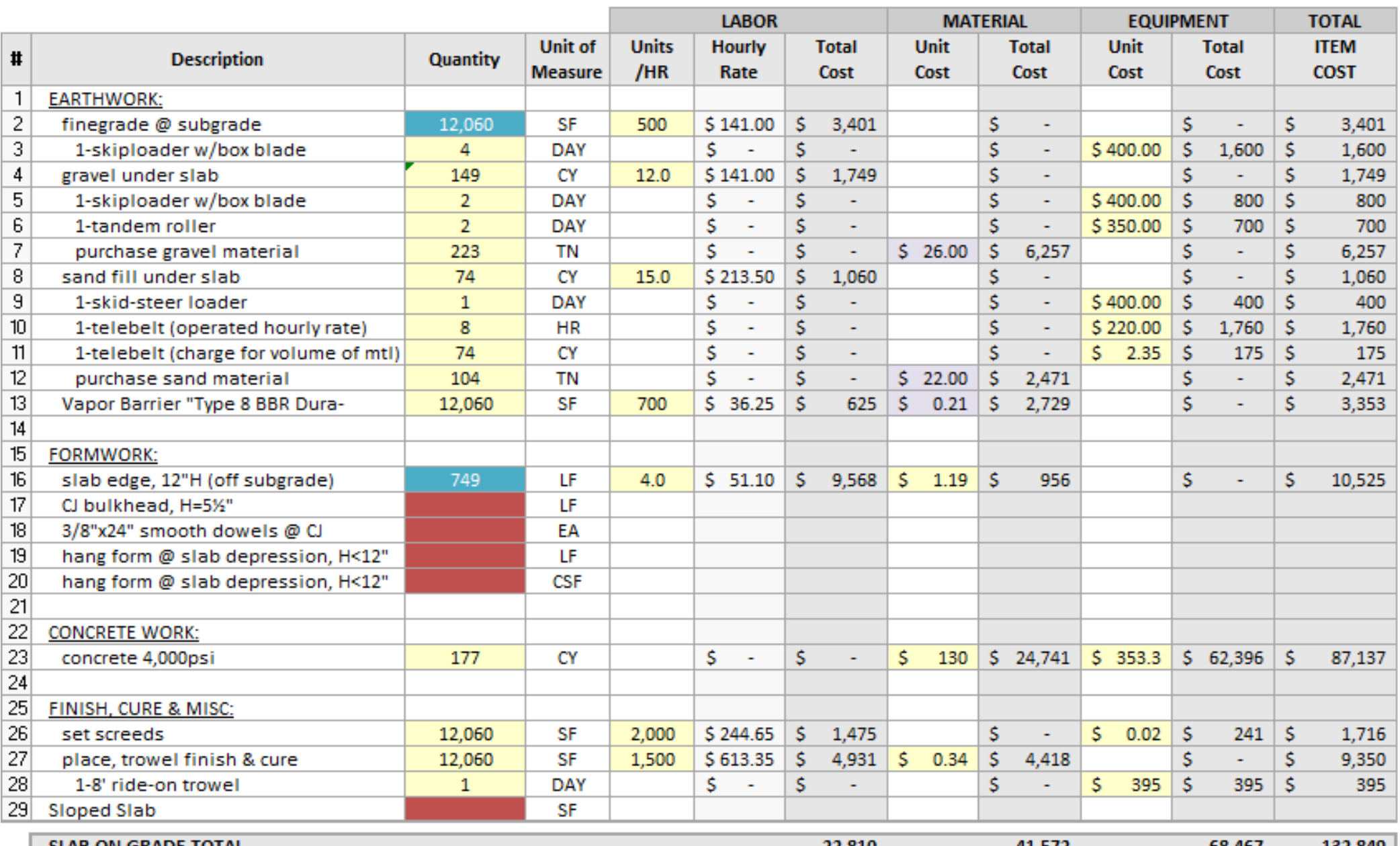

SLAB ON GRADE TOTAL

Figure 38 Traditional Cost Estimate Driven by Quantities from the BIM QTO 


\subsection{Model-Based Cost Estimate}

The Model-Based cost estimate was completed using a purpose-built Navisworks add-in. It facilitates interoperability between Revit, Navisworks, SQL, C\#, Revit, and Power BI. The add-in is intended to control the entirety of module three from within Navisworks and Revit. Modules one and two are completed in Excel, Power BI, and SQL and then can be reviewed and accessed through the Navisworks add-in. The QTO step in the model-based framework is completed automatically by the add-in. It transfers all the required BIM parameters into a SQL table. The add-in performs this transfer whenever a new BIM element is appended into the model. Some estimating parameters are not defined by the designers. The model-based estimate requires every parameter be derived from an authored BIM element. Therefore, the means and methods of construction are modeled as described in the framework (Chapter 4).

The means and methods of construction are authored using the Autodesk switchback feature. This feature enables the estimator to condition the BIM model. It allows the estimator to author the means and methods in Revit and reviews them in Navisworks. Figure 39 presents the conditioned BIM model. The blue element is the SOG from the designer's model, as in the BIM QTO method. The green elements were produced in Revit by the estimator. In the means and methods Revit file, the design model was used as a Revit link to prescribe the location of elements. There is possibly error introduced in the authoring process, but that can be visually checked against the 3D model. The authored elements are all within the 3D mass of the designer's model. This is 
one contractual requirement of the warranted accuracy clause for the proposed framework. The BIM authoring process took 3 minutes.

The Model-Based cost estimate was completed using module three of the prescribed framework, quantification and costing. The process was followed using the of the Navisworks add-in system. Many features of the add-in were not developed for the scope of this thesis. Those features were replicated with portions of the work performed using the "selection inspector", Excel, SQL, C\#, and Power BI in individual silos. The final add-in is intended to control the entire process from within Navisworks.

Figure 39 presents the conditioned BIM model. It constitutes the document means and methods sub-step of the framework, presented in section 4.4.1. The blue element is the building's SOG. It was imported from the designer's Revit model. It is quantified in the same fashion as the BIM QTO process. The green elements were produced in Revit by the estimator. In the means and methods Revit file, the design model was used as a Revit link to prescribe the location of BIM elements. The green elements are all within the 3D mass of the designer's model. Therefore, the designer did not violate the warranted model accuracy requirement. 


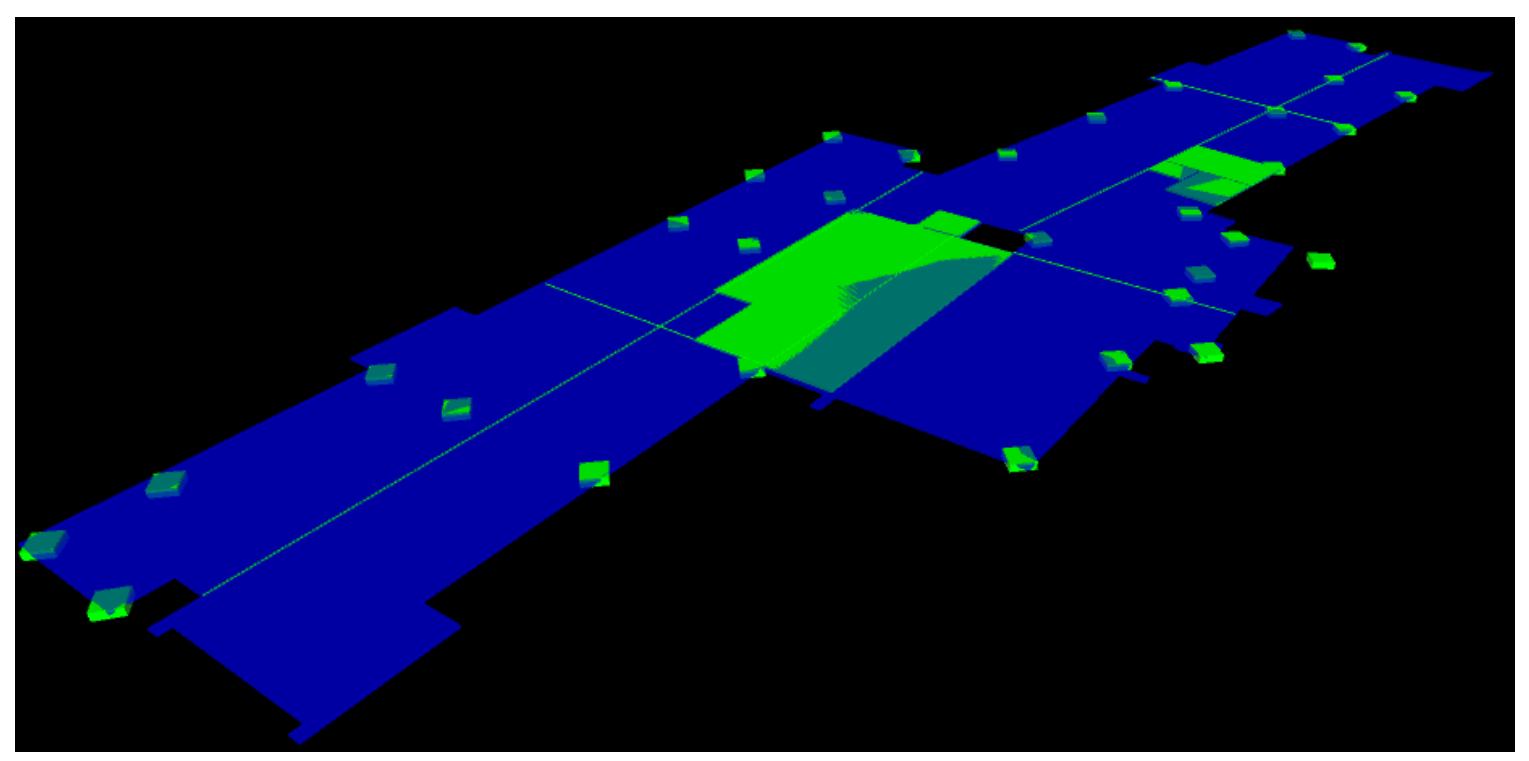

Figure 39 Conditioned Navisworks File for Completing a Model-Based Cost Estimate

The combined model parameters are presented in Table 4. This table represents the automatic QTO of BIM elements sub-step of the framework. These parameters are jointly defined by the design team and estimator. There is still no transcription or measurement error introduced in the QTO. There is the possibility of error introduced in the authoring process, but that can be visually checked against the $3 \mathrm{D}$ model.

Unlike the previous two methods, this does not constitute the complete QTO. These parameters are not transferred to the Excel spreadsheet for cost estimation. Instead, they're fed into a SQL table that stores the ID, name, and all other estimating parameters of each element in the BIM model. This SQL table is referenced when the estimator attaches work items to the model elements. The parameters in the table are used to drive the work items that the estimator assigns during the model-based estimate process. This QTO step adds the BIM model parameters to the model-based estimating environment. 
Table 4 SQL Table with all BIM Parameters Used to Complete the Model-Based Cost Estimate

\begin{tabular}{lll}
\hline $\begin{array}{l}\text { Element } \\
\text { Type }\end{array}$ & Element Id & $\begin{array}{l}\text { Primary } \\
\text { Quantity }\end{array}$ \\
\hline $\begin{array}{l}\text { Total: Concrete SOG } \\
\text { Control Joint }\end{array}$ & N/A & $401 \mathrm{ft}$ \\
$\begin{array}{l}\text { Total: Column Diamonds } \\
\text { Sloped Slab -4" }\end{array}$ & N/A & $34 \mathrm{EA}$ \\
$\begin{array}{l}\text { 1" Depressed Slab - 4" } \\
\text { thick }\end{array}$ & 280271 & $320 \mathrm{ft}^{2}$ \\
\hline
\end{tabular}

The work items are attached using the add-in tool panel shown in Figure 40. This figure shows the mapped category's under-slab accessories activities available to attach to the selected element. Each activity represents an assembly that can include material, labor, and equipment work-items. The estimator also has the option to modify each workitem of these individually.

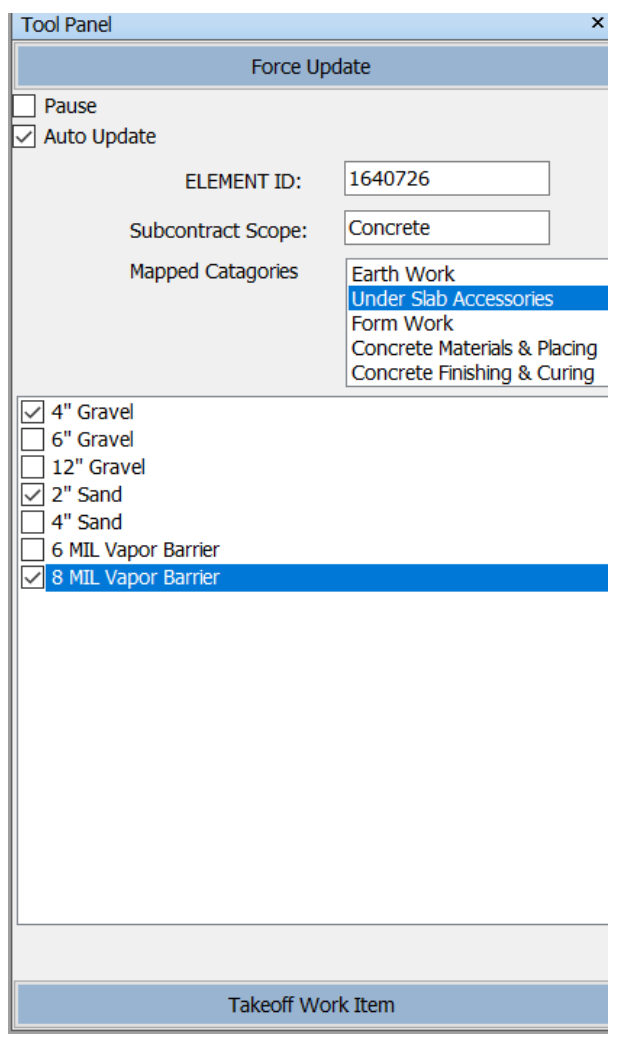

Figure 40 Work Item Attachment Using the Navisworks Add-in 
The complete results of the work-item attachment process for the SOG are presented in the appendix. This amalgamation of tables, which is hosted in a SQL server, constitutes the model-based cost estimate. The Navisworks add-in reads and writes to this SQL database using the C\# programming language. In the appendix table, blue columns represent BIM parameters, orange columns are work-items, grey columns are global project variables, and green columns are the subjective input identifiers. This single table references many other tables. Each referenced table contains a list of options for a column or a group of columns. Examples of these reference tables used in this case study are presented in the appendix as well. The complete work-item table is queryable within Navisworks using the add-in. This integration enables the spatial and temporal organization of cost estimate data and achieves a model-based cost estimate.

The results of the model-based cost estimate are presented in Figure 41 for comparison to the two previous methods in this case study. The results of the comparison show that the model-based estimate can attain the same accuracy as a traditional cost estimate while improving the audit trail and maintaining BIM QTO's speed. The modelbased cost estimate's accuracy is made possible by the construction intent that is documented in the means and methods BIM elements authored by the cost estimators. The audit trail is stored in the SQL tables that represent relationships of BIM element parameters to work-items. This spreadsheet is not representative of the actual modelbased cost estimate tables or report format, it was prepared for comparison purposes only. Examples of both the SQL table and the estimate Power BI report are presented in the appendix. 
Project Name: Building 4E SHS

Date: 1/25/2019

Estimator: Michael Clark
Quantitiy linked from BIM Total Slab Area: $12,060 \mathrm{SF}$

Quantity Linked Means \& Methods Total Conc Volume: $177 \mathrm{CY}$

Quantitiy generated by a relationship Sales Tax Rate: $7.75 \%$
$\$ 12.03 / \mathrm{SF}$ $\$ 821.24 / \mathrm{CY}$

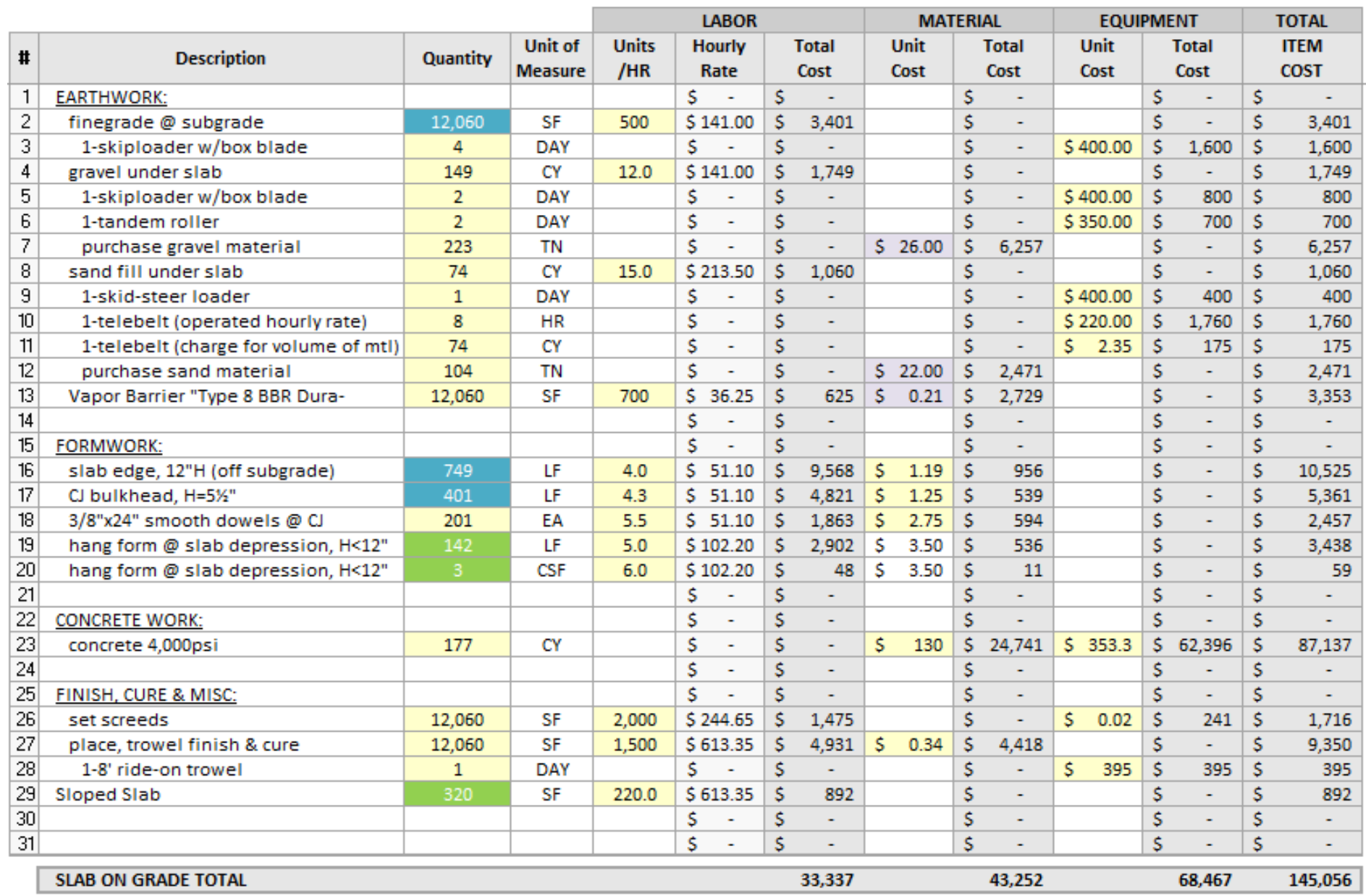

Figure 41 Traditional Cost Estimate Spreadsheet for Comparison purposes. 
The complete model-based cost estimate report is presented in the appendix. It is cumbersome to use on its own. The Power BI platform supports querying data or finding a specific metric from within that database. Figure 42 presents an application of a query to that cost estimate report. The question that the estimator asked was "how much of the total estimated cost for the SOG is purchasing and placing the concrete? Then what proportion of this cost is in material, labor, and equipment". The report shows that the total cost for the SOG concrete was $\$ 87,137$. Then divided by labor, material, and equipment the respective cost was $\$ 41,139, \$ 24,741$, and $\$ 21,257$. The pie chart at the right of Figure 28 shows that each respective SOG category constitutes $31.19 \%, 18.76 \%$, and $16.12 \%$ of the total project cost. This report answers questions that would otherwise require additional numerical manipulation of the data by the estimator. 


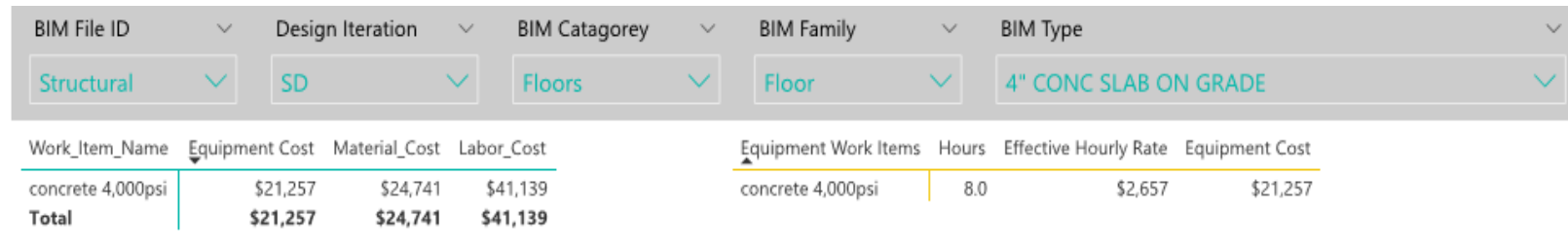

Project Cost Breakdown by Account Type

Distribution Material Equipment Labor

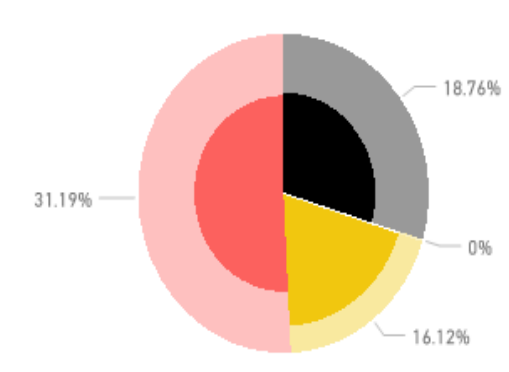

Project Cost Breakdown by Phase

Distribution SOG Pour Subgrade Prep SOG Finish

\begin{tabular}{|c|c|c|c|c|}
\hline Material Work Items & Quantity & UOM & Price Per Unit & Material_Cost \\
\hline 1-telebelt (charge for volume of $\mathrm{mt}$ ) & 74.44 & CY & 2.35 & $\$ 175$ \\
\hline concrete 4,000psi & 529.89 & $\mathrm{Cr}$ & 130.00 & $\$ 24,741$ \\
\hline place, trowel finish \& c cure & $24,120.00$ & SF & 0.34 & $\$ 4,418$ \\
\hline purchase gravel material & 223.33 & TN & 26.00 & $\$ 6.257$ \\
\hline slab edge, $12^{2} \mathrm{H}$ (off subgrade) & $1,498.00$ & LF & 1.19 & 5956 \\
\hline Vapor Barrier "Type 8 BBR Dura-Skrim" & $24,120.00$ & SF & 0.21 & $\$ 2,729$ \\
\hline
\end{tabular}

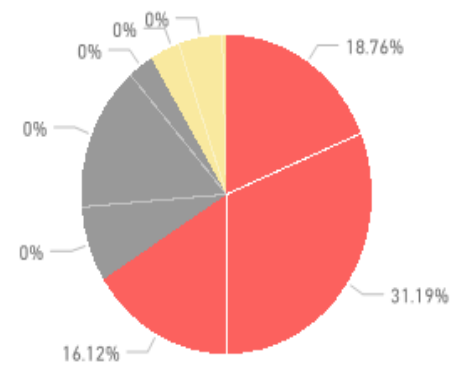

Figure 42 Report Query for Concrete Placing 


\subsection{Discussion of Results}

This section presents a comparison of the results from the three cost estimating methods: traditional, BIM QTO, and model-based. Metrics included in this discussion are the time to complete, accuracy of estimated activity costs, and completeness of the cost estimate. This section also reviews the time taken to prepare the cost estimate database.

\subsubsection{Discussion of Case Study Metrics}

Table 5 presents a comparison of the parameters that were captured in traditional and model-based cost estimates. The traditional method's parameters are taken as benchmarks and compared to the model-based results. In the improvement column, a positive value represents an improvement or benefit to the estimator while a negative value represents the opposite. Therefore, for any deviation in a quantity, the improvement column value is negative since the traditional method was used as a datum. This convention was chosen since current practices designate the drawings as the contract documents. Therefore, a QTO performed using the contract documents should be the benchmark for a cost estimate comparison.

Table 5 Comparison of the Estimating Parameters captured in the Traditional Method Estimate to the Estimating Parameters captured in the Model-Based Cost Estimate

\begin{tabular}{llll}
\hline Element Parameter & $\begin{array}{l}\text { Traditional QTO \& } \\
\text { Excel Estimate }\end{array}$ & $\begin{array}{l}\text { Model-Based } \\
\text { Estimate }\end{array}$ & Improvement \\
\hline Slab Area & $12,057 \mathrm{SF}$ & $12,060 \mathrm{SF}$ & $-0.02 \%$ \\
Slab Edge & $749 \mathrm{LF}$ & $749 \mathrm{LF}$ & $0 \%$ \\
CJ Bulkhead & $391 \mathrm{LF}$ & $401 \mathrm{LF}$ & $-3 \%$ \\
Column Diamonds & $35 \mathrm{EA}$ & $34 \mathrm{EA}$ & $-3 \%$ \\
Hung Form at Slab Depression & $138 \mathrm{LF}$ & $142 \mathrm{LF}$ & $-3 \%$ \\
Sloped Slab on Grade & $366 \mathrm{SF}$ & $320 \mathrm{SF}$ & $-13 \%$ \\
Estimated Activies $^{1}$ & $23 \mathrm{EA}$ & $23 \mathrm{EA}$ & $0 \%$ \\
Activities Missed & $0 \mathrm{EA}$ & $0 \mathrm{EA}$ & $0 \%$ \\
\hline
\end{tabular}

1) A count of the activities that could be quantified based on the available parameters or QTO information. 
Table 6 presents the net time to complete each method of cost estimation alongside their total estimated cost. The results show that for the building's SOG, the model-based cost estimate was completed over $50 \%$ quicker than the traditional method while maintaining a comparable level of accuracy. The QTO and estimate were both completed about $90 \%$ quicker than in the traditional method. This was possible since the designer's model met the required level of warranted accuracy for the cost estimating process. The only BIM elements that the estimator authored were to host the means and methods of construction, see Figure 39. If this wasn't the case, the estimating team should create their entire own BIM model for cost estimation. Creating this model would add additional time to the authoring process. Since the designer's BIM was useable, additional authoring was not required. The net time to complete was $52 \%$ quicker for the model-based estimating method.

Table 6 Comparison of the Time to Complete and Estimated Cost Results of the Traditional Method Estimate versus the Model-Based Cost Estimate

\begin{tabular}{|c|c|c|c|}
\hline Element Parameter & $\begin{array}{l}\text { Traditional QTO \& } \\
\text { Excel Estimate }\end{array}$ & $\begin{array}{l}\text { Model-Based } \\
\text { Estimate }\end{array}$ & Improvement \\
\hline Time to Complete $\mathrm{QTO}^{1}$ & 2.3 Minutes & 0.3 Minutes & $87 \%$ \\
\hline Time to Complete Estimate ${ }^{2}$ & 17.0 Minutes & 1.5 Minutes & $91 \%$ \\
\hline Time to Model Means \& Methods & 0 Minutes & 7.5 Minutes & $-100 \%$ \\
\hline Net Time to Complete & 19.3 Minutes & 9.3 Minutes & $52 \%$ \\
\hline Time to Prepare the Database ${ }^{3}$ & 0 Minutes & 127.0 Minutes & $-100 \%$ \\
\hline Total Time to Complete & 19.3 Minutes & 136.3 Minutes & $-606 \%$ \\
\hline Total Estimated Cost & $\$ 145,750$ & $\$ 145,907$ & $-0.1 \%$ \\
\hline
\end{tabular}

1) The time required to complete quantification of the SOG.

2) The time required to attach all the work items to the QTO Parameters.

3) The time spent mapping model-based parameters to corresponding work item quantities and defining the list of available work items for a specific category-family-type in BIM. 


\subsubsection{Results for Preparation of the Computation System}

The time to prepare the database is included in the comparison even though it is not directly part of the model-based cost estimating process. It does hoverer represent a large overhead task that must be completed prior to embarking on the first model-based cost estimate for each BIM category-family-type combination in the BIM model. While the $-606 \%$ difference in total time to complete seems large, it represents the first BIM element in the first cost estimate completed. One purpose of the SQL database is to take advantage of previously defined work-item maps by storing them in a searchable database. So, for the second model-base estimate performed using this framework, the time spent preparing the database to estimate any SOG should be zero. The SQL database should have stored all possible options for concrete thickness, gravel fill thickness, excavation, and re-compaction thickness, etc. With similar BIM elements, the estimator only completes the selection of work-items to complete the cost estimate.

Preparation of the database involved manually transcribing work items while adhering to the relational database structure. The researcher entered integer values for the foreign key constraints that manually linked the data in one table to the data in another table. The aggregate time to complete the cost estimate was $606 \%$ slower for the modelbased cost estimate when database preparation was considered. The report is presented to depict the worst possible circumstances for completing a model-based cost estimate. The worst circumstances for efficiency should be from evaluating the first few BIM elements in a model and when work items are added to the database for this first time. This is because the model-based estimating method is designed for repeatability. Subsequent SOG estimates should be completed with limited additional database authoring. 
The work items and parameter mappings can also be adapted to similar BIM types. The following example explains how additional BIM elements would be added to the database. Consider a concrete slab on metal deck. The category, floors, and family, floor, are the same as the SOG. However, the type is a slab on metal deck instead of SOG. So, the SOG parameter mapping could be copied, but new work items would be mapped to those parameters. This feature is what creates a flexible map that associates a group of work items to a specific BIM category-family-type combination. The flexible mapping feature will further reduce the time taken to prepare the database.

\subsection{Quality Control}

The case study does not follow the entire proposed framework due to a few limitations. First, this comparison was performed after construction was completed. Therefore, module four, Construction Phase Data Collection, could not be evaluated. Second, the Navisworks add-in is not fully developed. Manual data transcription, using Excel, was employed to complete some steps that would otherwise occur in the SQL database. The manual data transcription time was not included in the comparison. So, this limitation was not incorporated into the comparisons in Table 5 or Table 6 . This did result in an increased time to prepare the database. Any reduction in the time to prepare the database is a positive benefit for the model-based cost estimating process.

A single individual with one year of cost estimating experience completed each cost estimate and kept time using a stopwatch. The times were rounded to the first decimal place. All three cost estimates were performed by the same person in order that they appear in this chapter. They were performed on different dates to counteract the increase in efficiency due to practice and memory. 
The complete model-based cost estimate add-in has not been fully developed. The add-in should transfer BIM data into the SQL database table then transfer out the total work item costs and durations. The case study employed a manual transfer of data using Excel and the Navisworks" "selection inspector" feature. Automatic data transfer should only decrease the time to complete the model-based estimate and improve ease of use. Therefore, any improvement should further strengthen the case of adopting the modelbased cost estimating framework. 
The production rates and unit prices used in the estimate were acquired from the R.S. Means cost estimating database (Giordian, 2019) and an example project provided by a cost estimating professional (Roy, 2018). The cost data may not be representative of the actual construction cost. However, the cost data is consistently used in each of the three cost estimating methods. Therefore, any comparison made between the three methods should accurately represent the difference in estimated cost between the methods. The relative comparison made between methods is not adversely affected by potentially inaccurate cost data.

\subsection{Summary}

The model-based cost estimate for the SOG element was completed quicker than and with the same result as the traditional method. The model-based method increased accuracy compared to the BIM QTO method. There is a single succinct audit trail stored in a SQL database that is available to other stakeholders for quality control. The cost estimate is completed entirely within the BIM model environment and therefore is easier to visualize, attach work-items, and check completeness against the remaining BIM elements. The results of this case study enforce that the model-based method should be preferable to both traditional and BIM QTO methods of cost estimation. 


\section{CONCLUSIONS}

\subsection{Overview}

Chapters Two through Five present a comprehensive analysis and framework to conduct a model-based construction cost estimate. First, a literature review was conducted to develop the limitations that exist within the body of knowledge that hinder successful model-based cost estimation. Second, a methodology was presented that synthesized these limitations into a plan for an improved system. Third, a framework was developed to implement the system and address the limitations identified in the literature review. Fourth a case study evaluation of three cost estimating methods was completed. This evaluation compared the proposed framework and system to two methods of cost estimation that are popular in the construction industry today. The results of this case study exemplified the speed and completeness attainable with a succinct model-based cost estimating framework and system. Finally, these conclusions are presented based on the research findings. They include improvements yielded by the framework, prevailing limitations, and a guide for future development regarding this model-based construction cost estimation framework.

\subsection{Contributions of the Proposed Framework}

There are five improvements listed in this section. They are in direct response to the seven of the eight limitations identified in the literature review. The construction contract limitation is the only one that was addressed but not directly improved. The reasoning for this is expanded in the Prevailing Limitations (Section 6.4). The other seven limitations were improved upon in the development of the framework and are discussed in this section. 
Ease of use and software interoperability were addressed in conjunction with the framework. The system's suite of software includes SQL, Navisworks, Excel, Power BI, and Revit. The first improvement was eliminating the need for the estimators to learn SQL since they are not responsible for completing anything directly in SQL. All the system's features that employ SQL do so through the add-in. The other improvement was implementing the Autodesk "switchback" feature. This feature enables the estimator to author BIM in Revit and completes the estimate in Navisworks. These two features reduce the additional training that an estimator should require prior to implementing the model-based cost estimating framework.

The flexible mapping limitation was addressed by the system's SQL data structure. This data structure is presented in the Appendix. It enabled a detailed audit trail, cost estimation within a BIM model environment, and reports for multiple stakeholders derived from a single dataset. This data structure comprises the data model that is available in conjunction with the BIM model. This flexible mapping feature was the main driver behind the improvement in speed.

The subjective input limitation was addressed by the parametric estimate add-in. This add-in provided a feature in the parametric estimate step to modify the productivity and waste factors for a work item. These modifiable factors allow the estimators to incorporate their subjective understanding of difficulty into the BIM model environment. The premise of this framework is that no cost estimate information is blind to the BIM model. This feature allows the incorporation of subjective human understanding into the model-based cost estimate. 
The VDC cost control limitation was addressed by the historical data refinement module. This module incorporated a plan to harvest data and utilize it to reduce the risk of cost uncertainty in future estimates. The first step towards achieving this was made possible by the first three modules in the framework. The result of the first three modules is that all cost estimate information can be accessed through BIM. With the same data structure, the BIM elements can be utilized to control cost during construction. The data that is available for comparison as a result of this combination can be utilized to improve the assumptions of future cost estimates.

Addressing the parametric estimating limitation added a second improvement that was mentioned in Section 4.4.4. This improvement is named polymorphism. In this context, it is using a single BIM element to host the work items that belong to multiple Scopes of Work. Using a structural concrete example, consider three work items including rebar, concrete placing, and formwork all for a single SOG BIM element. All work items are attached to the same wall, but they each belong to a different sub-contract. This feature is not possible with traditional or BIM QTO methods. To represent this in other methods, the object parameters should be copied. However, the model-based method employs SQL to produce a "one-to-many” relationship. This allows all cost information to be associated with specific BIM elements, without duplicating any parameters or recycling data.

\subsection{Limitations of the Proposed Framework}

This framework requires the establishment of a relational SQL database. If a party adopting this framework currently keeps its data in Excel, they can import it into SQL using an import wizard. However, this excel data would need to be conditioned and 
parsed for each of the 36 tables in the framework's architecture. Excel data is not relational by default, so the relationships would have to be manually described, by manually establishing primary \& foreign key relationships. Alternatively, a $3^{\text {rd }}$ party application could be developed that would automate this migration process. That app would still have to be customized for each adopting party since there is no standard for storing existing historical cost data. In this thesis, the data migration was done manually, without any $3^{\text {rd }}$ party app. In practice, this would require a database administration professional to maintain and import new points into the database

The proposed framework was designed and tested only with Autodesk Revit BIM authoring software. The computation platform was built exclusively for Revit 2019 \& Navisworks 2019. Different versions may have reduced interoperability. Adding interoperability with other platforms would require the implementation of the IFC architecture, which was avoided because IFC element definitions are not rigid (see page 22). This severely limits the interoperability potential of the proposed framework. Future work should expand interoperability with other computation platforms.

The current solution to achieve flexible mapping is static. It depends on the static definitions of Category, Family, and Type. I.e. if " 4 " steel tube " was modified to "4" Steel Tube" by the designer, then the flexible mapping definitions to that element would be lost. Future work should evaluate a new flexible mapping strategy that does not solely rely on the naming of the hierarchy. Implementation of this framework was limited to Revit structural systems in BIM. It excluded architecture and MEP systems which have slightly different properties and definitions. Completing a model-based cost estimate of 
either MEP or architecture may require additional SQL columns for storing additional cost estimating parameters.

The platform for sharing cost reports is Microsoft Power BI. It is a hybrid free desktop and paid cloud computing application. Where the cloud computing service is billed per each query. The reports have limited functionality when printed out. A future project could be foregoing the Power BI platform and improving the cost reporting capabilities from within Navisworks.

\subsection{Future Developments}

This section describes five additional developments to the existing body of knowledge that should be emphasized in future related works. These developments were outside the scope of this thesis and thus not addressed.

- One development is addressing the high economic barrier to entry of adopting this framework. The barriers include training the estimators to properly use the system, updating hardware and software to meet the increased computational demand, seeding the cost estimate work item database, and maintaining the system as new software releases are issued. This limitation was identified by the AGCA, who surveyed firms that had adopted 5D BIM. They found that it took anywhere from six to eighteen months to see a return on monetary investment in 5D BIM software (AGCA, 2007).

- Another development is addressing the proprietary nature of historical cost data. Each construction firm accumulates its own production rate and cost data as they complete projects. This data is specific to the structure of their 
company and its operating procedures. Each firm uses its own data to estimate the cost of new work that they compete to win. If another competing firm were to gain access to their proprietary data, then that firm may gain a competitive advantage in the bidding process. The proprietary nature of this data is why the firm would likely hire an in-house database administrator. One responsibility of this administrator would be to maintain the security of the firm's cost and BIM data.

- Construction cost reporting is the practice of the contractor managing their spending in order to bill the client for the work that is installed. This framework can enable highly detailed cost reporting. This could be achieved by field personnel specifying the work items that are installed to specific BIM elements. The successful installation data could flow to the project management team who would bill the client for the work. Future research should integrate this framework with construction phase data collection. This integration could automate certain portions of the cost reporting process. Detailed cost reporting within the context of the modelbased cost estimate should also allow the project management team to better control cost. They could easily compare the estimated and reported cost for a work item when both data points are stored in the BIM model environment.

- This framework could reduce the cost of evaluating design alternatives. In current cost estimating practices, the overhead cost of evaluating design changes increases as the design is developed. This is because estimators 
spend more to complete an estimate as to the detail of the project documents increases. The growing cost can be reduced by reuse of previously established mappings and work items. The model-based framework enables re-use by storing data in SQL. This data is then available to other BIM models with similar data hierarchies. Successful data re-use using the SQL enabled structure reduces the time and cost to evaluate a design iteration. This reduction could lead to complex and iterative design cycles. Adopting this framework could benefit the project team since considering more alternatives in the design phase should provide improved value to the project's stakeholders.

- Perhaps the most promising future development that this framework enables is a temporal breakdown of the model-based cost estimate. This is commonly referred to as a "5D BIM cost estimate". A 5D BIM cost estimate synthesizes the three spatial dimensions along with the construction schedule and cost for constructing the design in that 3D model. A conceptual 5D estimate is achievable with current unit price estimating methods. Simulating the estimated cost and schedule alongside the BIM environment can provide valuable insights for many project stakeholders. Current practices do not attain the accuracy necessary to represent a bid-tender detailed estimate in the BIM environment. The model-based estimating framework incorporates enough detail into a 5D estimate for the bid-tender level of accuracy. 


\section{REFERENCES}

AACE Technical Board. (2015). AACE Recommended Practice No. 10S-90, Cost Engineering Terminology. AACE International.

ADEB-VBA. (2015, October). BIM-Belgian Guide for the Construction Industry. Retrieved from ADEB-VBA: http://adeb-vba.be/the-guide-to-bim.pdf

Alzraiee, H. H. (2013). Hybrid Simulation for Construction Operations. Montreal: Concordia University.

Antunes, R., Gonzalez, V., Walsh, K., Rojas, O., O'Sullivan, M., \& Odeh, I. (2018). Benchmarking Project-Driven Production in Construction Using Productivity Function: Capacity and Cycle Time. ASCE Journal of Construction Engineering and Management.

Arronson, R. (2018, September 25). Facilities Management Director, Preliminary Discussion on the Cal Poly Student Housing South Project. (M. T. Clark, Interviewer)

Autodesk. (2018). BIM and the Future of AEC. Retrieved from AUTODESK: https://www.autodesk.com/solutions/bim

Azhar, S. (2011). Building Information Modeling (BIM): Trends, Benefits, Risks, and Challenges for the AEC Industry. Leadership and Management in Engineering, 241-252.

Borhani, A., Dossick, C., Lee, H., \& Osburn, L. (2017). MBEst, A Technical Report on Standardization of Model-Based Estimating. Center for Education and Research in Construction.

Borrmann, A., Konig, M., Koch, C., \& Beetz, J. (2018). Building Information Modeling: Technology Foundations and Industry Practice. Springer International Publishing AG.

Brook, M. (2017). Estimating and Tendering for Construction Work. New York: Routledge.

Burnham, R., \& Nagata, M. (2016). Alternate Project Delivery: Claims in Design-Build, Guaranteed Maximum Price, and Other Delivery Methods. In R. Burnham, \& M. Nagata, Construction Contract Claims, Changes, and Dispute Resolution, Third Edition. ASCE.

Cal Poly. (2018, July 16). yakit'tut'u Residential Community. Retrieved from Youtube: https://www.youtube.com/watch?v=EPwFtJGafwM 
Chan, A. P., Scott, D., \& Chan, A. P. (2004). Factors Affecting the Success of a Construction Project. Journal of Construction Engineering and Management, 153-155.

Chen, K., Lu, W., Peng, Y., Rowlinson, S., \& Huang, G. (2015). Bridging BIM and Building: From a Literature Review to an Integrated Conceptual Framework. International Journal of Project Management, 1405-1416.

Chen, Y., John, D., \& Cox, R. (2018). Qualitatively Exploring the Impact of BIM on Construction Performance. ICCREM, (pp. 60-70).

Christensen, P., Dysert, L., Bates, J., Borowicz, J., Bredehoeft, P., Brown, R., . . Creese, R. (2011). AACE International Recommended Practice No. 17R-97, Cost Estimating Classification System. AACE.

Der Kiureghian, A. (2009). Probabilistic Methods for Engineering Risk Analysis. Berkeley: U.C. Berkeley.

Dodds, J., \& Johnson, S. (2011). Mastering Autodesk Navisworks 2012. John Wiley \& Sons.

Farnsworth, C., Beveridge, S., Miller, K., \& Christofferson, J. (2014). Application, Advantages, and Methods Associated with Using BIM in Commercial Construction. International Journal of Construction Education and Research, 218-236.

Fernández-Solís, J., \& Chugh, K. (2018). Structured Literature Review of DesignBuild/Bridging, Design-Bid-Build \& Design-Build. Retrieved from Texas A\&M University Libraries: http://hdl.handle.net/1969.1/166265

Franco, J., Mahdi, F., \& Abaza, H. (2015). Using Building Information Modeling (BIM) for Estimating and Scheduling, Adoption Barriers. Universal Journal of Management, 376-384.

Fulford, R., \& Standing, C. (2013). Construction industry productivity and the potential for. International Journal of Project Management, 315-326.

Ghaffarianhoseini, A., Tookey, J., Ghaffariahoseini, A., Naismith, N., Azhar, S., \& Efimova, O. (2017). Building Information Modelling (BIM) uptake: Clear benefits, understanding its implementation, risks, and challenges. Renewable and Sustainable Energy Reviews, 1046-1053.

Giordian. (2019, January 15). RSMeans Data Estimating Solution. Retrieved from RSMeans Data from Giordian : https://www.rsmeansonline.com/

Golaszewska, M., \& Salamak, M. (2017). Challenges in Takeoff and Cost Estimating in the BIM Technology, Based on the Example of a Road Bridge Model. Technical Transactions in Civil Engineering, 71-79. 
Hall, J. (2018, July 27). Top 10 Benefits of BIM in Construction. Retrieved from Autodesk BIM 360: https://connect.bim360.autodesk.com/benefits-of-bim-inconstruction

Hollmann, J., Bates, J., Burton, D., Creese, R., Dysert, L., Humphreys, K., . . Querns, W. (2003). AACE International Recommended Practice No. 19R-97, Estimate Preparation Costs in the Process Industries. AACE.

Hollmann, J., Borowicz, J., Bredehoeft, P., Brown, R., Dysert, L., Pickett, T., \& Pietlock, B. (2012). AACE International Recommended Practice No. 11R-88, Required Skills and Knowledge of Cost Engineering. AACE.

Isherwood, J. P. (1999). United States of America Patent No. US08357417.

Kam, C., Song, M., \& Senaratna, D. (2016). VDC Scorecard: Formulation, Application, and Validation. ASCE Journal of Construction Engineering and Management.

Kim, K., Cho, Y., \& Kim, K. (2018). BIM-Based Decision-Making Framework for Scaffolding Planning. ASCE Journal of Management in Engineering.

Kreider, R., Messner, J., \& Dubler, C. (2010). Determining the Frequency and Impact of Applying BIM for Different Purposes on Projects. Proceedings of the 6th International Conference on Innovation in Architecture, Engineering, and Construction (AEC). University Park, PA: Penn State University. Retrieved from http://bim.psu.edu/uses/

Lawrence, M., Pottinger, R., Staub-French, S., \& Nepal, M. (2014). Creating Flexible Mappings between Building Information Models and Cost Information. Automation in Construction, 107-118.

Lee, D.-G., Park, J.-Y., \& Song, S.-H. (2018). BIM-Based Construction Information Management Framework for Site Information Management. Hindawi Advances in Civil Engineering.

Lee, S.-K., Kim, K.-R., \& Uy, J.-H. (2014). BIM and Ontology-based Approach for Building Cost Estimation. Automation in Construction, 96-105.

Lobel, J. (2008). Building Information: Means and Methods of Communication in Design and Construction. Retrieved from Massachusetts Institute of Technology: https://dspace.mit.edu/bitstream/handle/1721.1/43747/263921735MIT.pdf;sequence=2

Ma, X., Xiong, F., Olawumi, T., Dong, N., \& Chan, A. (2018). Conceptual Framework and Roadmap Approach for Integrating BIM into Lifecycle Project Management. ASCE Journal of Management in Engineering. 
McDonald, D., Zack, J., Armstrong, D., Bess, J., Boyd, R., Bradley, B., \& Brake, R. (2004). AACE International Recommended Practice No. 25R-03, Estimating Lost Labor Productivity in Construction Claims. AACE.

McPhee, A. (2013). Practical BIM. Retrieved from http://practicalbim.blogspot.com/2013/03/what-is-this-thing-called-lod.html

Monteiro, A., \& Martins, J. P. (2013). A Survey of Modeling Guidelines for Quantity Takeoff-Oriented BIM-based Design. Automation in Construction, 238-253.

Niazi, A., Dai, J., Balabani, S., \& Senviratne, L. (2005). Product Cost Estimation: Technique Classification and Methodology Review. Journal of Manufacturing in Science and Engineering, 563-575.

Niknam, M., \& Karshenas, S. (2015). Integrating Distributed Sources of Information for Construction Cost Estimating Using Semantic Web and Semantic Web Service Technologies. Automation in Construction, 222-238.

Olsen, D., \& Taylor, J. (2017). Quantity Take-Off Using Building Information Modeling (BIM), and Its Limiting Factors. Procedia Engineering, 1098-1105.

Pickett, T., Bredehoeft, P., Dowen, T., Dysert, L., Elliot, B., Hollmann, J., \& Jacobson, S. (2014). AACE Recommended Practice No. 34R-05. AACE International.

Qian, L., \& Ben-Arieh, D. (2008). Parametric Cost Estimation based on Activity-based Costing: A Case Study for Design and Development of Rotational Parts. International Journal of Production Economics, 805-818.

Roy, T. M. (2018, September 24). Senior Estimator at McClone Concrete Construction, Preliminary Discussion on Traditional Estimating Methods. (M. T. Clark, Interviewer)

Sabol, L. (2008). Challenges in Cost Estimating with Building Information Modeling. Design + Construction Strategies, LLC.

Said, H., \& Reginato, J. (2018). Impact of Design Changes on Virtual Design and Construction Performance for Electrical Contractors. Journal of Construction Engineering and Management.

Sattineni, A., \& Bradford, H. (2011). Estimating with BIM: A Survey of US Construction Companies. International Association for Automation and Robotics in Construction (pp. 564-569). Seoul: IAARC.

Scroggins, M. (2018, March 7). How BIM Can Enable Construction Scheduling in 4D. Retrieved from Oracle Construction and Engineering Blog: https://blogs.oracle.com/construction-engineering/how-bim-can-transformconstruction-scheduling 
Sillak, G., Aaron, L., Burton, D., Christensen, P., Cort, T., \& Erickson, C. (2003). AACE Recommended Practice No. 20R-98, Project Code of Accounts. AACE International.

Stanford Engineering. (2018). VDC Program - Glossary of Terms. Retrieved from Stanford Engineering: Center for Integrated Facility Engineering: https://cife.stanford.edu/events/cifeppi-vdc-certificate-program/vdc-programglossary-terms

The American Institute of Architects. (2007). Integrated Project Delivery: A Guide. Retrieved from https://info.aia.org/SiteObjects/files/IPD_Guide_2007.pdf

The Associated General Contractors of America. (2007). The Contractors' Guide to BIM. Retrieved from https://www.engr.psu.edu/ae/thesis/portfolios/2008/tjs288/Research/AGC_Guide ToBIM.pdf

Trimble Navigation Limited. (2014). Trimble GCEstimator Suite. Retrieved from http://trl.trimble.com/docushare/dsweb/Get/Document-746574/022519101_TrimbleGCEstimatorSuite_TN_1014_2pp_LR.pdf

Turner and Townsend. (2018). International Construction Market Survey. Retrieved from Turner and Townsend: http://www.turnerandtownsend.com/media/3352/international-constructionmarket-survey-2018.pdf

Tuttle, J. (2018, September 24). Construction Superintendent, Preliminary Discussion on the Cal Poly Student Housing South Project. (M. T. Clark, Interviewer)

Wu, J., \& Zhang, J. (2018). Automated BIM Object Classification to Support BIM Interoperability. Construction Research Congress, (pp. 706-715).

Wyatt, T. (2018, September 25). Project Manager at Kitchell, Preliminary Discussion on the Cal Poly Student Housing South Project. (M. T. Clark, Interviewer)

Zhao, P., \& Wang, C. (2014). A Comparison of Using Traditional Cost Estimating Software and BIM for Construction Cost Control. Smart Construction and Management in the Context of New Technology. ASCE. 


\section{APPENDICES}

\section{Appendix A: Power BI Cost Estimate Report}
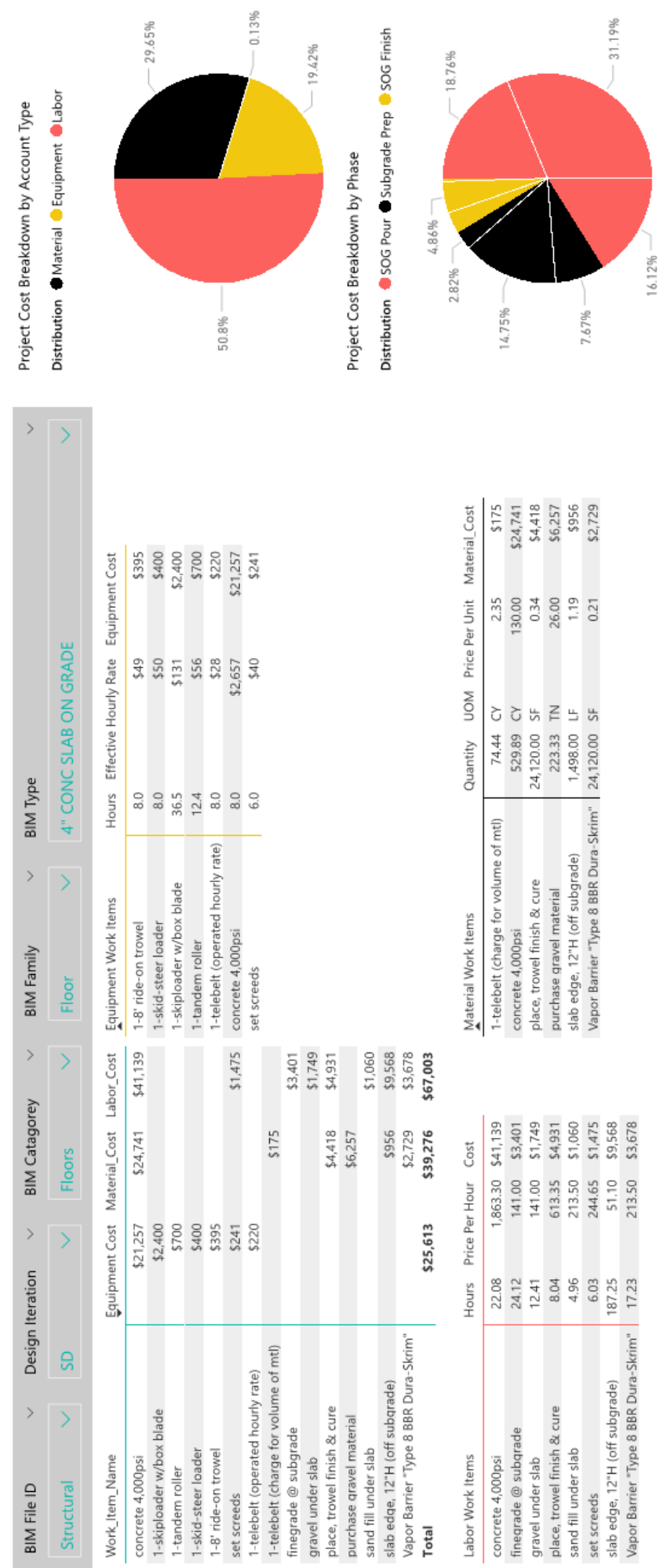


\section{Appendix B: All BIM elements in the Revit Model}

\begin{tabular}{|c|c|c|}
\hline BIM Catagorey & BIM Family & BIM Type \\
\hline Floors & Floor & 4" CONC SLAB ON GRADE \\
\hline Floors & Floor & 5 1/2" MIN-11 1/2" MAX P-T CONC SLAB \\
\hline Floors & Floor & 2 1/2" CONC W/ 6x6 W1.4xW1.4 WWF OVER 2"DPx20GA (W2) METAL DECK \\
\hline Floors & Floor & 1 1/2"DPx20GA (PLB) METAL DECK \\
\hline Floors & Floor & 7" P-T CONC SLAB \\
\hline Slab Edges & Slab Edge & $12 " W \times 24 " D P$ THKND SLAB EDGE \\
\hline Structural Columns & W-Wide Flange-Column & $\mathrm{W} 10 \times 30$ \\
\hline Structural Columns & HSS-Hollow Structural Section-Column & HSS6x6 \\
\hline Structural Columns & HSS-Hollow Structural Section-Column & HSS8x8 \\
\hline Structural Columns & HSS-Hollow Structural Section-Column & HSS6x6x1/4 \\
\hline Structural Columns & Concrete-Rectangular-Column & $12 " x 24 "$ \\
\hline Structural Columns & Concrete-Round-Column & 20"DIA \\
\hline Structural Foundations & Footing-Rectangular & 6'-0"SQx24"DP \\
\hline Structural Foundations & Footing-Rectangular & 4'-0"SQx24"DP \\
\hline Structural Foundations & Footing-Rectangular & 7'-0"SQx24"DP \\
\hline Structural Foundations & Footing-Rectangular & 2'-0"SQx24"DP \\
\hline Structural Foundations & Footing-Rectangular & $11^{\prime}-0 " x 17^{\prime}-6 " x 3$ '-0"DP \\
\hline Structural Foundations & Wall Foundation & 6'-0"Wx3'-0"DP CONT FTG \\
\hline Structural Foundations & Wall Foundation & $10^{\prime}-0 " W \times 33^{\prime}-0 " D P$ CONT FTG \\
\hline Structural Foundations & Wall Foundation & 8'-0"Wx3'-0"DP CONT FTG \\
\hline Structural Framing & HSS-Hollow Structural Section & HSS10x6 \\
\hline Structural Framing & HSS-Hollow Structural Section & HSS $12 \times 8$ \\
\hline Structural Framing & HSS-Hollow Structural Section & $\operatorname{HSS} 4 \mathrm{x} 4 \mathrm{x}$ \\
\hline Structural Framing & W-Wide Flange & W12x \\
\hline Structural Framing & W-Wide Flange & W8x10 \\
\hline Structural Framing & DCI-Concrete-Rectangular Beam & 2'-6"Wx18"DP CONC BEAM \\
\hline Walls & Basic Wall & 8" CONC WALL \\
\hline Walls & Basic Wall & 10" CONC SHEAR WALL \\
\hline Walls & Basic Wall & 12" CONC SHEAR WALL \\
\hline Walls & Basic Wall & 6" STL STUD WALL \\
\hline
\end{tabular}




\section{Appendix C: Parametric Estimate SQL Entity Amalgamated into an Excel Table}

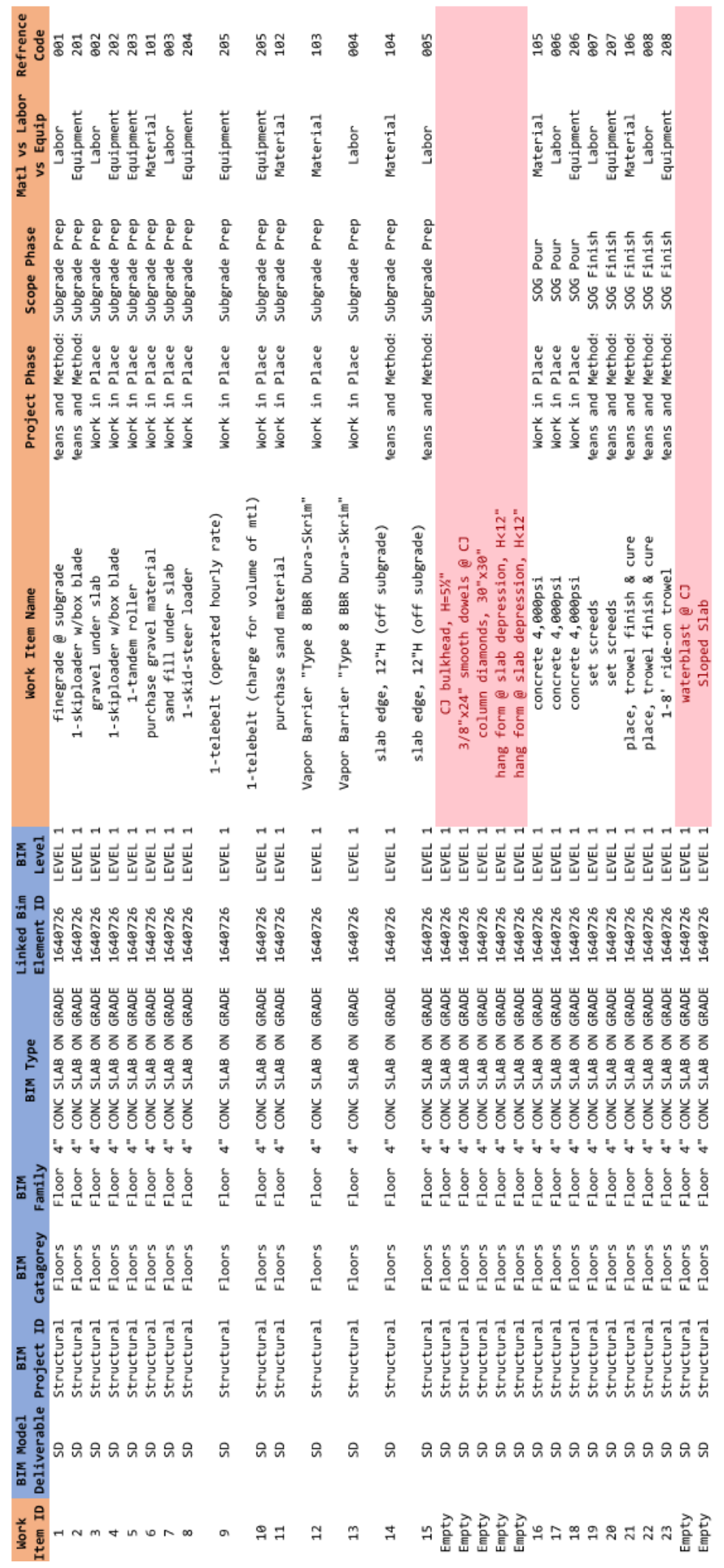




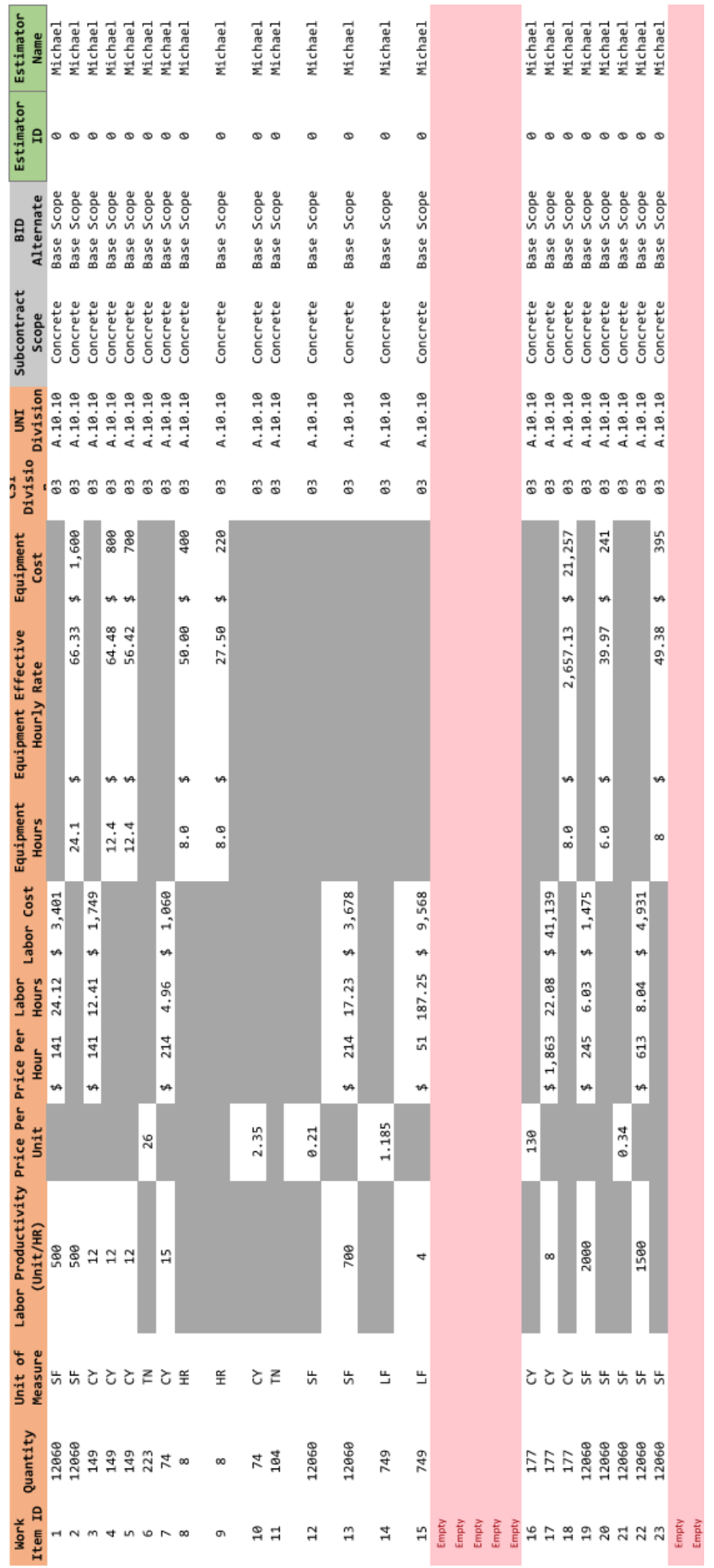

